Wilmar Carvajal Ossa

\title{
Projeto de um conversor analógico-digital para um receptor Bluetooth em tecnologia CMOS
}

Dissertação apresentada à Escola Politécnica da Universidade de São Paulo para obtenção do Título de Mestre em Ciências. 
Wilmar Carvajal Ossa

\title{
Projeto de um conversor analógico-digital para um receptor Bluetooth em tecnologia CMOS
}

\author{
Dissertação apresentada à Escola \\ Politécnica da Universidade de São \\ Paulo para obtenção do Título de \\ Mestre em Ciências. \\ Área de concentração: \\ Microeletrônica \\ Orientador: \\ Prof. Dr. Wilhelmus A. M. Van \\ Noije
}


Este exemplar foi revisado e alterado em relação à versão original, sob responsabilidade única do autor e com a anuência de seu orientador.

São Paulo, 21 de Janeiro de 2011

Assinatura do autor

Assinatura do orientador

Ficha Catalográfica

Ossa, Wilmar Carvajal

Projeto de um conversor analógico-digital para um receptor Bluetooth em tecnologia CMOS / W.C. Ossa - ed. rev. - São Paulo, 2011.

106 p.

Dissertação (Mestrado) - Escola Politécnica da Universidade de São Paulo. Departamento de Engenharia de Sistemas Eletrônicos.

1. Microeletrônica. 2. Conversores A/D e D/A. 3. Programação geométrica. I. Universidade de São Paulo. Escola Politécnica. Departamento de Engenharia de Sistemas Eletrônicos. II.t. 
A mis dos primeros sobrinos: la hermosa Juliana y una nueva vida que viene en camino. 


\section{AGRADECIMENTOS}

À minha família pelo apoio constante durante este meu caminho. Eles são a razão primordial pela que hoje eu sou o que sou, e pela que no futuro serei aquilo que poderei chegar a ser.

À Maria Eugênia por aparecer em um momento importante da minha vida, no que sem seu apoio, brincadeiras, conversas, tempo e carinho, tudo teria sido muito mais difícil.

Não posso deixar de agradecer a todos meus amigos e amigas nos diferentes cenários que a minha vida vai acontecendo. Tanto na Colômbia quanto no Brasil recentemente, e nas mais diversas circunstâncias, cada uma dessas pessoas tem participado e me acompanhado nesta experiência longa e difícil, porém de conquistas muito gratificantes.

Ao professor Dr. Wilhelmus Van Noije pela orientação, ajuda e discussões na pesquisa desenvolvida. Embora as conversas e a interação profissional tenham diminuído pela ausência, também agradeço ao professor Elkim Roa pela valiosa e motivante experiência inicial no campo da microeletrônica.

A todos meus amigos e colegas do Grupo de Investigación en Diseño de Circuitos Integrados (CIDIC) na Colômbia e no México, e do Laboratório de Sistemas Integráveis (LSI) no Brasil, pela sua colaboração, motivação e suporte constante. Uma grande parte dos resultados deste trabalho não teria sido conseguida sem nosso tradicional e valioso trabalho em equipe.

Ao Conselho Nacional de Desenvolvimento Científico e Tecnológico (CNPq) pela bolsa que serviu de suporte econômico para meus estudos de mestrado. Também à Fundação de Amparo à Pesquisa do Estado de São Paulo (FAPESP) que financiou a fabricação dos circuitos integrados. Finalmente, à Divisão de Qualificação e Análise de Produtos Eletrônicos do CTI Campinas, especialmente ao Rodrigo Farias de Sousa pela ajuda e tempo dedicado aos testes do OTA fabricado. 


\section{Resumo}

Neste trabalho aborda-se o projeto de um conversor analógico-digital $(A D C)$ que deve atingir as especificações do padrão Bluetooth. Este bloco faz parte do estágio de recepção de um transceptor sem fio integrado em tecnologia $C M O S$.

Inicialmente é feita a análise do $A D C$ como sistema, ao mesmo tempo que as especificações nesse nível são desenvolvidas. A arquitetura adaptada da literatura é conhecida como time-interleaved pipeline. Os seus principais blocos, o $S \& H$ e o estágio básico incluindo o sub-ADC e o $M D A C$, são explicados posteriormente junto com a estratégia de correção digital através do bit de redundância entre estágios consecutivos. Seguindo essa ordem de ideias, é estudada a implementação com portas digitais da estratégia anterior e da geração das fases de relógio necessárias para os blocos da cadeia pipeline. Os dois circuitos mais elementares, o amplificador operacional de transcondutância $(O T A)$ e o comparador de tensão, também são apresentados antes de introduzir a programação geométrica como ferramenta de projeto auxiliar. Tal ferramenta permite otimizar o consumo de potência desses circuitos básicos e, portanto, descobrir uma nova perspectiva no projeto de circuitos analógicos do estado da arte.

Finalmente, os resultados obtidos e as simulações dos diferentes blocos e circuitos que constituem o $A D C$ são mostrados. Esses resultados também incluem as medições e testes feitos em um OTA projetado com PG e fabricado em tecnologia CMOS $0,35 \mu \mathrm{m}$. A conclusão mais importante deste trabalho se deriva da aplicação simultânea da programação geométrica e a análise cuidadosa dos requisitos reais dos circuitos, levando portanto à otimização do desempenho global do $A D C$ projetado.

Palavras-chave: Microeletrônica. Conversores A/D e D/A. Programação geométrica. 


\section{Abstract}

In this work, an Analog to Digital Converter (ADC) fulfilling the Bluetooth standard specifications is designed. This block stays at the reception side of an integrated wireless transceiver in CMOS technology.

Initially, an analysis of the ADC as a system is carried out, at the same time that the specifications at that level are developed. The architecture adapted from the literature is known as time-interleaved pipeline. Its main blocks, the $\mathrm{S} \& \mathrm{H}$ and the basic cell including sub-ADC and MDAC circuits, are then explained together with the digital correction strategy based on the bit of redundancy between consecutive stages. Furthermore, digital gate implementation of previous strategy and generation of the different clock phases required by pipeline chain blocks, are covered. The two most elementary circuits, operational transconductance amplifier (OTA) and voltage comparator, are also presented before introducing geometric programming $(P G)$ as an auxiliary design tool. Such a tool allows the power consumption optimization of these basic circuits and thus leads to a new perspective in analog circuit design for the state of the art.

Finally, the reached results and the different ADC block simulations are presented. Those results include tests and measurements of an OTA designed using $P G$ and fabricated in a CMOS $0,35 \mu \mathrm{m}$ technology. The most important conclusion of this work is derived from the joint application of geometric programming and careful analysis of the real circuit requirements, allowing the global performance optimization in the designed ADC.

Keywords: Microelectronic, A/D and D/A Converters, Geometric programming. 


\title{
Lista de símbolos
}

\author{
$A_{o} \quad$ Ganho DC do OTA. \\ B Largura de banda absoluta do filtro. \\ $\boldsymbol{B} \quad$ Saída digital de 7 bits em código binário. \\ $C_{i} \quad$ Carry de entrada no esquema de soma Carry-Lookahead Adder. \\ $C_{o} \quad$ Carry de saída no esquema de soma Carry-Lookahead Adder. \\ $C_{S} \quad$ Capacitor de amostragem. \\ $C_{u} \quad$ Capacitor unitário no banco de amostragem do $M D A C$. \\ $\boldsymbol{D} \quad$ Saída digital termométrica do $s u b-A D C$ de 3 bits. \\ $\Delta \quad$ Tamanho de passo em tensão $(1 L S B)$ do conversor.

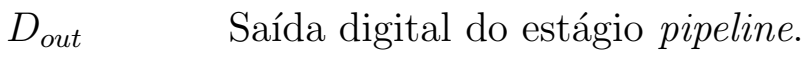 \\ e Tensão de erro. \\ $f_{s} \quad$ Frequência de amostragem total do $A D C$. \\ G Ganho do amplificador do estágio pipeline. \\ $\gamma \quad$ Constante de efeito de corpo. \\ $\boldsymbol{H}$ Varáveis Generate no esquema de soma Carry-Lookahead Adder. \\ $k \quad$ Constante de Boltzman. \\ M Número de canais time-interleaved no ADC. \\ m Número de estágios da cadeia pipeline no $A D C$. \\ n Resolução ou número de bits de um estágio na cadeia pipeline. \\ $\mathrm{N}$ Resolução ou número total de bits do $A D C$. \\ P Potência. \\ $\phi \quad$ Fase de relógio. \\ $\phi_{f} \quad$ Potencial de Fermi. \\ $\boldsymbol{P} \quad$ Varáveis Propagate no esquema de soma Carry-Lookahead Adder. \\ $R S D_{\text {offset }} \quad$ Offset digital introduzido no estágio pipeline para aplicar $R S D$. \\ $\boldsymbol{S} \quad$ Código digital final de saída do $A D C$ de 6 bits. \\ T Duração de símbolo. \\ $\boldsymbol{T} \quad$ Saída digital termométrica do $s u b-A D C$ de 4 bits. \\ $T \quad$ Temperatura dos portadores no canal do transistor. \\ $\boldsymbol{U} \quad$ Saída digital de 7 bits em código Gray.
}


$V_{c m} \quad$ Tensão em modo comum.

$V_{D D} \quad$ Tensão da fonte de alimentação.

$V_{D S} \quad$ Tensão entre o dreno (D) e a fonte (S) do transistor.

$V_{F S} \quad$ Faixa de excursão do sinal em escala total na entrada do $A D C$.

$V_{L A T C H} \quad$ Sinal de controle dos comparadores.

$\overline{v_{n, \text { out }}^{2}} \quad$ Potência de ruído total na saída do $S \mathscr{E H}$.

$\overline{v_{n, a m p}^{2}}$

Ruído equivalente na saída do amplificador.

$V_{\text {ref }}$

Tensão de referência, equivalente a $V_{F S} / 2$.

$V_{S B}$

Tensão entre a fonte (S) e o corpo (B) do transistor.

$V_{T} \quad$ Tensão de limiar do transistor.

$V_{T 0} \quad$ Tensão de limiar do transistor sem efeito de corpo $\left(V_{S B}=0 V\right)$.

$V_{\mathbf{T}_{\text {noRSD }}} \quad$ Tensão reconstruída a partir de um código digital sem usar $R S D$.

$V_{\mathbf{T}_{R S D}} \quad$ Tensão reconstruída a partir de um código digital usando $R S D$.

$\zeta \quad$ Fator de excesso de ruído. 


\section{Sumário}

1 Introdução 1

1.1 Motivação . . . . . . . . . . . . . . . . . . . . . . 1

1.2 O padrão Bluetooth . . . . . . . . . . . . . . . . . . . . 3

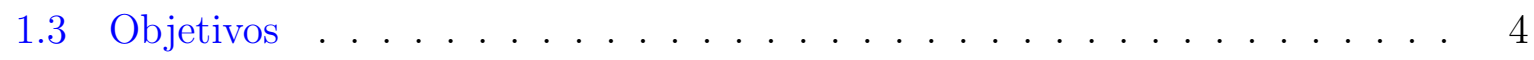

1.4 Levantamento bibliográfico . . . . . . . . . . . . . . . . . . 4

1.5 Organização do documento . . . . . . . . . . . . . . . 7

2 O sistema e a arquitetura $\quad 9$

2.1 Linearidade . . . . . . . . . . . . . . . . . . . . . . . 10

2.2 Relação sinal ruído $(S N R)$, faixa dinâmica $(D R)$ e resolução . . . . . . . . 11

2.3 Largura de banda e frequência de amostragem . . . . . . . . . . . . . . 15

2.4 Consumo de potência . . . . . . . . . . . . . . . 15

2.5 Generalidades da arquitetura time-interleaved . . . . . . . . . . . . 16

2.6 O canal com arquitetura pipeline . . . . . . . . . . . . . . 19

2.6.1 Princípio de funcionamento . . . . . . . . . . . . . . . . 19

2.6.2 Descrição da arquitetura . . . . . . . . . . . . . . . . . 19

2.6.3 Formação de códigos digitais . . . . . . . . . . . . . . . . . . . . 21

2.7 Otimização do consumo de potência da arquitetura . . . . . . . . . . . . . 22

2.7.1 Escolha do número de canais . . . . . . . . . . . . . . . 23

2.7.2 Escolha da resolução por estágio . . . . . . . . . . . . . . 23

2.8 Não idealidades e extração das especificações por estágio . . . . . . . . . . . 24 
$\begin{array}{lll}3 & \text { Os blocos da arquitetura } & 27\end{array}$

3.1 Circuito de amostragem e retenção $(S \mathscr{G} H) \ldots \ldots$. . . . . . . . . . 28

3.1.1 Generalidades sobre os circuitos $S \& H \ldots \ldots$. . . . . . . . 28

3.1 .2 Descrição da arquitetura do $S \& H \ldots \ldots$. . . . . . . . . . 29

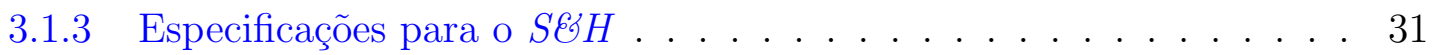

3.2 Estágio básico pipeline . . . . . . . . . . . . . . . . . . . . . . . 32

3.2 .1 Correção digital . . . . . . . . . . . . . . . . . . . . . 33

3.2 .2 O sub-ADC com arquitetura flash . . . . . . . . . . . . . 37

$3.2 .3 \quad \mathrm{O} M D A C \ldots \ldots \ldots \ldots \ldots \ldots$

3.3 Circuitos digitais . . . . . . . . . . . . . . . . . . . 45

3.3.1 Gerador de fases de relógio . . . . . . . . . . . . . . . . . . . 45

3.3.2 Conversões e correções de códigos digitais . . . . . . . . . . . . . . . 45

4 Circuitos básicos e resultados $\quad 51$

4.1 Programação Geométrica . . . . . . . . . . . . . . . . . . . . . 51

4.2 Amplificador Operacional de Transcondutância . . . . . . . . . . . . 53

4.2 .1 O $C M F B \ldots \ldots \ldots \ldots \ldots \ldots$

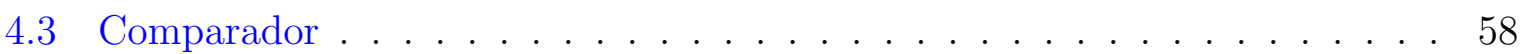

4.4 Simulações . . . . . . . . . . . . . . . . . . . . . . 60 60

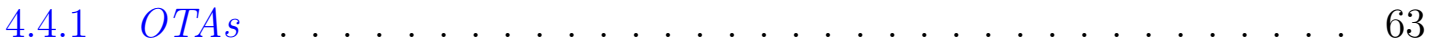

4.4 .2 Comparadores . . . . . . . . . . . . . . . 66

$4.4 .3 \quad S \& H \ldots \ldots \ldots \ldots \ldots \ldots \ldots$

4.4.4 Canal pipeline . . . . . . . . . . . . . . . . . 70

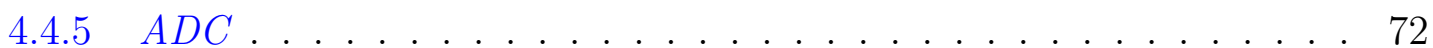

4.5 Fabricação e testes . . . . . . . . . . . . . . . . . . . . . 77

5 Conclusões e recomendações $\quad 81$ 
5.1 Conclusões . . . . . . . . . . . . . . . . . . . . . . . 81

5.2 Observações e recomendações . . . . . . . . . . . . . . . . . . . . 83

$\begin{array}{ll}\text { Apêndice A - PG no projeto do } O T A & 87\end{array}$

A.1 Polarização, condições de operação e geometria. . . . . . . . . . . . . . 88

A.1.1 Leis de Kirchhoff . . . . . . . . . . . . . . . . . 88

A.1.2 Potência em estado estável . . . . . . . . . . . . . . . . . . . . 89

A.1.3 Transistores ativos e saturados . . . . . . . . . . . . . . . . 89

A.1.4 Faixas de excursão de tensão . . . . . . . . . . . . . . . . . . . . . . 90

A.1.5 Limite inferior para a corrente . . . . . . . . . . . . . . . . 90

A.1.6 Dimensões dos transistores . . . . . . . . . . . . . . . . . . . . . . . 91

A.1.7 Relação geométrica no cascode . . . . . . . . . . . . . . . . . 91

A.2 Parâmetros de desempenho. . . . . . . . . . . . . . . . . . 92

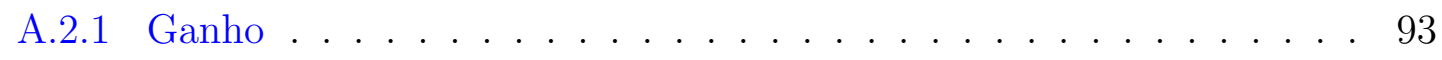

A.2.2 Função de transferência . . . . . . . . . . . . . . . . . . 93

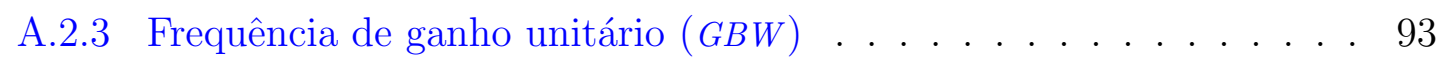

A.2.4 Margem de fase . . . . . . . . . . . . . . . 94

A.2.5 Slew Rate . . . . . . . . . . . . . . . . . . . 95

A.3 Estratégia de projeto e modificações. . . . . . . . . . . . . . 95

A.3.1 Limites para $V_{D S 9} \ldots \ldots \ldots \ldots \ldots$. . . . . . . . . . . 97

A.3.2 Limites para $V_{D S 11} \quad \ldots \ldots \ldots \ldots$

A.3.3 Inclusão dos $V_{D S}$ resultantes do processo iterativo . . . . . . . . . . 98

A.3.4 Formulação padrão do programa geométrico . . . . . . . . . . . . . 98 


\section{Introdução}

\subsection{Motivação}

Dois fatores do ambiente que o homem contemporâneo desenvolve e interage são a tecnologia e a comunicação, os quais avançam de forma convergente e rápida em busca de conforto tanto quanto de progresso. Nesse mesmo sentido, as comunicações sem fio fazem parte das tecnologias de vanguarda, e portanto, continuamente são desenvolvidos novos padrões que visam viabilizá-las. Assim sendo, os transceptores com compatibilidade multipadrão têm ganhado atenção e importância na fabricação de dispositivos versáteis e configuráveis nesse campo tecnológico.

As especificações e desafios propostos nos padrões de comunicação sem fio têm dirigido durante anos a inovação no projeto de transceptores. Com o sucesso das Redes de Área Pessoal (PAN) Bluetooth, os esforços dos projetistas e fabricantes de sistemas sem fio se focam na otimização do custo, desempenho e compatibilidade entre padrões e aplicações diferentes. Esses três critérios têm criado um novo enfoque na integração de sistemas portáveis sem fio, no qual é desejável que o estágio encarregado da recepção tenha a adaptabilidade necessária para processar eficientemente sinais de diferentes padrões. Esse processamento deve ser realizado sem precisar de grandes modificações nos parâmetros de circuito dos blocos analógicos que conformam o receptor.

Atualmente, os esquemas de modulação e os protocolos digitais são dominantes no cenário das comunicações sem fio. Por isso, faz-se necessário que o processamento da informação em banda base (nos níveis acima da camada física neste tipo de sistema) seja efetuado no domínio digital mediante $D S P s^{1}$ reconfiguráveis. No entanto, o sinal recebido na antena de radiofrequência e seu processo inicial de adequação e conversão a $I F^{2}$, bem

\footnotetext{
${ }^{1}$ Abreviatura do inglês para Processador Digital de Sinais (Digital Signal Processor). Para diferenciar os termos em inglês, neste documento eles serão escritos em letra itálica.

${ }^{2} I F$ é a abreviatura de Frequência Intermediária. Dependendo da aplicação e padrão utilizados pode ser $D C(0 \mathrm{~Hz}$, como no caso do receptor de conversão direta) ou um valor específico de frequência (menor que a frequência da portadora) que ofereça vantagens na recepção do sinal.
} 


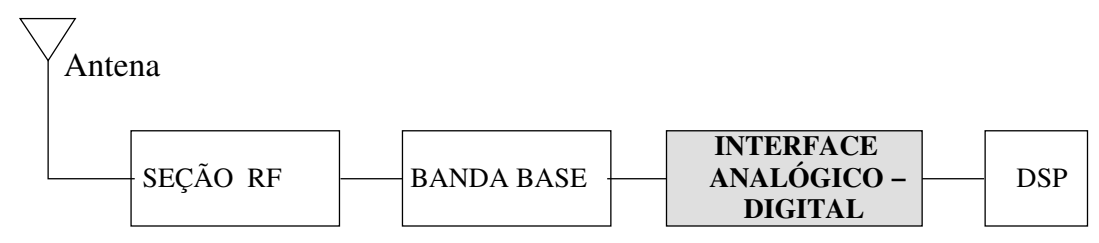

Figura 1.1: Modelo geral dos receptores sem fio de conversão direta.

como todos os blocos envolvidos nele, encontram-se geralmente no domínio analógico. Pela razão acima, é necessária a existência de um Conversor Analógico-Digital $(A D C)$, que assume o papel de interface ou ponte entre esses dois tipos de sinais de natureza diferente dividindo o sistema receptor sem fio, conforme mostra a figura 1.1 [1].

A configurabilidade do $A D C$ é uma das principais contribuições na adaptabilidade dos receptores multipadrão. Além disso, este bloco permite a integração da parte analógica e o processamento digital em um mesmo chip, mantendo a filosofia $S o C^{3}$ para os sistemas portáveis modernos. Como bloco fundamental dentro do processamento em banda base do receptor, o Conversor Analógico-Digital projetado para as condições de operação expostas acima tem se tornado uma área ativa de pesquisa e desenvolvimento nos últimos anos. Essas considerações fazem com que o projeto do $A D C$ seja um ponto chave para os receptores multipadrão.

A partir dos argumentos anteriores, o foco inicial deste trabalho foi o projeto de um $A D C$ configurável integrado em tecnologia CMOS que iria satisfazer as especificações de dois padrões de comunicações sem fio: Bluetooth e GSM. Sob o ponto de vista dessa ideia inicial, foram produzidos dois artigos aceitos em eventos internacionais: [2] para o Iberchip em Puebla, México e [3] para o DCIS em Grenoble, França; e também foi concluído um trabalho de formatura [4] que ainda levou à publicação de um livro para consulta universitária [5]. Apesar dos resultados anteriores, durante o desenvolvimento deste projeto se determinou que a complexidade da proposta inicial estava além do escopo de um trabalho de mestrado. Assim sendo, o trabalho foi reespecificado apenas para um dos padrões, mas as decisões em nível de sistema e de arquitetura foram mantidas para já preparar um possível trabalho futuro na versão multipadrão do $A D C$. Devido a sua grande popularidade e preferência no mercado atual para $P A N s$, a banda de frequências livre em que opera e sua compatibilidade com os processos de fabricação $C M O S$ de baixo custo, o padrão Bluetooth foi o escolhido para esta aplicação.

Como ferramenta auxiliar na definição e otimização de projeto dos circuitos mais

\footnotetext{
${ }^{3}$ System on Chip. Uma das tendências da eletrônica cuja ideia principal é que todo sistema analógicodigital possa ser projetado e implementado dentro de uma mesma pastilha de silício.
} 
elementares do conversor, a Programação Geométrica (PG) [6, 7] é apresentada e aplicada conforme a função e posição deles dentro do sistema. Assim, o resultado da estratégia adotada é um conversor analógico-digital que satisfaz as especificações do padrão sob o qual opera, e que ainda segue as tendências do estado da arte por conceber circuitos integrados com baixo consumo de potência, especialmente para aplicações portáveis.

\subsection{O padrão Bluetooth}

Adaptado do padrão IEEE 802.15.1, Bluetooth foi desenvolvido originalmente para redes de área pessoal. É uma interface universal de rádio que tem sido desenvolvida visando permitir a comunicação sem fio de curto alcance entre dispositivos eletrônicos através de conexões de rádio ad $h o c^{4}$. Tem ampla aplicação em sensores e configuração de PANs, bem como na conexão de telefones celulares e laptops com seus respectivos periféricos, tais como fones de ouvido handsfree e impressoras.

Os sistemas Bluetooth funcionam na banda $I S M^{5}$ de 2,4GHz. Dentre as características mais atrativas desta tecnologia, encontram-se seu baixo custo, integração em um único chip e seu reduzido consumo de potência. Porém, um sistema Bluetooth necessita se apoiar sobre outra rede sem fio, por exemplo de telefonia celular ou $W i$ $F i$, para aproveitar ao máximo sua funcionalidade. Isto é necessário porque seu cenário operacional se expande quando combinado com outros sistemas sem fio de alcance maior $[1,8]$.

Finalmente, os processos CMOS são geralmente preferidos no projeto de sistemas Bluetooth por causa do seu alto nível de integração e baixo custo de implementação, quando comparados com de outras tecnologias de fabricação. Além disso, seu desenvolvimento e avanços permitem que as tecnologias CMOS atuais produzam circuitos em $R F$ com bom desempenho e altas velocidades na faixa de $G H z$.

\footnotetext{
${ }^{4}$ Uma rede sem fio ad hoc é uma conexão que não precisa de um nó central ou AP (Access Point) entre dois ou mais aparelhos. Ao invés disso, cada um dos dispositivos tem as mesmas condições.

${ }^{5}$ Industrial, Scientific and Medical band: banda de frequências de uso público disponibilizada mundialmente para diversas aplicações como a pesquisa espacial, exploração da terra e serviço fixo por satélite, radioamadores, radiolocalização, radionavegação e aeronáutica. Também é usada por sistemas de baixa potência e curto alcance.
} 


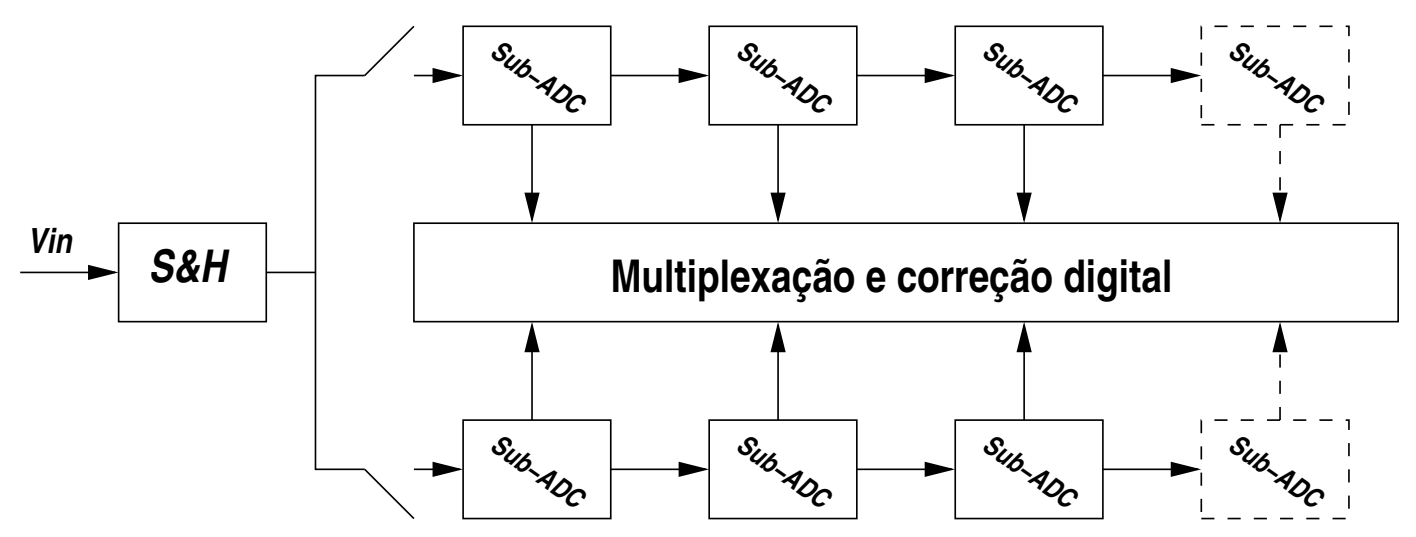

Figura 1.2: Arquitetura básica do $A D C$ a ser seguida.

\subsection{Objetivos}

Os principais objetivos deste trabalho de mestrado são:

- Projetar um Conversor Analógico-Digital integrado em tecnologia CMOS, para ser usado dentro do estágio de recepção de um transceptor no padrão Bluetooth.

- Usar a programação geométrica como ferramenta auxiliar no projeto dos circuitos elementares do $A D C$ : o $O T A$ e o comparador.

- Desenvolver uma estratégia de simulação para o $A D C$ completo.

- Implementar e fazer testes experimentais sobre um dos circuitos fundamentais do $A D C$ : o folded cascode OTA e seu circuito $S C$-CMFB.

\subsection{Levantamento bibliográfico}

Na mesma área de aplicação deste trabalho, [9] propõe uma arquitetura configurável composta por duas topologias chamadas de pipeline e time-interleaved, conforme ilustra a figura 1.2. A primeira versão dela foi publicada dois anos antes em [10]. Este $A D C$ é focado para receptores de modo dual (2 padrões), sendo um deles o padrão Bluetooth. A arquitetura é composta por dois canais pipeline idênticos que funcionam paralelamente, igual a um esquema time-interleaved. O uso dessas duas configurações permite atingir altas velocidades com resoluções moderadas. Aliás, a possibilidade de desligar blocos em cada canal ou um canal completo, permite variar a resolução e a velocidade do $A D C$, além de ajudar a diminuir o consumo de potência. Os benefícios descritos são obtidos em troca do aumento na área de silício e na complexidade do $A D C$ projetado. 


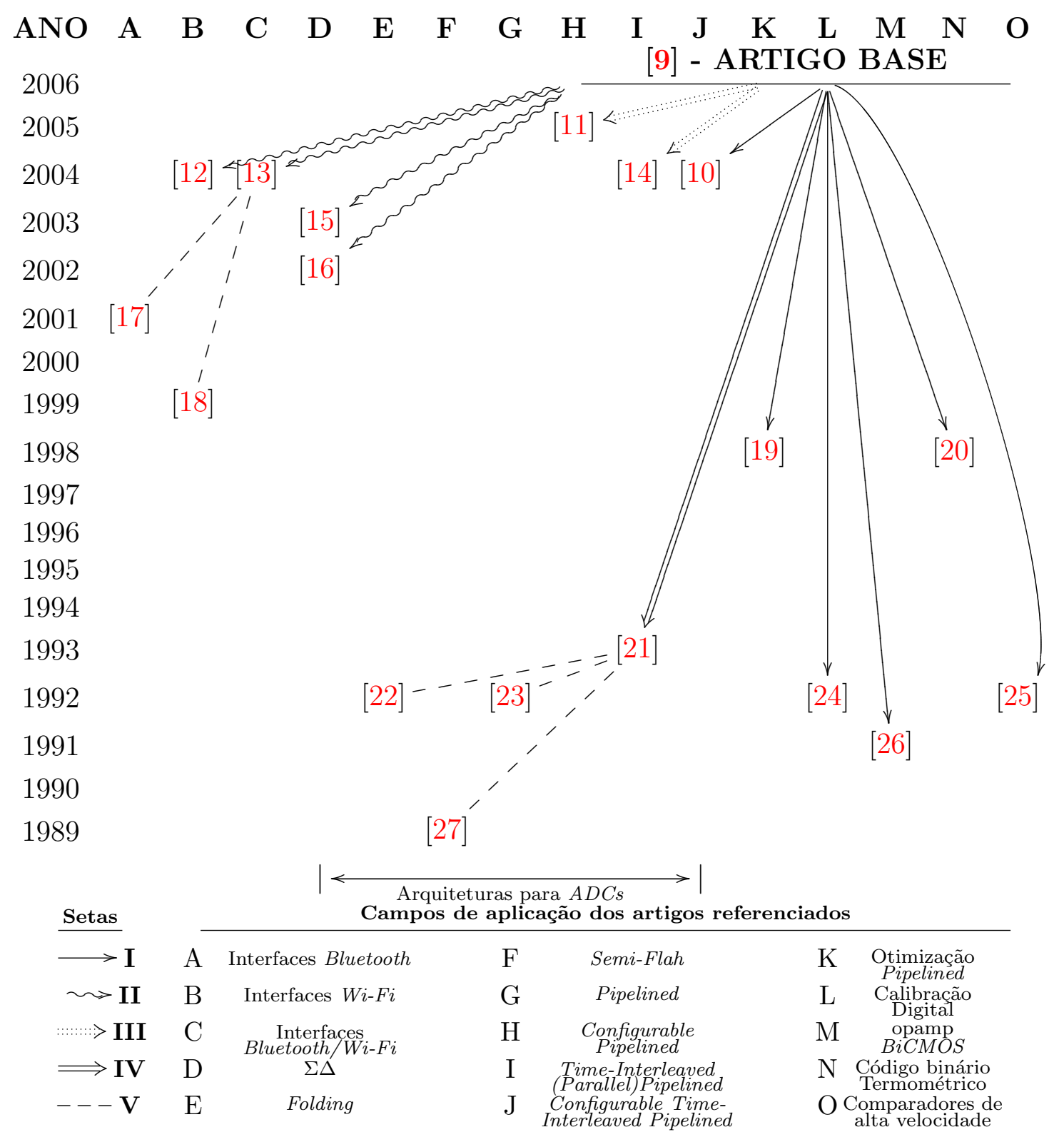

Figura 1.3: Árvore de referências do artigo guia.

Pelas características anteriores, além do interesse por explorar, estudar e aproveitar a flexibilidade dessa arquitetura, ela é a proposta escolhida para o $A D C$. O intuito é aprofundar nos detalhes da topologia para facilitar a futura implementação de uma versão multipadrão, que está além do escopo deste trabalho de mestrado. Portanto, esta dissertação aborda o projeto do time-interleaved pipeline $A D C$ para atender as especificações de apenas um padrão de comunicação sem fio: Bluetooth.

A figura 1.3 apresenta o desenvolvimento feito sobre o trabalho publicado em [9]. O significado dos diferentes tipos de setas usadas nessa figura para assinalar algumas das referências do artigo base é apresentado a seguir: 
I - Contribuições à implementação, desde o nível de sistema até os transistores.

II - Contextualização e área de aplicação no estado da arte.

III - Trabalhos com os quais se comparam os resultados obtidos.

IV - Guia e raiz da união de arquiteturas utilizada.

V - Referências não derivadas do artigo base.

Os padrões Bluetooth e Wi-Fi aparecem na coletânea de artigos referidos na figura 1.3, o que é resultado da sua grande popularidade no mercado atual das comunicações sem fio. Além disso, a sua frequente coexistência e campos de aplicação comuns têm chamado a atenção dos projetistas de receptores multipadrão nos últimos anos.

Em [21], os autores divulgam que se trata da primeira vez que as arquiteturas timeinterleaved e pipeline são associadas, o que permite contornar as tradicionais desvantagens do paralelismo nos $A D C s$, como o mismatch ${ }^{6}$ nos ganhos, offsets e temporização. Isso é conseguido mediante a reutilização das cadeias de resistores, circuitos de polarização e de sincronismo nos $M D A C s^{7}$, os quais fazem parte dos blocos que compõem uma cadeia pipeline. No entanto, [21] está focado em aplicações de alto desempenho da sua época, como HDTV , comunicações digitais e instrumentação. Dessa forma, o artigo apresenta o $A D C$ mais rápido referido nessa data, ultrapassando o patamar de $50 \mathrm{MS} / \mathrm{s}$ de trabalhos anteriores com tecnologia $C M O S$.

Alguns anos depois, o trabalho [19] expõe um estudo em detalhe sobre a forma de escolher a resolução por estágio de um ADC pipeline. Esse artigo contrasta com a ideia de trabalhos anteriores que preferem a minimização do número de bits por estágio. Com esse objetivo, demonstra-se através da análise automatizada de um exemplo de projeto o seguinte: quando desejadas resoluções superiores a 10 bits e altas velocidades, a solução ótima é a combinação de resoluções altas e médias por estágio. Dessa forma se consegue diminuir a dissipação de potência e a área, respectivamente.

O $A D C$ implementado em [9] é um dos blocos que fazem parte do receptor referido em [28]. Esse projeto contrasta com a tendência de trabalhos em campos de aplicação similares, como [12] e [13], nos quais o $A D C$ não é incluso no estágio da recepção.

\footnotetext{
${ }^{6}$ Termo em inglês para se referir ao descasamento existente entre elementos ou parâmetros de circuito, que em princípio deveriam ser iguais, devido às limitações e imperfeições dos processos de fabricação.

${ }^{7}$ Multiplying Digital to Analog Converter
} 


\subsection{Organização do documento}

Com o intuito de oferecer uma visão geral da abrangência do presente documento, segue uma apresentação da estrutura do seu conteúdo.

Logo após a introdução, o capítulo 2 apresenta uma primeira perspectiva do $A D C$ como sistema. Sua arquitetura e as variações que dela podem ser concebidas constituem o enfoque principal dessa parte. Em seguida, é completada a descrição dos blocos funcionais que compõem o sistema de conversão analógico-digital, acompanhando o estudo que vai da identificação das não idealidades à especificação dos parâmetros que as compensam.

A arquitetura usada no $A D C$ deste trabalho é conhecida na literatura como timeinterleaved pipeline. A porta de acesso dessa arquitetura constitui a primeira seção do capítulo 3: o bloco de amostragem e retenção $(S \mathscr{G} H)$. A descrição e especificação são desenvolvidas de forma progressiva, visando elucidar a ideia básica do funcionamento dos circuitos com capacitores chaveados $(S C)$. Esses últimos, além de serem fundamentais para implementação do $S \mathscr{G} H$, fornecem o princípio de operação primário para quase toda a arquitetura do $A D C$, assim como para muitas outras aplicações que estão além do escopo desta dissertação. A segunda seção do capítulo 3 expõe a composição da cadeia de conversão pipeline. Os tópicos tratados em ela são a correção digital através de um bit de redundância e as topologias selecionadas para implementação dos grandes blocos que estão dentro do estágio básico: o $s u b-A D C$ e o $M D A C$. Além desses tópicos, explorase a interdependência que existe entre estes blocos, ressaltando o impacto que têm as estratégias e decisões sobre os mesmos.

O conteúdo apresentado nos capítulos anteriores permite identificar dois circuitos analógicos que são a base de toda a arquitetura do $A D C$. Tais blocos básicos são o comparador de tensão e o amplificador operacional de transcondutância (OTA), cuja contextualização e projeto são tratados ao longo do capítulo 4. Como ferramenta auxiliar de valiosa contribuição neste trabalho, a programação geométrica (PG) também é introduzida para desvendar uma nova perspectiva no projeto analógico. Encerrando o capítulo 4, os resultados obtidos são explicados desde as simulações da operação dos blocos individuais projetados ao longo do trabalho, até o sistema conversor completo. Alguns resultados de teste do OTA fabricado também são apresentados.

Finalmente, no capítulo 5 se condensam as experiências, resultados obtidos e conhecimentos adquiridos em forma de observações, conclusões e recomendações para trabalhos futuros. 


\section{O sistema e a arquitetura}

O principal tópico de interesse deste capítulo é a especificação geral do $A D C$ abstraído como sistema que converte sinais analógicos em digitais. Continuando com a caracterização do conversor, a topologia escolhida é explorada e compreendida. Através de um percurso detalhado e focado em forma gradual nas diferentes características e seções que constituem a arquitetura time-interleaved pipeline, exibe-se a natureza do processo da conversão analógico-digital de sinais elétricos. Paralelamente, as especificações gerais são distribuídas e atribuídas aos diferentes blocos que compõem o $A D C$ a ser projetado.

O primeiro passo é o conhecimento em detalhe do padrão de comunicações sem fio escolhido. Portanto, a tabela 2.1 apresenta um resumo das principais especificações de operação do padrão Bluetooth. Essas especificações são determinadas pensando na cadeia receptora completa, desde a antena até a entrada do processador digital de dados banda base. O passo seguinte é a tradução e utilização dos parâmetros da tabela 2.1 para caracterização do conversor analógico-digital, inicialmente em nível de sistema. A fim de conseguir isto, este bloco deve ser enxergado mediante seu conceito básico: uma caixa

Tabela 2.1: Especificações do padrão Bluetooth.

\begin{tabular}{|c|c|}
\hline Parâmetro & Valor \\
\hline \hline Banda de frequências & $2400-2483,5 \mathrm{MHz}$ \\
\hline Método de acesso & TDD/FHSS \\
\hline Modulação de amplitude constante & 0,5 \\
\hline Produto BT & 79 \\
\hline Número de canais & $1 \mathrm{MHz}$ \\
\hline Separação entre canais & $500 \mathrm{kHz}$ \\
\hline Máxima largura de banda de sinal & $-70 \mathrm{dBm}\left(10^{-3}\right)$ \\
\hline Sensibilidade (BER requerida) & $-20 \mathrm{dBm}$ \\
\hline Máximo nível de potência recebido & $625 \mu \mathrm{s}$ \\
\hline Duração total dos pacotes de dados (canal) & $4 \mu \mathrm{s}$ \\
\hline Duração do preâmbulo dos pacotes de dados & $1(625 \mu \mathrm{s})$ \\
\hline $\mathrm{N}^{o}$ frames /nntervalo de tempo (Duração) & $254 \mu \mathrm{s}$ \\
\hline Tempo de assentamento & $1600 \mathrm{saltos} / \mathrm{s}$ \\
\hline Taxa de saltos de frequência & $\mathrm{s}$ \\
\hline
\end{tabular}

* BT é o produto da largura de banda absoluta do filtro (B) e a duração de símbolo (T). 


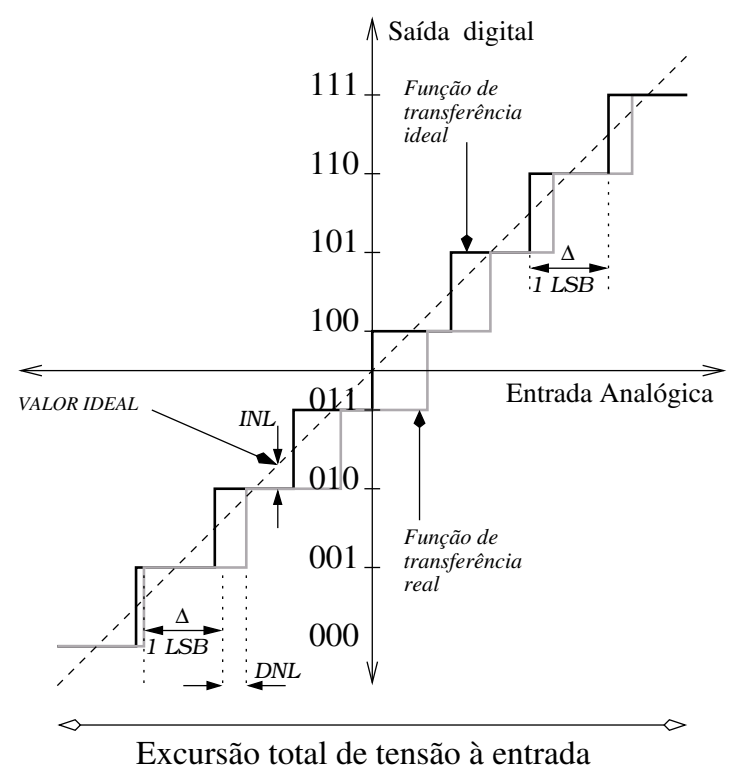

Figura 2.1: Função de transferência do $A D C$ junto com os erros $I N L$ e $D N L$.

preta cujas entradas são sinais analógicos, os quais são amostrados em tempo (a uma frequência determinada) e amplitude (com uma resolução determinada) e codificadas em níveis binários, para ser finalmente entregues na saída.

Algumas das especificações na tabela 2.1 são relevantes para o projeto do $A D C$. Dentre elas, cabe ressaltar o esquema de modulação utilizado, a largura ou separação entre canais e a sensibilidade, definida como aquele nível de potência mínimo requerido para cumprir certo desempenho, avaliado geralmente através da taxa de erro de bits $(B E R)$. A seguir, as principais especificações de projeto relacionadas com o $A D C$ serão brevemente explicadas. Para uma revisão mais profunda e em detalhe, pode referir-se a [29].

\section{$2.1 \quad$ Linearidade}

A faixa de excursão em escala total do sinal na entrada do $A D C$ é expressada em Volts, e denota-se como $V_{F S}$. O tamanho do passo em tensão $\Delta$ na função de transferência do $A D C$ (figura 2.1) corresponde também ao valor do bit menos significativo ( $L S B)$. Assumindo que o sinal varia entre $-V_{F S} / 2$ e $+V_{F S} / 2$, determina-se que $\Delta=1 L S B=V_{F S} / 2^{N}$, onde $N$ é o número de bits ou a resolução do conversor.

Os erros estáticos na função de transferência do $A D C$ são descritos pela não linearidade diferencial $(D N L)$ e a não linearidade integral $(I N L)$. Ambos os erros são mostrados na figura 2.1 e relacionam-se conforme a equação (2.1), onde $k$ representa qualquer um dos degraus da função de transferência do $A D C$. O $D N L$ mede o grau de 
desvio dos degraus de tensão reais quando comparados ao valor nominal de 1 LSB. Já o $I N L$ corresponde ao acúmulo do $D N L$, e representa a diferença entre o valor ideal analógico do sinal (mostrado na linha reta de inclinação 1, sem erros de ganho e de offset) e o valor real da saída do $A D C$ (associado com a função de transferência escalonada real).

$$
I N L_{k}=\sum_{i=1}^{k} D N L_{i}
$$

Esses dois parâmetros indicam a precisão real de um conversor e incluem os erros de quantização, não linearidades, ruído, erros de offset e ganho. Eles podem ser representados graficamente como função do código digital de saída, ou através do seu valor máximo, que é um simples número em unidades de $L S B$. Sendo assim, para garantir que o $A D C$ seja monotônico ${ }^{1}$, deve-se cumprir que $I N L_{k}<0,5 L S B$, o que implica então que $D N L_{k}<1 L S B$.

\subsection{Relação sinal ruído $(S N R)$, faixa dinâmica $(D R)$ e resolução}

Uma análise exaustiva para determinação da resolução mínima necessária em um $A D C$ que faz parte de um receptor em banda ultralarga $(U W B)$ é apresentado em [30]. Esse estudo, bem como outras referências da literatura, explica a grande dependência do requisito da resolução sobre o esquema de modulação, as características do canal utilizado, a natureza das interferências não desejadas dentro e fora da banda, a arquitetura de receptor usada e a maioria dos blocos que a constituem, desde o LNA na entrada até o filtro que precede o $A D C$, incluindo ainda a participação do sintetizador de frequência.

Sendo assim, na referência [30] demonstra-se que se for considerado o verdadeiro impacto de todos os fatores citados, pode-se achar um requisito real de resolução do $A D C$ menos superdimensionado que aquele obtido quando aplicada a estratégia tradicional da maioria dos projetos. Um estudo assim aprofundado está além dos objetivos deste trabalho, razão pela que aqui se usa o método tradicional que será explicado nos próximos parágrafos.

A resolução do $A D C$ está ligada ao seu requisito de faixa dinâmica $(D R)$, que é derivado das especificações de sensibilidade, máximo nível de potência recebida e perfis de

\footnotetext{
${ }^{1} \mathrm{Um} A D C$ é monotônico quando se cumpre que para incrementos no valor do sinal analógico de entrada, igualmente se incrementa o valor do sinal digital na saída. A monotonicidade de um $A D C$ evita a perda de códigos digitais na saída.
} 


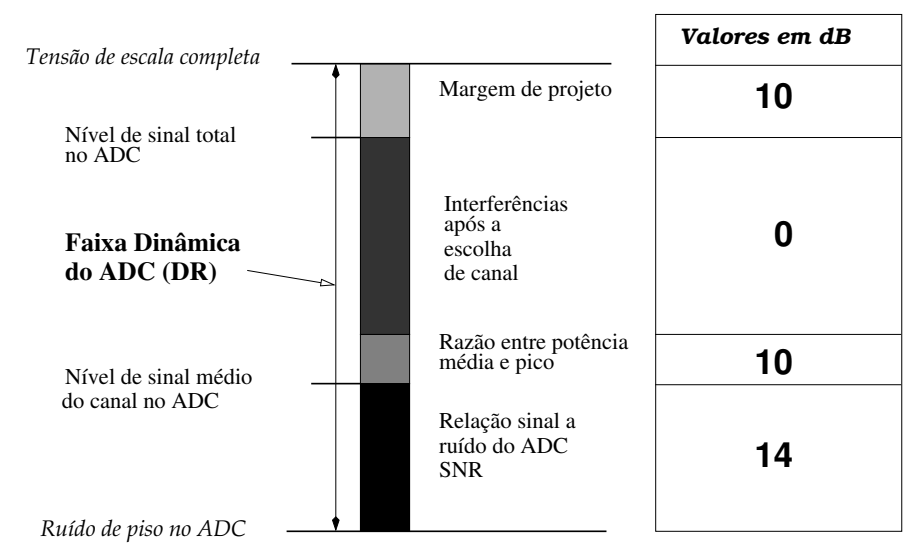

Figura 2.2: Especificação da faixa dinâmica do $A D C$ (adaptado de [31]).

blockers ${ }^{2}$ para um padrão e uma arquitetura de receptor específicos. O esquema conceitual da figura 2.2 mostra a distribuição da $D R$ em outras quatro especificações, as quais são definidas agora para o padrão Bluetooth.

O primeiro requisito que deve cumprir a $D R$ é cobrir o erro irreversível de quantização introduzido pelo $A D C$ no processo de atribuição de valores discretos ao sinal analógico da entrada. Esse erro impõe um limite inferior para $D R$ do $A D C$, e seu impacto é quantificado mediante a $S N R$. A extração da $S N R$ está muito relacionada ao desempenho exigido para o esquema de modulação utilizado em um determinado padrão de comunicações sem fio.

Para entender os seguintes modelos, deve-se esclarecer que para a recepção de sinais modulados digitalmente, há a opção de fazê-lo em forma coerente ou não coerente. A primeira delas envolve a disponibilidade de réplicas exatas do sinal transmitido no demodulador, o qual as correlaciona com o sinal recebido para fazer escolhas quando comparado com limiares definidos. Por outro lado, a demodulação não coerente não precisa de tal conhecimento do sinal transmitido. A complexidade do receptor na última opção é menor, mas o preço a pagar é a degradação do desempenho do sistema.

O requisito de BER na tabela 2.1 determina o desempenho exigido pelo padrão Bluetooth. Para satisfazer esse parâmetro, um mínimo nível de $S N R$ deve ser atingido, tal como mostrado na figura 2.4. Essa figura está baseada nos resultados de simulação de dois modelos: o primeiro, de um demodulador ótimo não coerente implementado especificamente para Bluetooth, que é reportado em [1]; e o outro, implementado nesta dissertação, que é apresentado na figura 2.3.

O próximo componente da $D R$, chamado de razão entre potência média e pico,

\footnotetext{
${ }^{2} \mathrm{Na}$ documentação de um padrão de comunicações sem fio [8], chamam-se de blockers os fortes sinais modulados de interferência em canais adjacentes ao canal desejado. Essas interferências devem ser toleradas pelo receptor mantendo um nível mínimo de desempenho $(B E R)$.
} 


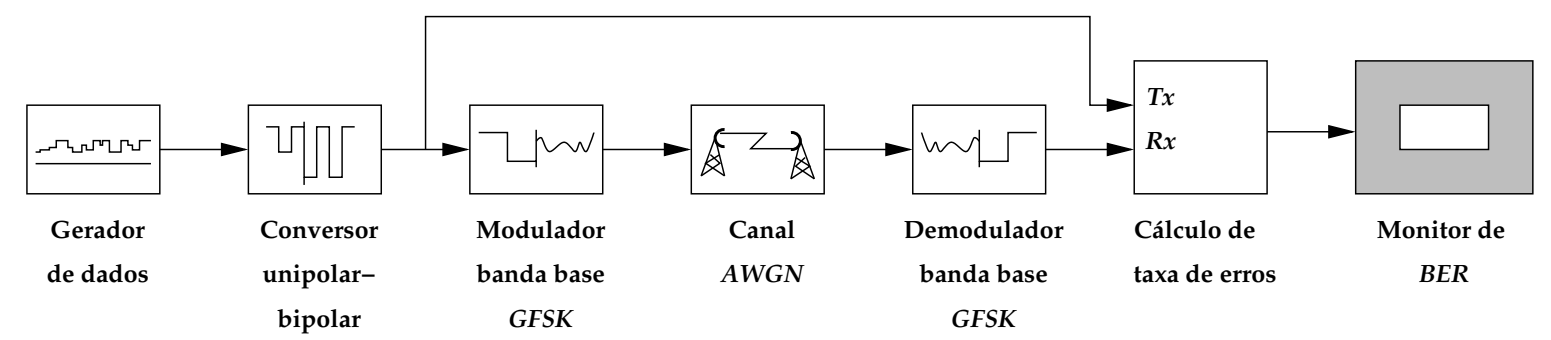

Figura 2.3: Modelo utilizado para análise de desempenho do padrão Bluetooth.

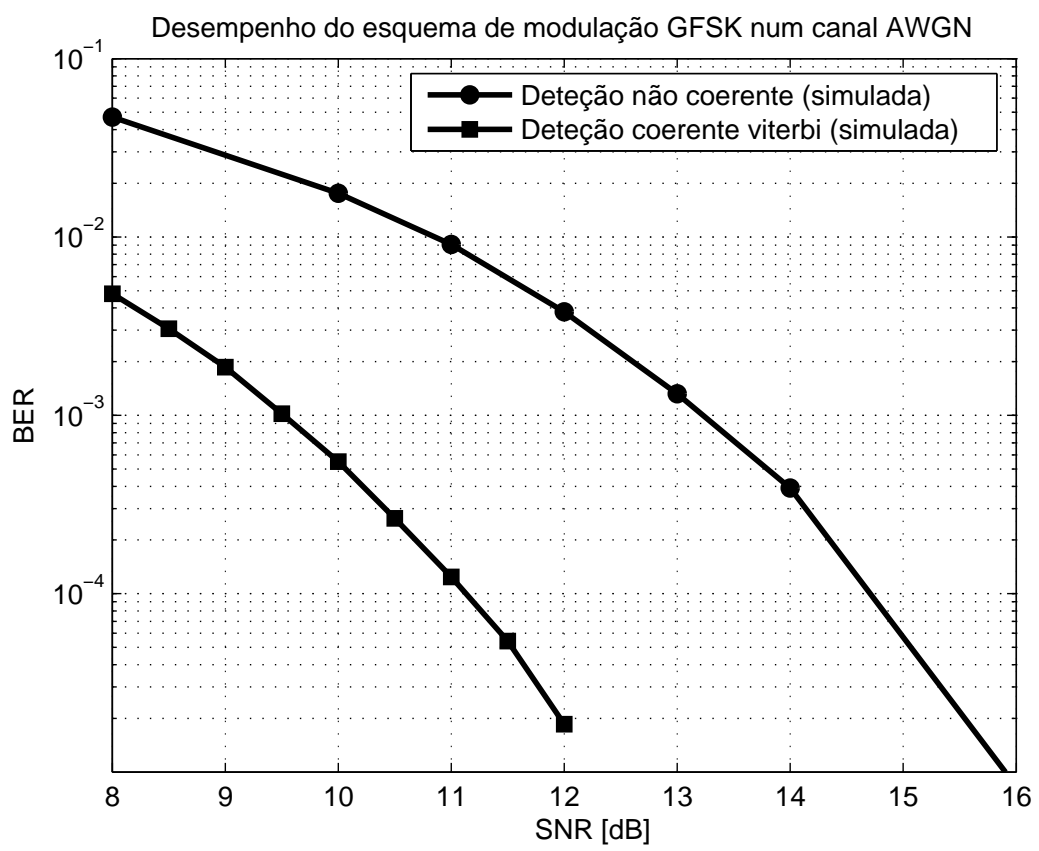

Figura 2.4: $B E R$ vs. SNR para o esquema de modulação utilizado por Bluetooth.

visa evitar o recorte de picos ou incrementos no sinal analógico de entrada, que geraria distorção harmônica. De [31] sabe-se que no caso de esquemas de modulação de envolvente constante, por exemplo GFSK no padrão Bluetooth, um mínimo de 3 dB pode ser usado para este componente, que acaba sendo de certa forma outra restrição de projeto.

Em um receptor de conversão direta não existe um filtro seletivo de canal em $R F$ e apenas as interferências fora de banda são rejeitadas pelos elementos passivos do filtro externo. Portanto, o deslocamento para banda base feito pelo circuito misturador de sinal (um bloco passa tudo) traz consigo os grandes blockers que estão ao lado de um determinado canal desejado. Um filtro banda base anti-aliasing ${ }^{3}$ que precede o $A D C$ é utilizado quando a escolha de canal é feita no domínio analógico.

A forma mais fácil de enxergar o exposto acima é através da figura 2.5, que mostra

\footnotetext{
${ }^{3}$ Chama-se de aliasing a superposição que pode acontecer entre as componentes espectrais de um sinal analógico amostrado quando não é obedecido o teorema de Nyquist. Esse teorema diz que a frequência de amostragem deve ser no mínimo o dobro da máxima frequência presente no sinal original.
} 


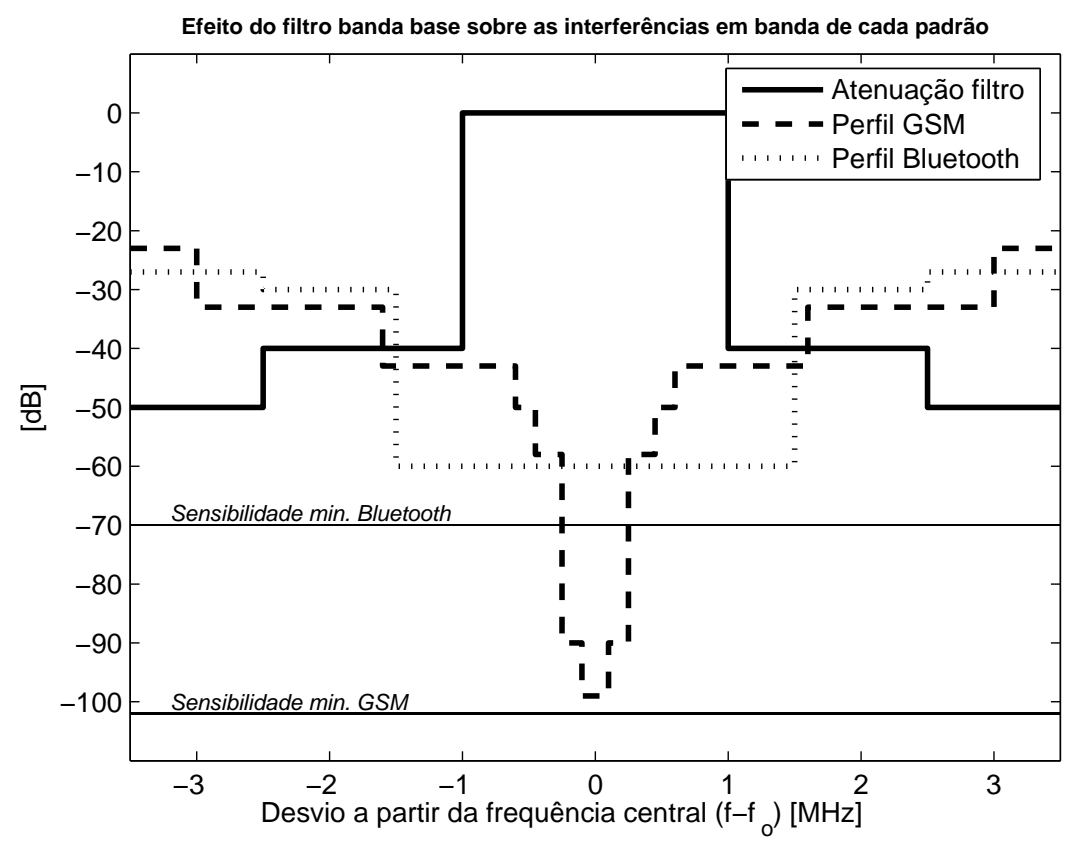

Figura 2.5: Perfis de blockers e máscara de atenuação do filtro banda base.

os perfis de blockers para o padrão Bluetooth junto a um desenho ideal da máscara de atenuação de um filtro já projetado para o transceptor do que fará parte o $A D C$ deste trabalho [32]. Os perfis de blockers são apenas a interpretação gráfica da correspondente especificação extraída do padrão [8]. Visando dar um exemplo para comparação, o padrão de telefonia móvel GSM (com $200 \mathrm{kHz}$ de separação entre seus canais [33]) também é exibido na figura 2.5. Enquanto o blocker mais forte de GSM dentro da banda de passagem do filtro pode estar até $56 \mathrm{~dB}^{4}$ por cima da referência do sinal desejado, Bluetooth tem a vantagem adicional de que o canal adjacente encontra-se no mesmo nível do canal escolhido. Portanto, este componente da $D R$ não acrescenta a especificação, como mostrado na figura 2.2 .

A última componente da $D R$ na figura 2.2 é mais um patamar superior de projeto, que visa compensar erros de offset, de ganho e transientes na amplitude do sinal de entrada. Em [1] sugere-se que seu valor pode variar entre 4 e $10 \mathrm{~dB}$.

A SNR no $A D C$ devido ao erro de quantização pode ser formulada como:

$$
S N R=6,02 \cdot N+1,76 \quad d B
$$

onde $N$ é o número de bits ou a resolução do $A D C[1,29,31]$.

\footnotetext{
${ }^{4}$ Usando o filtro da figura 2.5 e fazendo as contas da figura 2.2, o $A D C$ para o padrão GSM precisa de 12 bits de resolução. Essa maior complexidade tanto para o projeto quanto para futuros testes é uma das razões pelas que o conversor multipadrão é considerado além do escopo deste trabalho de mestrado.
} 
O número de bits no $A D C$ é escolhido normalmente para garantir que a contribuição do ruído de quantização à $S N R$ total na entrada do demodulador implementado dentro do $D S P$, seja desprezível quando comparada com o ruído introduzido pelo estágio inicial de $R F$. Juntando isso à definição da $S N R$ como uma medida da máxima faixa dinâmica do $A D C$, o requisito de resolução do conversor pode ser derivado usando a $D R$ e a equação (2.2). Então, a partir da figura 2.2, o $A D C$ operando sob o padrão Bluetooth precisa de uma $D R$ de $34 \mathrm{~dB}$ ou 6 bits.

\subsection{Largura de banda e frequência de amostragem}

O teorema de Nyquist é o principal critério para escolha da mínima frequência de amostragem necessária nos $A D C s$. No entanto, fatores adicionais fazem com que este parâmetro seja maior que esse patamar inferior. No caso do padrão Bluetooth, análises e simulações em nível de sistema em [1] levam à conclusão que uma taxa de amostragem mínima de $11 \mathrm{M} \mathrm{Hz}$ é necessária para atingir uma sincronização suficiente no demodulador. A especificação anterior é consequência do preâmbulo muito curto (tabela 2.1) no pacote de dados deste padrão. A importância desta seção do pacote de dados Bluetooth surge a partir de que o receptor (e o $A D C$ fazendo parte dele) a utiliza para ajustar e corrigir seus desvios e transientes.

\subsection{Consumo de potência}

Os dispositivos sem fio visam oferecer mobilidade ao usuário final. Portanto, usualmente são alimentados por baterias, as quais são geralmente as partes mais volumosas, pesadas e caras desses sistemas. Nessas condições, aumentar o tempo de duração da bateria

Tabela 2.2: Especificações de projeto do $A D C$.

\begin{tabular}{|c|c|}
\hline Parâmetro & Valor \\
\hline \hline Arquitetura & Time Interleaved Pipeline \\
\hline Tecnologia & $C M O S 0,35 \mu \mathrm{m}$ \\
\hline Tensão de alimentação & $3,3 \mathrm{~V}$ \\
\hline Máxima largura de banda de sinal & $500 \mathrm{kHz}$ \\
\hline Frequência de amostragem & $11 M \mathrm{Mz}$ \\
\hline Faixa Dinâmica na entrada & $34 \mathrm{~dB}$ \\
\hline Resolução & $6 \mathrm{bits}$ \\
\hline Excursão total na entrada $\left(V_{F S}\right)$ & $2 \mathrm{~V}_{p p}$ \\
\hline$I N L$ & $<0,5 L S B$ \\
\hline$D N L$ & $<1 L S B$ \\
\hline
\end{tabular}


ou otimizar o consumo de potência é e será sempre o alvo de maior prioridade em todos os níveis da hierarquia de projeto dos sistemas sem fio. $\mathrm{O} A D C$ como um dos principais blocos do receptor, usualmente contribui com mais do que $2 / 3$ do gasto de energia dele. Então, o projeto do $A D C$ deve procurar o menor consumo de potência, e qualquer economia na especificação desse bloco será valiosa na otimização de potência do receptor completo. Além disso, um menor consumo de corrente ajuda a manter a temperatura de operação do $A D C$ em um nível adequado.

A fim de fornecer uma visão geral do projeto do $A D C$, um resumo das especificações extraídas até agora é apresentado na tabela 2.2. Os parâmetros relacionados com a tecnologia de fabricação, a tensão de alimentação e a excursão de tensão esperada na entrada do $A D C$, foram determinados a partir das condições de projeto do transceptor completo.

\subsection{Generalidades da arquitetura time-interleaved}

Um dos principais atrativos da aplicação de técnicas time-interleaving consiste na possibilidade de aumentar a velocidade de operação de um conversor, mediante o funcionamento alternado de vários $A D C s$ controlados por diferentes fases de um sinal de

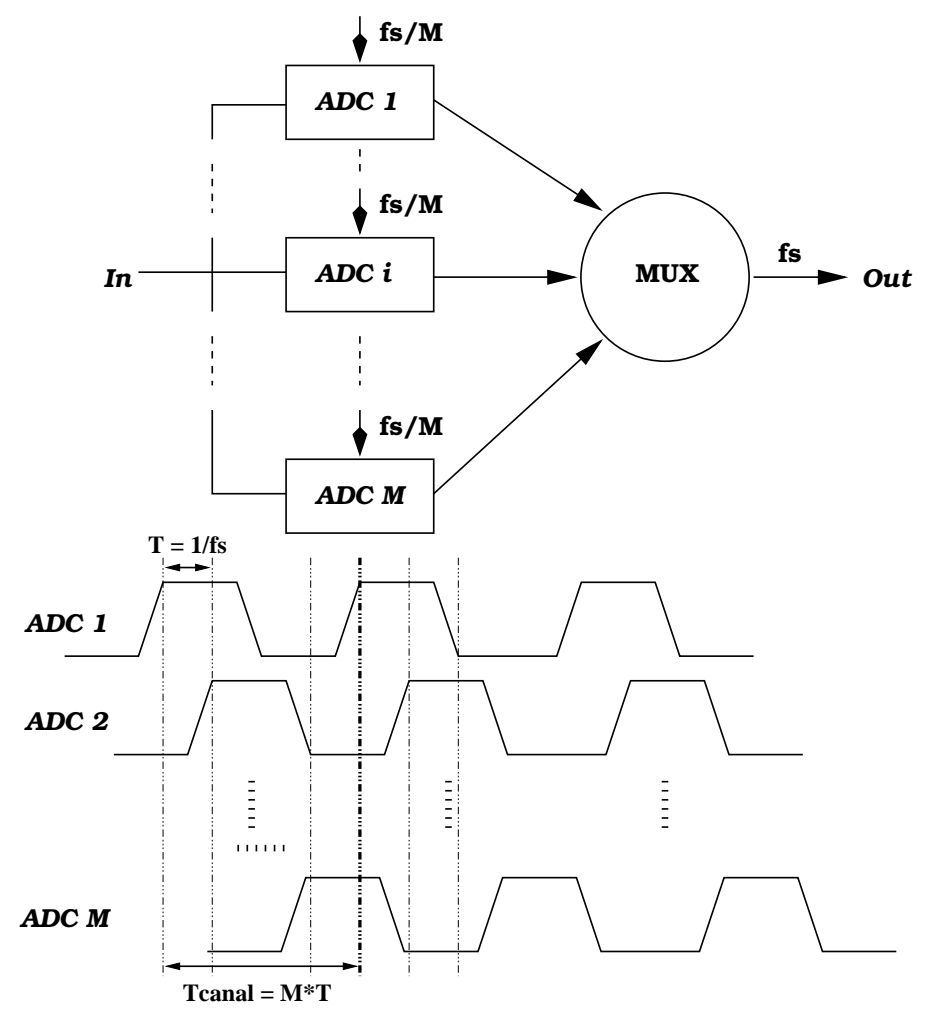

Figura 2.6: Esquema conceitual de time-interleaving e sua sequência temporal. 


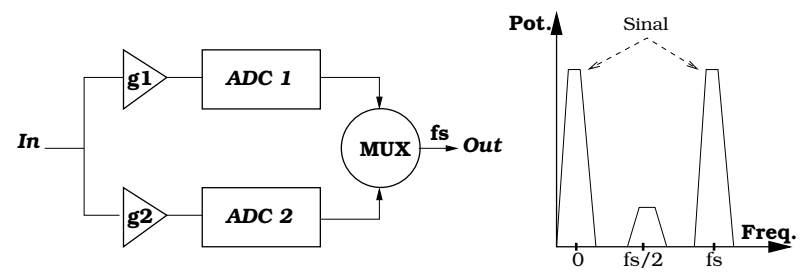

(a)

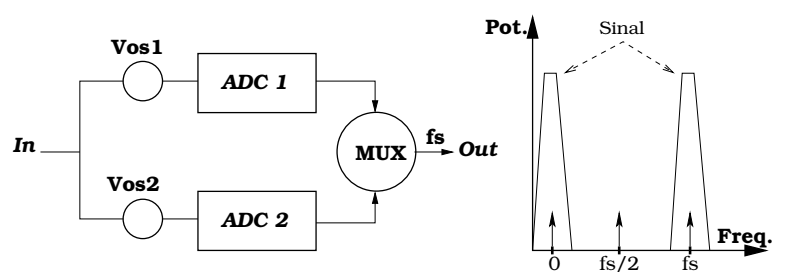

(b)

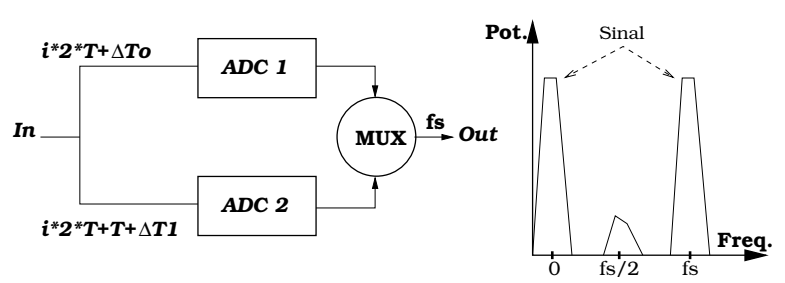

(c)

Figura 2.7: Limitações de desempenho da arquitetura time-interleaved: (a) erro de ganho; (b) erro de offset; (c) erro por desvios de fase.

relógio. Além disso, sob um ponto de vista diferente, a grande vantagem desta arquitetura consiste na redução da frequência de operação dos canais em paralelo dada uma taxa de amostragem específica.

O conceito de time-interleaving é mostrado na figura 2.6, onde os conversores podem usar qualquer arquitetura e funcionam a uma taxa de amostragem de $f_{s} / M$, com $f_{s}$ denotando a frequência de amostragem total do $A D C$ e $M$ o número de canais revezando conversões. Todos os canais paralelos têm a mesma resolução do $A D C$ completo e igual estrutura entre eles. Os bits de saída dos diferentes canais são multiplexados para formar a palavra digital correspondente a uma amostra do sinal analógico. Depois, ou simultaneamente, um algoritmo de correção digital pode ser aplicado aos bits de saída.

Conforme o esquema de temporização da figura 2.6, enquanto o $A D C$ do canal $i$ captura amostras e segura o valor do sinal analógico na sua entrada, os outros conversores estão ocupados convertendo amostras anteriores e posteriores. De forma similar, o multiplexador é controlado também por uma combinação das fases do relógio, de tal forma que ele escolhe a saída do canal $i$ quando o respectivo $A D C$ acabou a conversão da amostra. 
Enquanto a operação revezada de cadeias pipeline permite diminuir a velocidade de amostragem de cada canal, o mismatch ou descasamento entre parâmetros dos canais faz esta arquitetura suscetível à degradação da sua precisão e desempenho. É o caso dos erros por descasamento nos ganhos, offsets e desvios de fase, os quais são de especial relevância para o projeto do $A D C$ porque influenciam nas suas características espectrais, conforme mostrado na figura 2.7 para $M=2$ [29].

A estratégia mais simples para reduzir os erros por desvios de fase ou sincronização entre canais é o uso de um circuito de amostragem-retenção (SEGH - Sample and Hold) global na entrada do $A D C$, como é mostrado na figura 2.8. Após o $S \mathscr{G} H$ que opera com a taxa de amostragem total do conversor, $f_{s}$, o sinal de entrada não é mais contínuo. Portanto, quando os primeiros estágios de cada cadeia pipeline tomarem amostras deste novo sinal de entrada idealmente constante, e com velocidade menor que $f_{s}$, o instante de amostragem deixa de ser crítico.

Se além do dito acima, técnicas de amostragem dupla (double sampling) são usadas de tal forma que o opamp no $S \mathscr{G H}$ da entrada possa ser reutilizado e compartilhado entre as duas cadeias pipeline paralelas, a mudança entre as fases de amostragem e retenção será idêntica para ambos canais, minimizando então os desvios de fase. Os descasamentos de ganho e offset também podem ser atenuados mediante o reuso de opamps, tornando o mismatch de capacitores no $S \mathscr{E H}$ praticamente na fonte mais importante de erros.

A clara desvantagem da amostragem dupla surge a partir de que o $S \& H$ na entrada do $A D C$ deve ser operado com a taxa de conversão total $f_{s}$. Por isto, o projeto dos seus circuitos em tecnologia CMOS é bastante exigente devido à alta velocidade e precisão com que devem funcionar. Sendo assim, as qualidades e as falhas do $S \mathscr{G} H$ influenciam de forma importante o desempenho do $A D C$. Portanto, a arquitetura time-interleaved pipeline é melhor que a mais simples e rápida flash, apenas se a velocidade de aquisição do $S \mathscr{E} H$ na entrada é suficientemente maior que a conversão A/D dos $A D C s$ em cada canal.

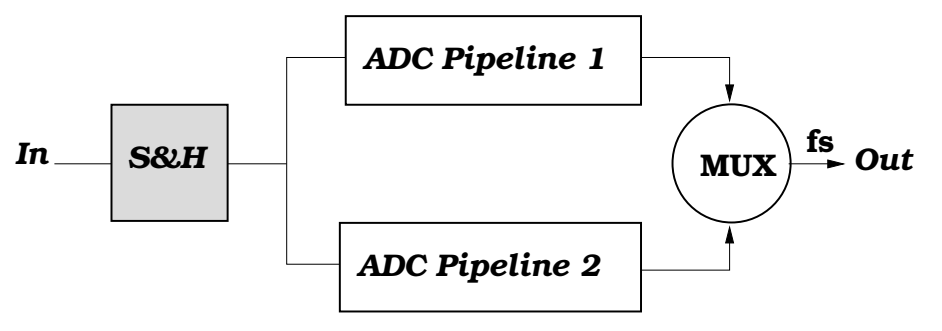

Figura 2.8: Arquitetura time-interleaved pipeline com circuito $S \mathscr{G} H$ na entrada. 


\subsection{O canal com arquitetura pipeline}

Já havendo identificado as vantagens e limitações do paralelismo na arquitetura timeinterleaved, é o momento de aprofundar mais na exploração da estrutura do $A D C$. Em vista disso, no restante desta seção será apresentado o estudo de um dos canais revezando funções no conversor, que usa a arquitetura pipeline pela sua inerente flexibilidade derivada dos seus estágios com diferentes especificações.

\subsubsection{Princípio de funcionamento}

A ideia básica por trás da conversão analógico-digital na cadeia pipeline consiste em encontrar um número de tensões de referência cuja soma seja igual ao valor da amostra do sinal contínuo original. Associando essas tensões de referência aos símbolos binários (0 e 1) conforme um sistema de codificação determinado, constrói-se a palavra digital de saída do $A D C$. Porém, tais códigos binários precisam de certo tratamento digital adicional para multiplexar, alinhar e corrigir os bits (a partir das tensões de referência) de saída de cada estágio.

O procedimento de conversão de sinais analógicos em códigos digitais é feito subtraindo as tensões de referência da amostra através dos diferentes estágios da cadeia pipeline. O resíduo de cada estágio, que usualmente é amplificado para melhorar a precisão, é aplicado na entrada do estágio seguinte. O objetivo é fazer o resíduo se aproximar de zero, indicando que a soma total dos níveis de referência ao longo do $A D C$ iguala ao valor analógico da amostra em conversão.

\subsubsection{Descrição da arquitetura}

Em um $A D C$ com estrutura pipeline a quantização dos sinais analógicos é distribuída ao longo de estágios operando sequencialmente, o que permite a implementação de conversores de moderada velocidade e considerável resolução com menor área. Um esquema geral da topologia pipeline é mostrado na figura 2.9. A cadeia inclui $m$ estágios em cascata e um bloco $S \mathscr{H} H$ que pode ser acrescentado na entrada visando evitar descasamentos de temporização nos dois caminhos de sinal até o subtrator do primeiro estágio, para sinais de entrada com variação rápida.

Cada um dos estágios exceto o último (o estágio $m$ é apenas um $s u b-A D C$ ), inclui um circuito $S \& H H$, um $s u b$ - $A D C$, um conversor digital-analógico $(D A C)$, um subtrator que 


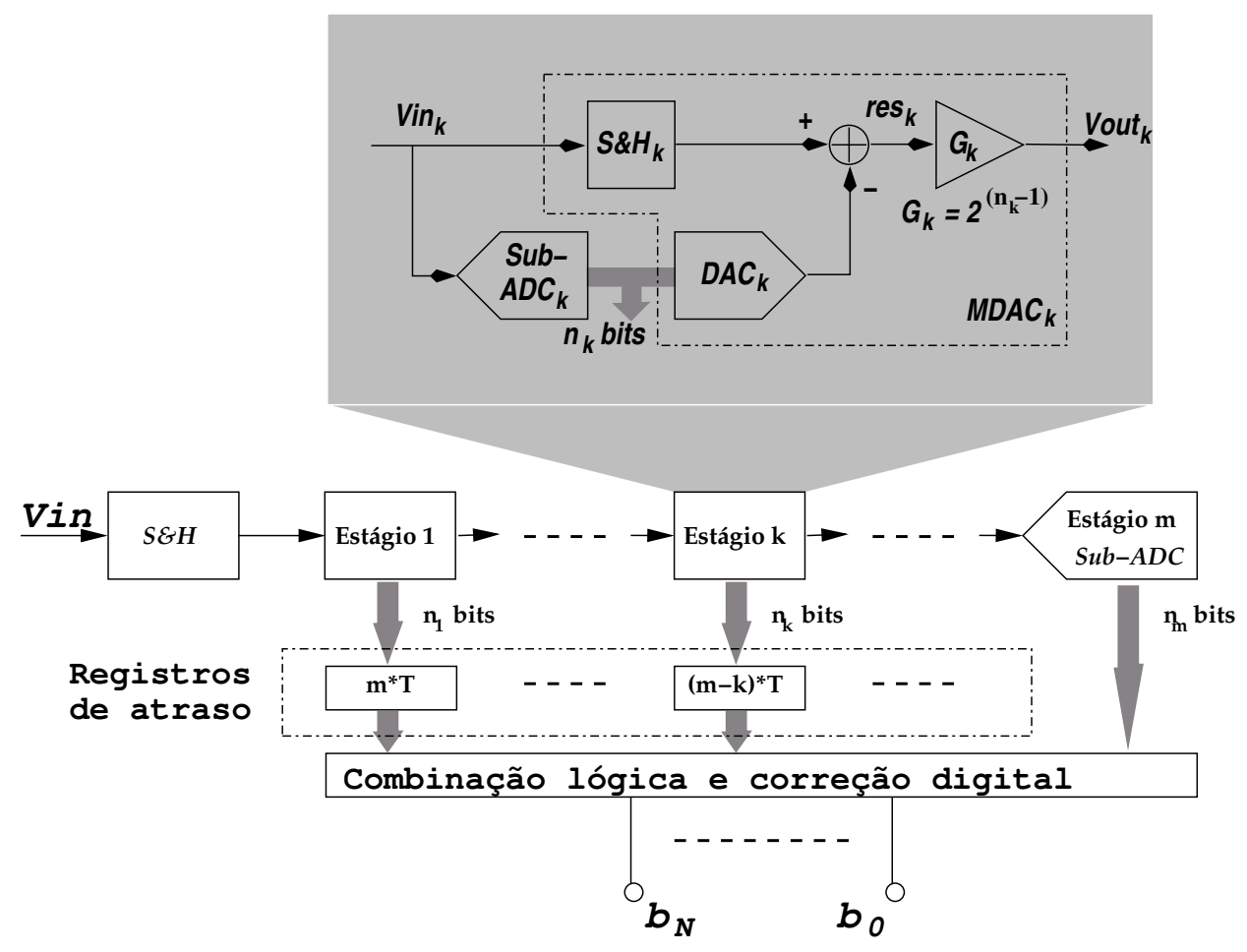

Figura 2.9: A arquitetura pipeline.

detecta o resíduo e um estágio de ganho, como mostra a figura 2.9. Cada estágio processa o sinal entrante em duas fases. Na primeira delas, é tomada uma amostra da tensão na entrada pelo bloco $S \mathscr{G} H$, ao mesmo tempo que é digitalizada pelo $s u b-A D C$. Na segunda fase, o resultado da conversão A/D é levado de volta ao domínio analógico pelo $D A C$ e subtraído da amostra armazenada no passo anterior, terminando com a amplificação do resíduo e sua retenção como sinal de entrada ao estágio seguinte na cadeia [19].

Em implementações com circuitos SC (Switched Capacitors), a operação de amostragem e retenção $(S \mathscr{E} H)$, a conversão D/A, a subtração e a amplificação do resíduo, são todas realizadas por apenas um bloco chamado de $M D A C$ (Multiplying $D A C$ ), que é composto por um opamp e um arranjo de capacitores e chaves MOS. Por outro lado, os quantizadores de baixa resolução geralmente são construídos usando a arquitetura flash, devido à forma rápida e direta da sua conversão. Esses sub-ADCs consistem em alguns comparadores, geradores de tensões de referência e portas lógicas. É comum utilizar as mesmas tensões de referência ao longo de todos os estágios na cadeia pipeline, a fim de diminuir descasamentos, área e consumo de potência do $A D C$.

Devido ao funcionamento da arquitetura pipeline baseado em circuitos $S \mathscr{E} H$, os estágios básicos na cadeia operam em forma concorrente para conseguir altas throughputs ${ }^{5}$,

\footnotetext{
${ }^{5} \mathrm{O}$ termo throughput refere-se à taxa de bits efetivos ou informação útil transmitida - ou convertida no caso particular do $A D C$.
} 


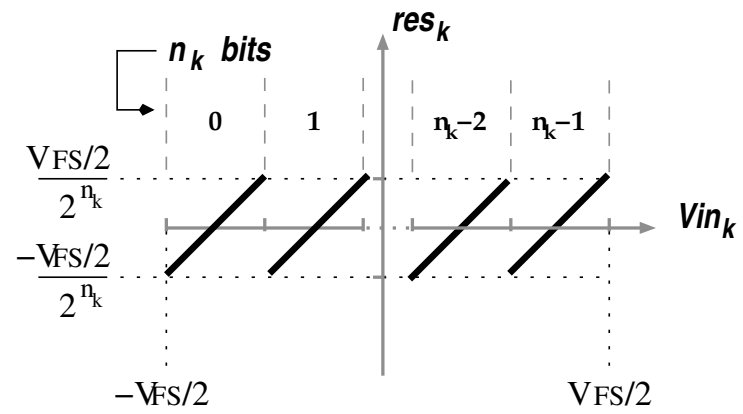

Figura 2.10: O sinal de resíduo em um estágio pipeline.

embora isso seja obtido em troca de um compromisso com a latência ${ }^{6}$ do sistema. Estágios consecutivos funcionam em fases opostas, pelo que uma amostra atravessa dois estágios em um ciclo de relógio. Desse modo, os bits dos diferentes estágios são produzidos em diferentes instantes, precisando-se então de blocos extras de circuitos digitais para atrasar, misturar, e finalmente corrigir os códigos digitais na saída da cadeia pipeline, como mostrado na figura 2.9.

\subsubsection{Formação de códigos digitais}

A função de transferência de cada estágio na cadeia pipeline antes da amplificação do resíduo tem a forma de dente de serra, indo de $+V_{F S} / 2^{n_{k}}$ a $-V_{F S} / 2^{n_{k}}$, onde $V_{F S}$ e $n_{k}$ representam a faixa em escala completa de excursão em tensão na entrada do $A D C$ e a resolução em bits do estágio $k$, conforme mostrado na figura 2.10. A amplificação do resíduo é necessária para aproveitar a faixa de excursão total na entrada do estágio seguinte, e portanto conseguir características uniformes nos circuitos e as tensões de referência ao longo da cadeia. O estágio seguinte digitaliza novamente essa tensão amplificada, atribuindo níveis de amplitude discretos a cada um dos segmentos do sinal com forma de serra. Esse processo de formação de palavras digitais é apresentado na figura 2.11, para dois estágios adjacentes com 2 bits de resolução [29].

Cada estágio tem uma resolução de $n_{k}$ bits que não precisa ser igual. O estágio 1 produz os bits mais significativos $(M S B)$, enquanto o estágio $m$ produz os bits menos significativos $(L S B)$. Aliás, frequentemente existe uma superposição entre os bits de saída de estágios adjacentes na cadeia pipeline. Sendo assim, a resolução efetiva de cada estágio é menor, mas a quantidade de bits redundantes é constante entre eles [1]. É usual escolher um bit de redundância ao longo da cadeia, exceto no último estágio, cuja resolução efetiva

\footnotetext{
${ }^{6}$ Tempo requerido para a conversão AD, desde o instante de amostragem até a disponibilização da palavra digital de saída. Normalmente é medida em ciclos de relógio.
} 


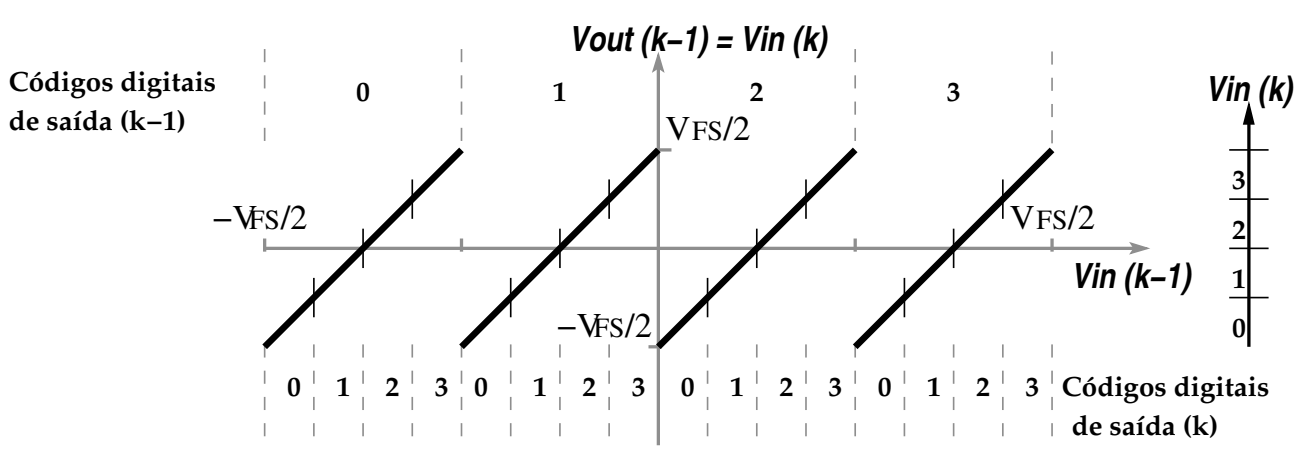

Figura 2.11: Formação de códigos digitais de saída entre estágios adjacentes.

corresponde aos $n_{m}$ bits de saída do seu sub-ADC. Desse modo, a resolução total de um $A D C$ que usa a arquitetura pipeline com 1 bit de redundância entre estágios, está dada pela equação (2.3).

$$
N=\sum_{k=1}^{m-1}\left(n_{k}-1\right)+n_{m}
$$

Um nível mínimo de redundância correspondente a um bit entre estágios vizinhos é suficiente para aplicar a correção digital aos códigos de saída do $A D C$ mediante algoritmos como RSD (Redundant Sign Digit), que será abordado em 3.2.1. Esta estratégia reduz os erros causados pelas não idealidades dos sub-ADCs e as diferentes fontes de mismatch ao longo da cadeia pipeline. Para introduzir tal nível de redundância, o ganho de amplificação do resíduo de cada estágio deve ser diminuído, e portanto, ocupar apenas uma parte da faixa de excursão em tensão na entrada do seguinte estágio [29]. Logo, o ganho aplicado ao resíduo de cada estágio é $2^{\left(n_{k}-1\right)}$, conforme mostrado na figura 2.9 .

\subsection{Otimização do consumo de potência da arquitetura}

Seguindo a tendência atual de minimização do consumo de potência dos circuitos integrados, os requisitos em nível de sistema da arquitetura do $A D C$ são avaliados dentro desse mesmo cenário. Então, foi feita uma análise aproximada do impacto do número de canais time-interleaved (ou número de cadéias pipeline) e da resolução por estágio pipeline no consumo de potência do conversor analógico-digital. Os principais resultados e conclusões são apresentados nas seguintes subseções. 


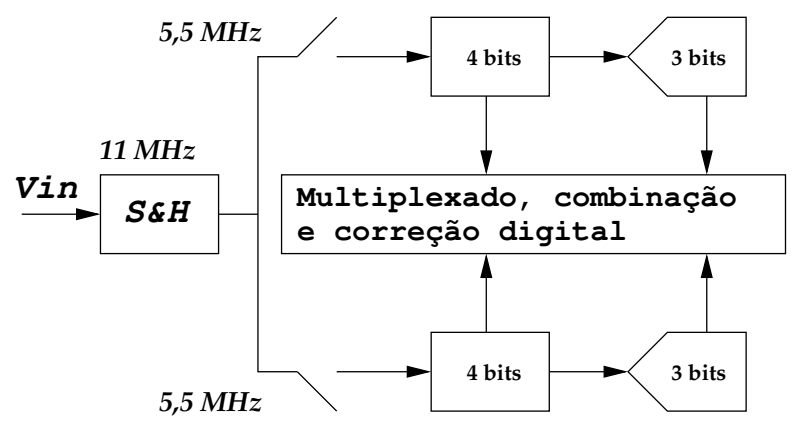

Figura 2.12: Resoluções por estágio do $A D C$ proposto.

\subsubsection{Escolha do número de canais}

A relação inversa entre o número de canais paralelos e o consumo de corrente do $A D C$ é devida principalmente à utilização de técnicas como a amostragem dupla e o reuso de amplificadores. Por outro lado, é bom usar a menor quantidade de canais time-interleaved devido às desvantagens associadas ao mismatch entre eles. Aliás, a partir da análise gráfica de variações paramétricas desenvolvidas em MATLAB, foi determinado que na faixa de frequências (dezenas de $M H z$ ) que vai operar o $A D C$ deste trabalho, o sacrifício em potência por utilizar menos canais paralelos é pequeno. Sendo assim, neste trabalho se escolhem 2 canais com ADCs utilizando a arquitetura pipeline. Cada uma dessas cadeias pipeline opera a $5,5 \mathrm{MS} / \mathrm{s}$, para atingir em conjunto a taxa de $11 \mathrm{MS} / \mathrm{s}$ requerida pelo padrão Bluetooth.

\subsubsection{Escolha da resolução por estágio}

Quanto menor a resolução nos estágios, a quantidade necessária deles é maior para atingir uma resolução total determinada para o $A D C$ proposto. Isso conduz a um maior número de amplificadores que incrementam o consumo de potência, mas também alguns requisitos menos exigentes para os comparadores de cada $s u b-A D C$. Por outro lado, cada bit a mais em um estágio pipeline duplica o número de comparadores e reduz pela metade o offset permitido no sub- $A D C$, incrementando ainda sua capacitância de entrada, e portanto, a carga vista pelos estágios anteriores.

Em cenários de moderada e alta resolução, incrementar o número de bits do primeiro estágio ajuda a relaxar os requisitos de projeto e tolerâncias de erro nos últimos estágios, conforme a equação de erro total referido na entrada em $(2.4)[31,34]$, onde $e_{k}$ e $G_{k}$ representam a tensão de erro e ganho do estágio $k$, respectivamente. Essas tensões de erro são devidas principalmente ao ruído térmico e ao mismatch nos capacitores. Desse 
modo, também é possível aplicar a técnica de escalonamento para reduzir o tamanho dos capacitores dos últimos estágios, e portanto, diminuir a área e a dissipação de potência de amplificadores menos carregados e mais velozes ao final da cadeia pipeline.

$$
e_{\text {TOTAL }}^{2}=e_{1}^{2}+\left(\frac{e_{2}}{G_{1}}\right)^{2}+\left(\frac{e_{3}}{G_{1} \cdot G_{2}}\right)^{2}+\cdots+\left(\frac{e_{m}}{\prod_{k=1}^{m-1} G_{k}}\right)^{2}
$$

Os $M D A C s$ fazem a principal contribuição ao consumo de potência do $A D C$. Então, outra vantagem de usar estágios com maiores resoluções é a diminuição do número de MDACs, como consequência da redução do número de estágios na cadeia pipeline. O dito anteriormente é válido mesmo que os $M D A C s$ dos estágios multibit consumam mais corrente que aqueles dos estágios de baixa resolução [1]. Além dos benefícios anteriores, a utilização de uma quantidade menor de estágios com maiores resoluções resulta em uma menor latência do sistema.

A partir das ideias apresentadas nos parágrafos anteriores, além de simulações em nível de sistema, escolhe-se uma estrutura de 2 estágios para as 2 cadeias pipeline paralelas do $A D C$. O primeiro estágio tem uma resolução de 4 bits (3 bits efetivos), e o segundo (formado apenas por um sub-ADC) trabalha com uma resolução de 3 bits (efetivos). A arquitetura descrita é mostrada na figura 2.12.

\subsection{Não idealidades e extração das especificações por estágio}

Neste ponto, o $A D C$ ainda é visualizado em nível de sistema, e desde essa mesma perspectiva, são extraídas as especificações de cada um dos estágios ou subsistemas que o constituem. O ponto inicial para determinação dos requisitos mínimos da arquitetura em estudo é o reconhecimento daqueles fatores que desviam o $A D C$ do seu desempenho ideal. Quando essa avaliação for feita, ressaltam-se as características do conversor que ajudam

Tabela 2.3: Especificações para os estágios na cadéia pipeline do $A D C$.

\begin{tabular}{|c|c|c|c|}
\hline Especificação & $\begin{array}{c}\boldsymbol{S} \boldsymbol{G} \boldsymbol{H} \\
\text { na entrada }\end{array}$ & $\begin{array}{c}\text { Estágio 1 } \\
\mathbf{4} \text { bits }\end{array}$ & $\begin{array}{c}\text { Estágio 2 } \\
\mathbf{3} \text { bits }\end{array}$ \\
\hline \hline $\begin{array}{c}\text { Erro no } s u b-A D C e_{A D C}(\mathrm{bits}) \\
\text { Tensão de } \text { offset } v_{\text {offset }}(\mathrm{mV})\end{array}$ & 16 & 6 & 3 \\
\hline Erro de ganho $e_{G}(\%)$ & 1,6 & 12,25 & 125 \\
\hline Erro no $D A C e_{D A C}(\mathrm{bits})$ & & 6 & \\
\hline Nível de ruído (dBc) & -34 & -34 & -25 \\
\hline Clock jitter & \multicolumn{3}{|c|}{$226 \mathrm{ps}$} \\
\hline
\end{tabular}


a suprimir o efeito das não idealidades, como por exemplo, a resolução dos estágios, a precisão do ganho dos amplificadores, as tensões de offset e os níveis de ruído, entre outras. Continuando no procedimento de projeto, determinam-se valores e limites para alguns desses parâmetros, a fim de garantir certo grau de desempenho exigido desde os padrões de comunicação sem fio.

Para sintetizar os resultados da análise descrita acima, a tabela 2.3 apresenta as especificações de cada um dos estágios e/ou blocos que fazem parte da arquitetura escolhida para o $A D C$, cujo procedimento de projeto é o tema deste documento. Nos capítulos seguintes, essas especificações são levadas ao nível de circuito para cada estágio básico da cadeia pipeline, ao mesmo tempo que se exploram as não idealidades derivadas desse novo cenário. 


\section{Os blocos da arquitetura}

Com o estudo da arquitetura do $A D C$ realizado no capítulo anterior, finaliza a análise sob o ponto de vista de sistema. Agora serão descritos em nível de circuito cada um dos blocos que constituem o conversor, apresentando as técnicas de projeto aplicadas para cumprir com as especificações e diminuir os efeitos das não idealidades. Na figura 3.1 é apresentado um esquemático completo do conversor proposto neste trabalho, incluindo todos os blocos.

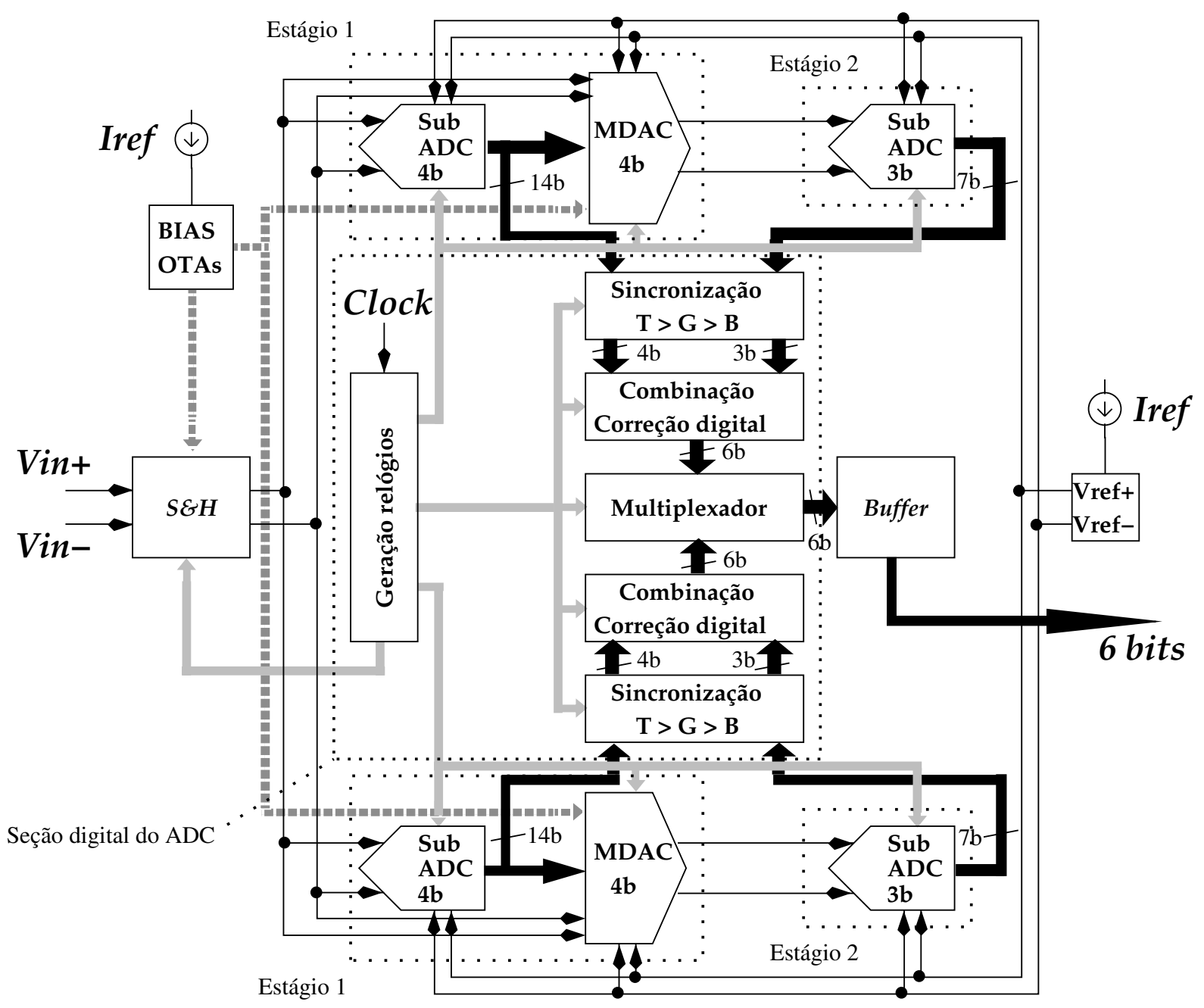

Figura 3.1: Esquema geral em nível de blocos do ADC time-interleaved pipeline. 


\subsection{Circuito de amostragem e retenção $(S \mathscr{G} H)$}

Nesta seção se aborda a análise do circuito de amostragem e retenção (sample and hold, $S \mathscr{G} H$ ) na entrada do conversor analógico-digital. Devido à importância desse circuito para enfrentar algumas das não idealidades derivadas do paralelismo, as suas características e desempenho são determinantes para a operação do sistema completo. De maneira semelhante, a função do $S \mathscr{G} H$ como interface entre os sinais de natureza contínua e discreta na entrada do conversor, faz com que sua compreensão e correta especificação sejam fundamentais para o projeto do $A D C$.

\subsubsection{Generalidades sobre os circuitos $S \xi H$}

A função principal de um circuito $S \mathscr{E} H$ é tomar amostras de um sinal entrante, e depois segurar ou armazenar o resultado em um elemento de memória até o instante seguinte de amostragem. Os sinais amostrados são frequentemente armazenados como tensões em capacitores, devido a sua maior facilidade e integrabilidade em circuitos monolíticos quando comparado com o armazenamento de correntes em indutores. Além disso, as amostras são adquiridas em intervalos de tempo uniformes, determinados pela frequência de operação do sistema global.

Os circuitos $S \mathscr{G} H$ operam em dois modos: modo amostragem (ou modo de aquisição) e modo retenção, cuja duração não precisa ser a mesma. Na fase de retenção, a saída do circuito é igual ao valor da amostra tomada previamente. No modo de amostragem, a saída pode seguir o sinal entrante ou ser fixada em algum valor de tensão. No primeiro caso, trata-se de um bloco de seguimento e retenção (track and hold, TEGH), enquanto o segundo representa o anteriormente citado $S \& H$, conforme mostrado na figura 3.2. Aliás, em alguns casos a tensão de saída amostrada do circuito $S \mathscr{G H}$ é segurada durante o ciclo completo do relógio, eliminando dessa maneira o reset durante a fase de aquisição.

No entanto, na prática um sinal não pode ser amostrado instantaneamente (figura 3.2), o qual cria a necessidade de uma janela temporária para aquisição. Então, em sistemas de alta velocidade, as saídas dos blocos $S \mathscr{E} H$ e $T \mathscr{G} H$ são muitos similares por causa da redução relativa do tempo em modo de amostragem quando comparado com essa janela de aquisição. Pela razão anterior, é comum achar na literatura o uso indistinguível de ambas denominações para os circuitos de amostragem em geral, enquanto neste documento prefere-se o termo $S \& H$. 


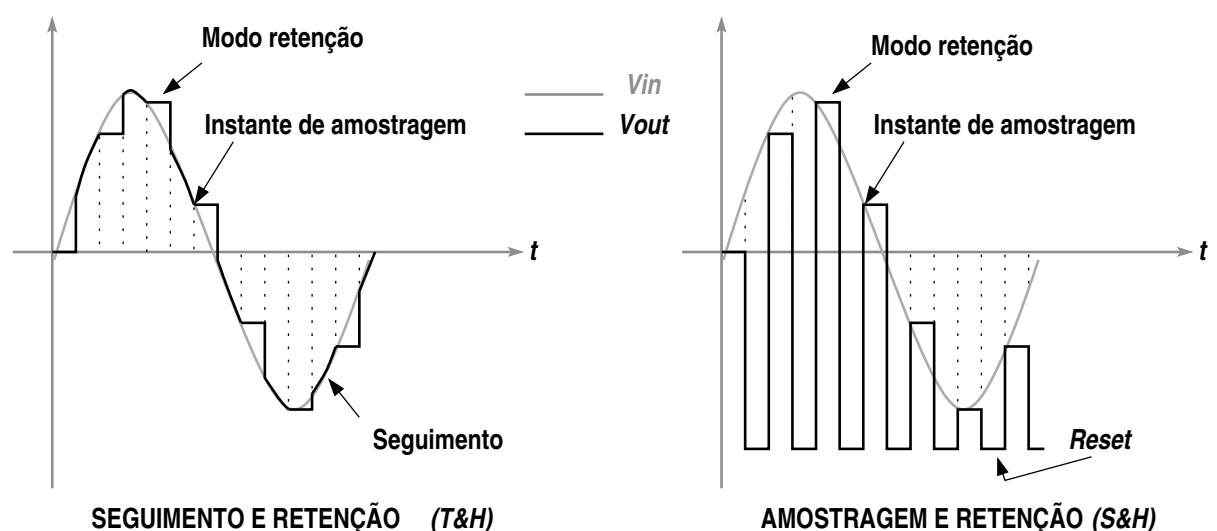

Figura 3.2: Modo de operação dos circuitos de amostragem.

\subsubsection{Descrição da arquitetura do $S \mathscr{E} H$}

Na figura 3.3 se mostra o diagrama esquemático do $S \& \xi H$ na entrada do $A D C$ com arquitetura time-interleaved pipeline, bem como o esquema de temporização das diferentes fases de relógio que controlam sua operação. Neste ponto é importante lembrar que este bloco é o primeiro na cadeia do conversor, e portanto recebe o sinal analógico de entrada na sua faixa completa de excursão em tensão diferencial e montada sobre um nível de tensão fixa, que neste caso é $V_{c m}=1,65 \mathrm{~V}$. O $S \mathscr{E} H$ adquire essas variações contínuas em níveis discretos de amplitude e tempo, antes de entregá-las em forma alternada a cada uma das duas cadeias pipeline que funcionam em paralelo e à metade da frequência total de conversão, $f_{s}$, que é a mesma na que opera o amostrador.

A figura 3.3 apresenta uma arquitetura diferencial baseada em capacitores chaveados $(S C)$ com amostragem dupla, insensível a descasamentos de temporização e que utiliza bottom-plate sampling e chaves CMOS. Deve notar-se que o uso de transistores PMOS e NMOS controlados por fases de relógio complementares é exclusivo daquelas chaves presentes na trajetória de transferência do sinal e que podem gerar limitações na faixa de excursão de tensão, sendo o caso de $S 1 N-S 4 N$ e $S 1 P-S 4 P$. O restante das chaves são implementadas com transistores $N M O S$.

Continuando com a exploração do circuito da figura 3.3, as chaves que definem os instantes de amostragem $(S 7 N, S 8 N, S 7 P, S 8 P)$ aplicam a estratégia de bottom-plate sampling usando fases de relógio apenas um pouco adiantadas na borda de descida $\phi_{1 e} \mathrm{e}$ $\phi_{2 e}$. Por outro lado, as chaves compartilhadas pelos dois circuitos de amostragem, $S 9 \mathrm{~N}$ e $S 9 P$, controladas pelos pulsos de $\phi$ à frequência $f_{s}$, tornam a arquitetura de amostragem dupla insensível a desvios de fase. O fato de que essas chaves conectem uma das placas dos capacitores ao nível de tensão comum $V_{c m}$ durante a fase e o instante de amostragem, 

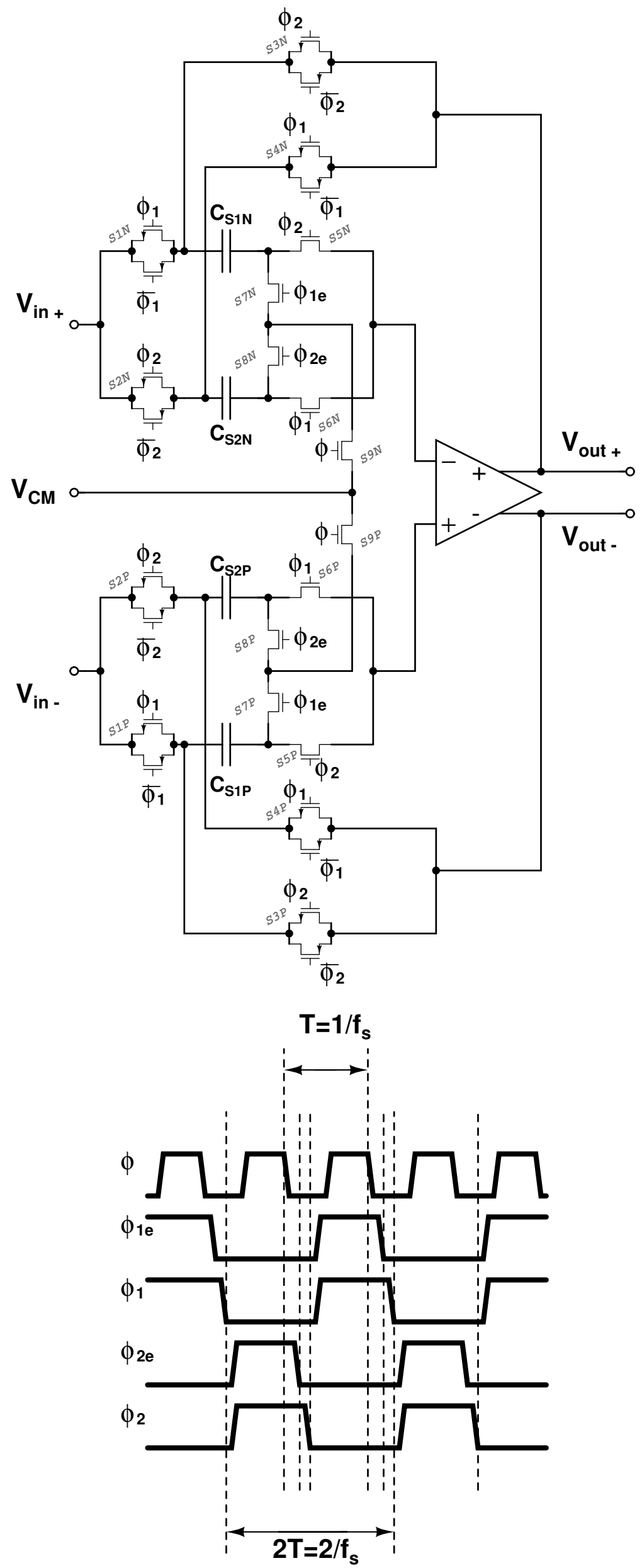

Figura 3.3: Arquitetura do $S \& H$ para o $A D C$ e seus sinais de controle. 

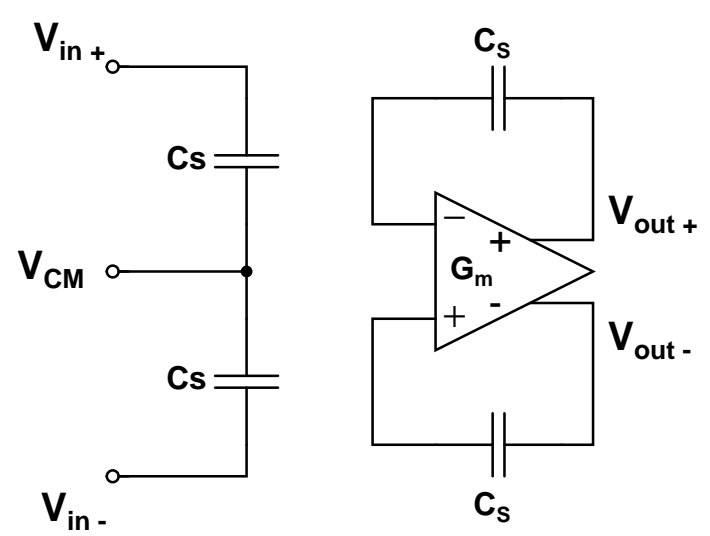

Figura 3.4: Circuito equivalente do $S \mathscr{E} H$ durante qualquer uma das fases $\left(\phi_{1}\right.$ ou $\left.\phi_{2}\right)$.

elimina a componente $D C$ no sinal entrante e atribui valores discretos só às variações contínuas do sinal adquirido em forma diferencial pelos capacitores de amostragem.

O esquema comum que opera em cada fase de relógio é mostrado na figura 3.4, onde foi estabelecido que $C_{S 1 N}=C_{S 2 N}=C_{S 1 P}=C_{S 2 P}=C_{S}$ para favorecer a simetria e casamento do circuito. Dependendo do sinal de relógio $\left(\phi_{1}\right.$ ou $\left.\phi_{2}\right)$ ativo, cada par diferencial de capacitores $C_{S}$ troca sua função entre amostragem e retenção, ao mesmo tempo que um dos canais pipeline é habilitado para adquirir a saída diferencial $V_{\text {out }}^{+}-$ $V_{\text {out }}^{-}$do $S \mathscr{E} H$. Como cada instante de amostragem envolve apenas um par de capacitores $C_{S}$, além de que o amplificador também acrescenta ruído térmico proveniente dos seus dispositivos ativos (que pode ser representado em uma fonte simples $\overline{v_{n, a m p}^{2}}$ ), a potência de ruído total na saída (e na entrada, pois é um sistema de ganho unitário) pode quantificarse com a equação (3.1). Nessa equação, $k$ é a constante de Boltzman, $T$ é a temperatura dos portadores no canal dos transistores funcionando como chaves e $\zeta$ é um fator de excesso de ruído. Este último fator é aproximadamente igual a $2 / 3$ para transistores de canal longo e toma maiores valores dependendo da polarização para transistores de canal curto [34]. A expressão (3.1) é utilizada para especificar o tamanho mínimo do capacitor permitido segundo os requisitos de ruído para este projeto.

$$
\overline{v_{n, \text { out }}^{2}}=2 \zeta \frac{k T}{C_{S}}+\overline{v_{n, a m p}^{2}}
$$

\subsubsection{Especificações para o $S \mathscr{G} H$}

Já havendo compreendido a função de cada elemento no circuito da figura 3.3, é o momento de determinar as características requeridas nesses elementos. O ponto de partida para essa 
tarefa são as especificações em nível de sistema para o $S \mathscr{G} H$ na tabela 2.3. A mínima capacitância de amostragem para cumprir com o nível de ruído requerido nessa tabela pode ser calculada a partir da expressão (3.1). Para isso, deve se assumir que o OTA é projetado para que sua contribuição de ruído térmico seja desprezível na frequência de operação do $S \mathscr{E} H$. A condição anterior torna $C_{S}$ o único elemento de controle para garantir os $-34 \mathrm{dBc}$ de ruído permitidos na entrada do circuito de amostragem. Então, utilizando as quantidades certas na equação (3.1), determina-se que uma capacitância menor que 1 fF pode cumprir com a especificação. Porém, um valor maior de capacitância deve ser especificado através de limitações derivadas de componentes parasitas e mismatch. Já no caso do amplificador, a tabela 3.1 apresenta os requisitos do OTA extraídos a partir de considerações de velocidade e precisão.

\subsection{Estágio básico pipeline}

O bloco $S \mathscr{G} H$ na seção anterior segura na sua saída níveis de tensão $D C$ como amostras do sinal analógico entrante, os quais estão disponíveis para cada um dos canais que funcionam de forma paralela, a cada par de ciclos da frequência total do conversor, $f_{s}$. Isto reduz os requisitos de largura de banda e velocidade dos seguintes blocos constituindo o verdadeiro núcleo do conversor com arquitetura pipeline, cujo estudo é o tema principal desta seção.

Conforme mostrado na figura 3.5, cada estágio básico na cadeia pipeline inclui um sub-ADC e um $M D A C$, exceto o último, que prescinde do segundo circuito e não precisa de redundância nos seus bits de saída. Para compreender esses estágios, são apresentados ao longo desta seção cada um dos seus componentes, as respectivas técnicas de circuito e a descrição detalhada tanto do processo de quantização quanto da correção digital desenvolvidos no interior deles.

Tabela 3.1: Especificações do $O T A$ dentro do $S \mathscr{B} H$.

\begin{tabular}{|c|c|}
\hline Especificação & Valor \\
\hline \hline Ganho $D C, A_{o}(\mathrm{~dB})$ & 40 \\
\hline Frequência de ganho unitário, $G B W(M H z)$ & 22 \\
\hline Slew rate, $S R(\mathrm{~V} / \mu \mathrm{s})$ & 20 \\
\hline Margem de fase, $P M\left({ }^{\circ}\right)$ & 60 \\
\hline Fonte de alimentação, $V_{D D}(\mathrm{~V})$ & 3,3 \\
\hline
\end{tabular}




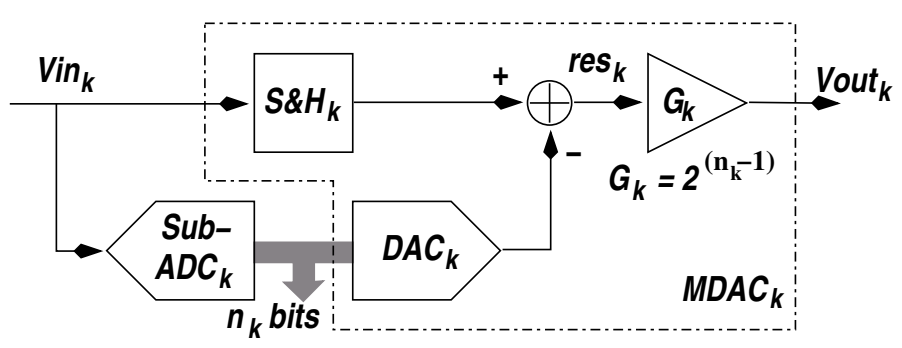

Figura 3.5: O estágio básico da arquitetura pipeline.

\subsubsection{Correção digital}

Conforme apresentado na subseção 2.6.3, o uso da correção digital mediante um bit de redundância $(R S D)$ permite relaxar as especificações de projeto do $s u b-A D C$ no estágio básico pipeline. Ainda a análise sobre a resolução por estágios desenvolvida na subseção 2.7.2 levou à escolha de uma configuração 4-3, com o primeiro estágio usando um bit de redundância. Então, a fim de estudar as implicações no projeto de circuitos a partir da utilização de $R S D$ se usará como guia visual a função de transferência da figura 3.6.

A figura 3.6(a), que usa o bit de redundância, mostra que um desvio significativo de qualquer um dos níveis de referência no $s u b-A D C_{1}$ pode fazer a curva com forma de serra exceder a faixa de excursão em tensão permitida $\left(V_{F S}\right)$ para o seguinte estágio. Se isto acontecer, provavelmente a saída do $s u b-A D C_{2}$ estará saturada para faixa $-V_{F S} / 2>$ $V_{\text {out }, 1}=V_{i n, 2}>V_{F S} / 2$, o que pode gerar grandes erros na conversão por perda de códigos e redução da resolução total efetiva do $A D C$ [29]. Por outro lado, em um estágio com um bit de redundância, o ganho é reduzido a $G_{1}=2^{\left(n_{1}-1\right)}$, onde $n_{1}$ é a resolução do estágio 1 . Dessa forma utiliza-se apenas a metade da faixa de excursão em tensão $\left(V_{F S} / 2\right)$ permitido na entrada do estágio 2, conforme mostrado na função de transferência da figura 3.6(b).

Como consequência do explicado no parágrafo anterior, enquanto não acontecerem desvios nos limiares do $s u b-A D C_{1}$ que gerem excursões maiores do que $V_{F S} / 2$ na figura 3.6(b), os códigos $0,1,6$ e 7 do estágio 2 não são utilizados. Essas palavras digitais servem como reserva para aplicação da correção digital mediante algoritmos como $R S D$. Sendo assim, o máximo desvio permitido das linhas de decisão ou referências na figura 3.6(b) corresponde a $L S B_{1} / 2=V_{F S} / 2^{\left(n_{1}+1\right)}$. Portanto, o máximo offset permitido nos comparadores do $s u b-A D C_{1}$ é também $L S B_{1} / 2=2 / 2^{(4+1)}=62,5 \mathrm{mV}$. Esta especificação aplica para todos os comparadores do primeiro estágio da cadeia pipeline, a partir de que ele usa 4 bits, incluso um bit de redundância.

A palavra digital de saída de uma configuração 4-3 sem bit de redundância é construída conforme mostrado na figura 3.7. Como pode ser visto, é necessário o deslocamento em 


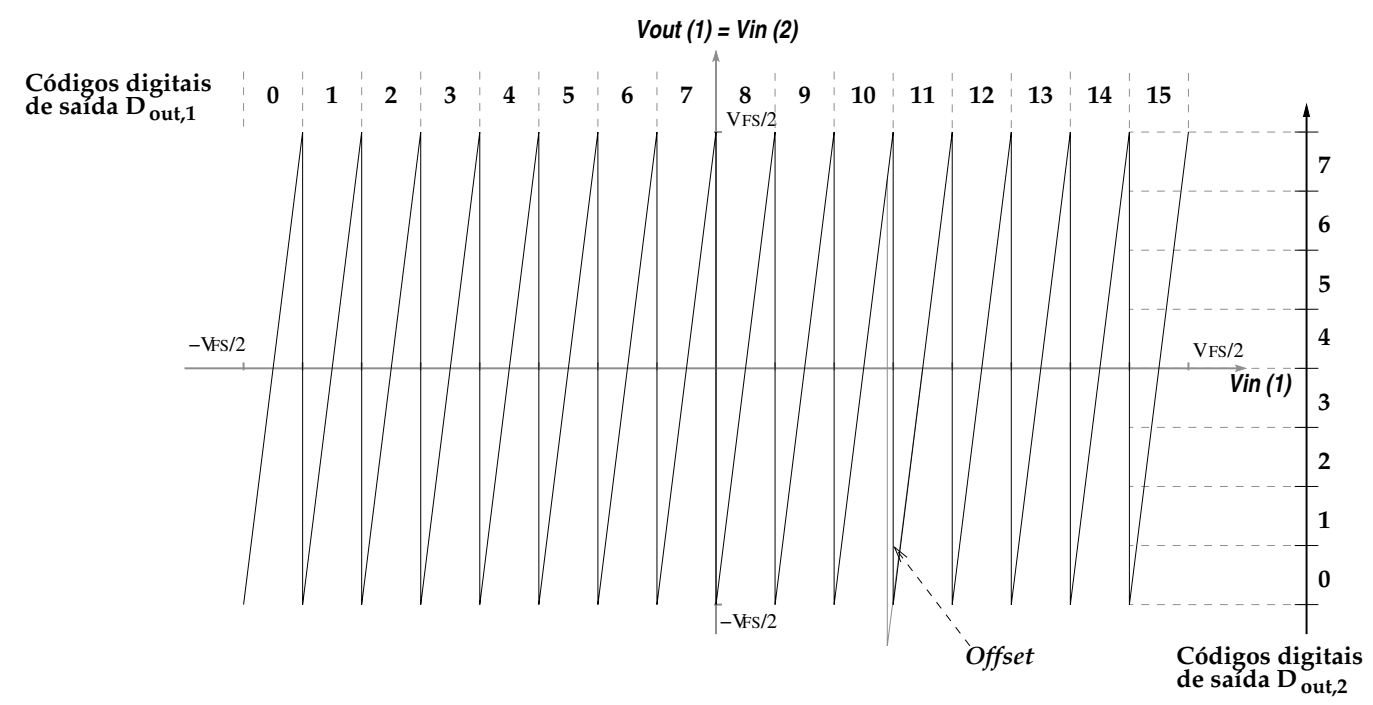

(a)

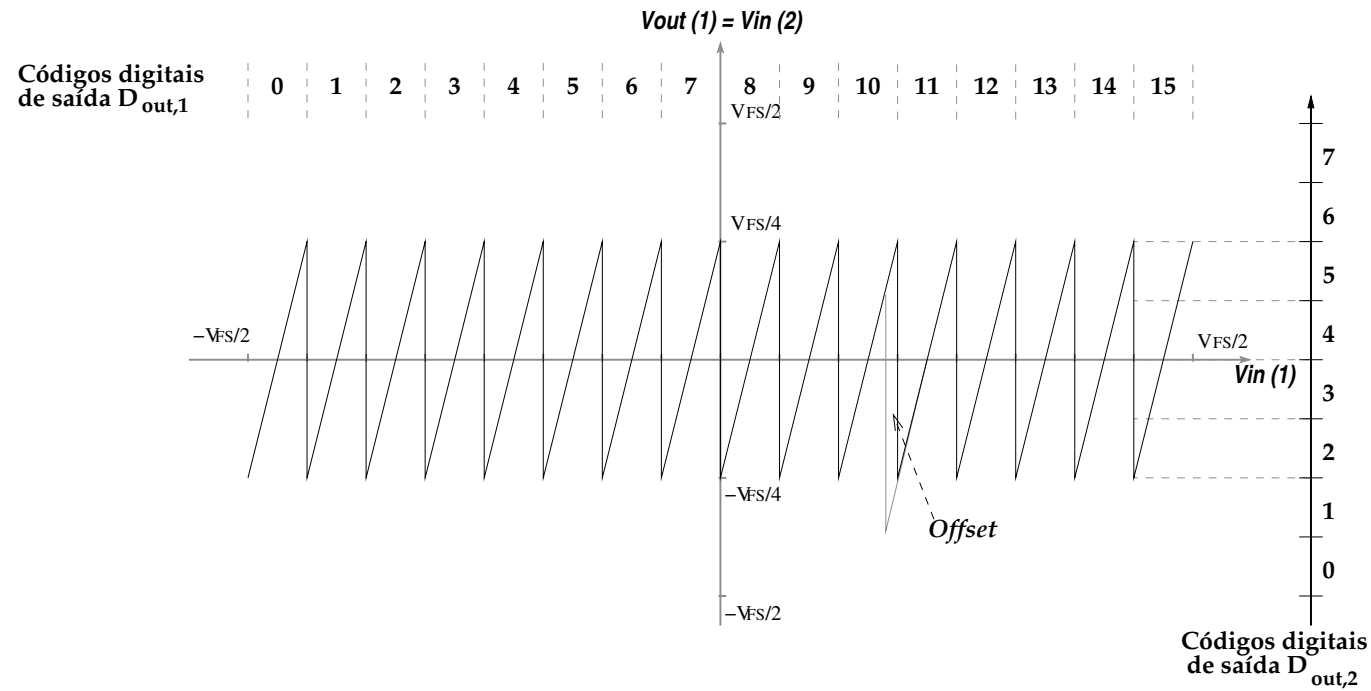

(b)

Figura 3.6: Formação de códigos digitais para estágios consecutivos 4-3: (a) sem bit de redundância, $G_{1}=2^{4}$; (b) com bit de redundância, $G_{1}=2^{(4-1)}$.

3 posições da saída do primeiro estágio antes de somá-la ao código do seguinte. Estas operações são muito simples de realizar com os circuitos digitais adequados. Por outro lado, a formação do código de saída quando utilizada a correção digital mediante $R S D$, realiza-se conforme o esquema da figura 3.8. Neste caso, desloca-se a saída do primeiro estágio apenas em 2 posições, o qual causa a superposição dos bits $L S B_{1}$ e $M S B_{2}$, ao mesmo tempo que surge a necessidade de somar com dígitos "vai um".

A construção da palavra digital de saída mediante somas com dígitos "vai um"e superposição de bits introduz um novo inconveniente que envolve os bits $L S B_{1}$ e $M S B_{2}$, ambos ressaltados na figura 3.8. Para evitar o transbordamento no resultado de 6 bits da 


$$
\begin{aligned}
& D_{\text {out }, 1} \longrightarrow \quad X \quad X \quad X \quad X \quad 0 \quad 00 \\
& +\quad X X X \longleftarrow D_{\text {out }, 2} \\
& \begin{array}{lllllll}
X & X & X & X & X & X & X
\end{array}
\end{aligned}
$$

Figura 3.7: Geração da saída digital sem $R S D$.

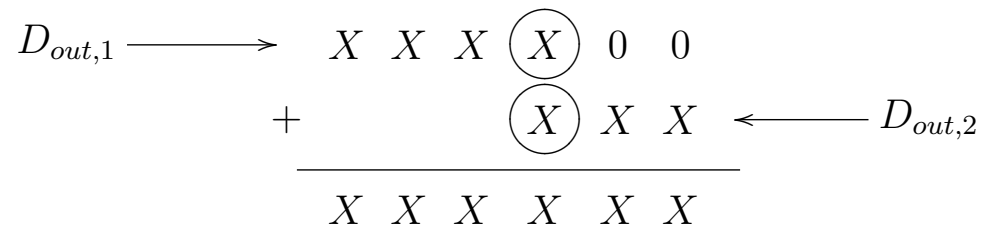

Figura 3.8: Geração da saída digital com $R S D$.

soma, esse par de bits não pode ser simultaneamente 1 quando o resto de $D_{\text {out }, 1}$ também é 1 , quer dizer, quando $D_{\text {out }, 1}=15$. Conferindo na figura 3.6(b), é claro que no caso dos níveis máximos de $V_{i n, 1}$ e $V_{i n, 2}$, ou seja, $V_{F S} / 2$ e $V_{F S} / 4$ respectivamente, as combinações de $D_{\text {out }, 1}=15$ e $D_{\text {out }, 2}=4$ ou 5 infringem a restrição anterior. No outro caso, isto é, para os níveis mínimos de $V_{i n, 1}=-V_{F S} / 2$ e $V_{i n, 2}=-V_{F S} / 4$, observa-se na figura 3.6(b) que o mínimo código digital de saída é 2 , obtido como resultado de combinar $D_{\text {out }, 1}=0$ e $D_{\text {out }, 2}=2$ conforme o esquema na figura 3.8. É claro então que existe um offset digital que deve ser eliminado.

Uma estratégia para resolver o problema apresentado anteriormente é introduzir offset nos estágios pipeline, conforme mostrado na figura 3.9. Se for aplicado só um dos offsets mostrados na figura 3.9, a construção da palavra digital precisaria de somas e subtrações (em complemento de 2). Em vez disso, quando aplicados os dois offsets, tal construção pode ser resolvida usando apenas somas e deslocamentos, como mostrado na figura 3.8. Devido à modificação anterior no estágio básico, a sua função de transferência se desloca para direita em $L S B / 2$, como exibido na figura 3.10(a). Sendo assim, agora o mínimo código digital de saída é 0 , e $D_{\text {out }, 1}=15$ combina-se só com $D_{\text {out }, 2}=2$ ou 3 , o que não produz nenhum transbordamento na palavra digital de saída. Mais uma vantagem desta

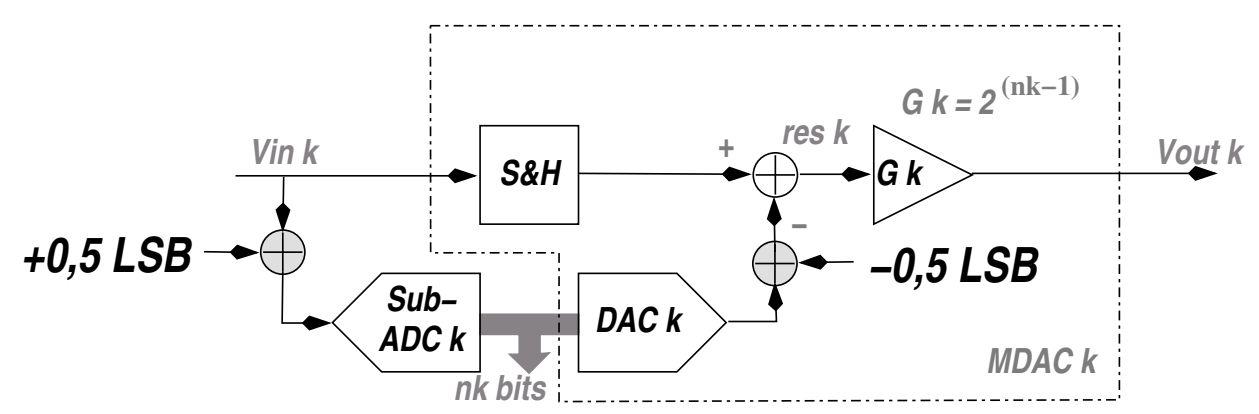

Figura 3.9: Modelo de um estágio básico pipeline com offset digital. 


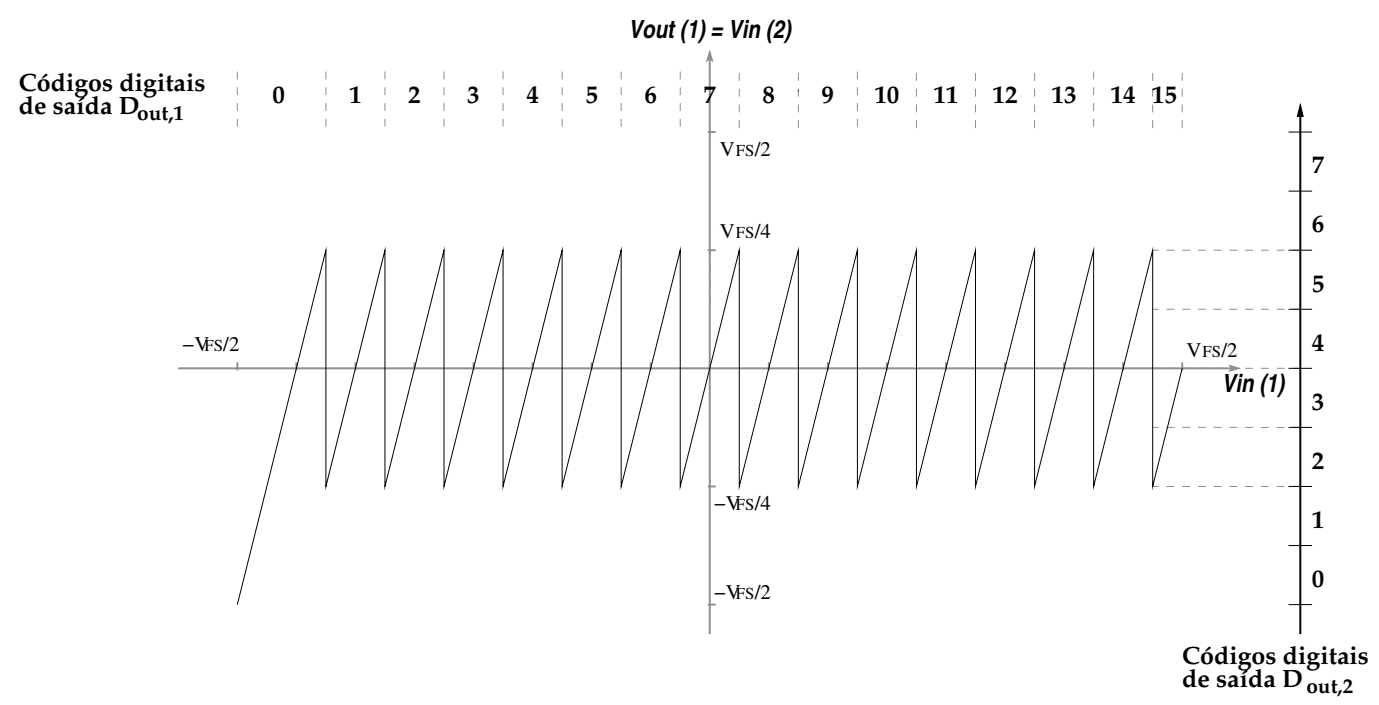

(a)

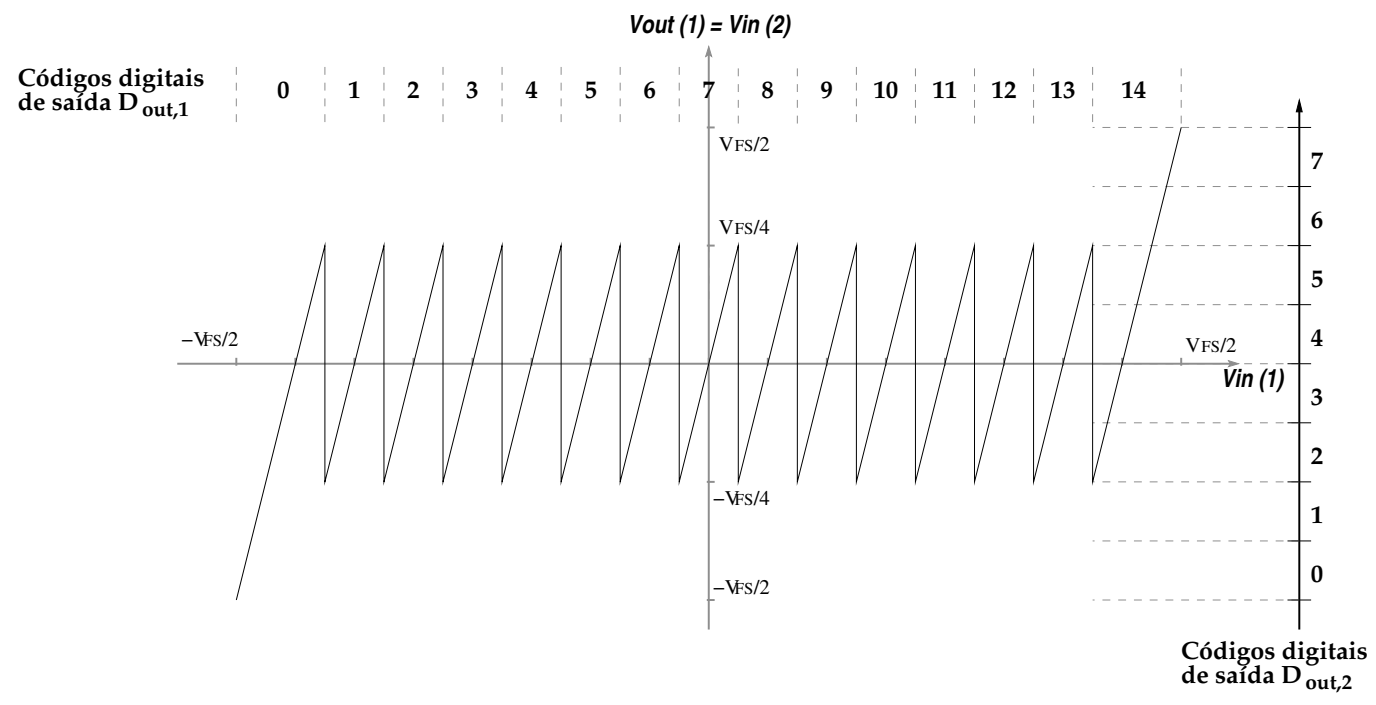

(b)

Figura 3.10: Função de transferência com $R S D$ : (a) assimétrica com desvio de $L S B_{1} / 2$; (b) simétrica com um nível de quantização e um comparador menos.

mudança é que o limiar de decisão em zero também se deslocou, melhorando a linearidade para sinais pequenos na entrada [29].

No entanto, a nova curva com forma de serra na figura 3.10(a) agora não é mais simétrica. Para resolver essa dificuldade a mais, o último nível de quantização à direita, correspondente a $D_{o u t, 1}=15$, é suprimido. Dessa forma, agora há apenas 14 níveis de quantização, mas a faixa de excursão na saída foi expandida, conforme mostrado na figura 3.10(b). Da explicação anterior, fica claro que o número total de códigos é o mesmo que antes. Finalmente, a aplicação da correção digital mediante 1 bit de redundância $(R S D)$, faz com que a distribuição dos limiares de decisão para os dois estágios pipeline do $A D C$ 


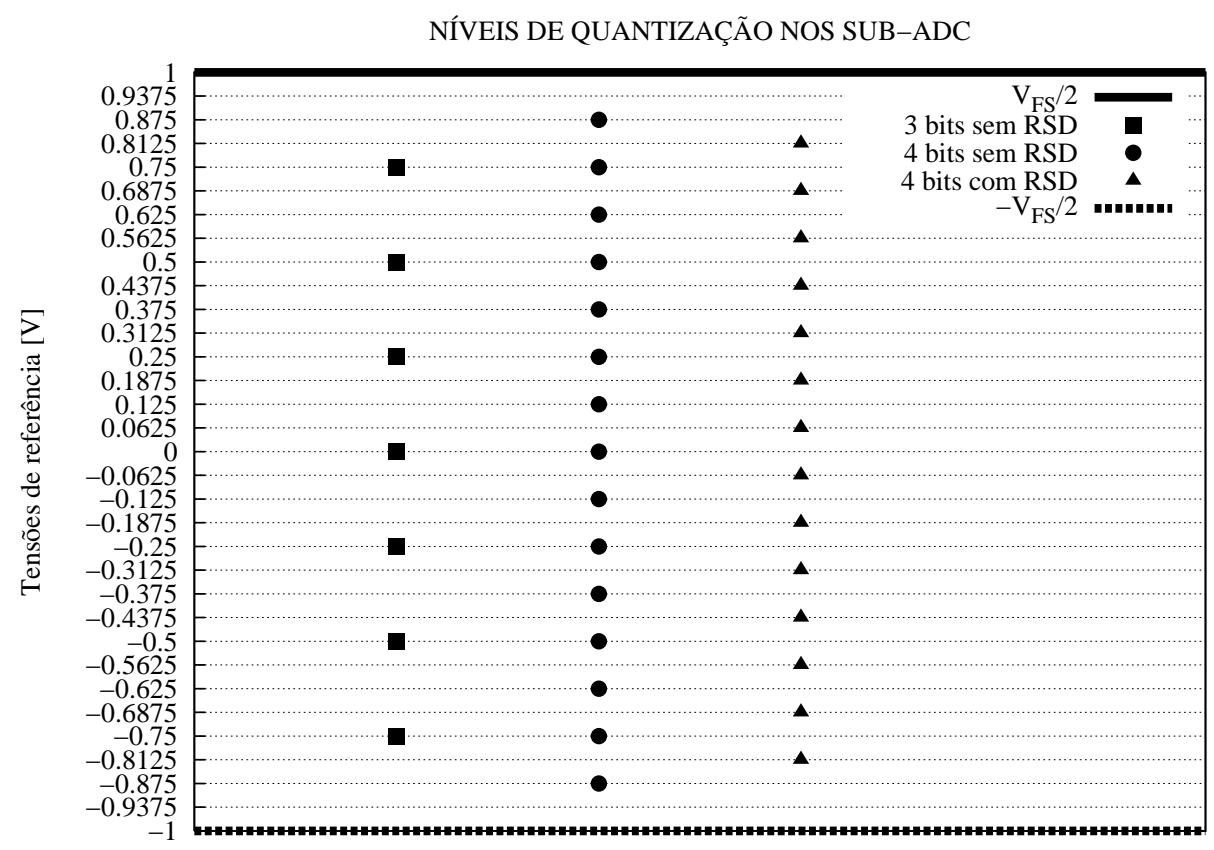

Figura 3.11: Efeito da correção digital na quantização dos sub-ADCs.

seja conforme apresentado em detalhe na figura 3.11 .

\subsubsection{O sub-ADC com arquitetura flash}

O processo de quantização apresentado na subseção anterior, é realizado no interior de cada estágio mediante um conversor analógico-digital de baixa resolução ou sub-ADC. Conforme a figura 3.5, este bloco recebe diretamente o sinal de entrada de um estágio e opera simultaneamente com a função $S \mathscr{E} H$ do $M D A C$. Portanto, o atraso entre esse par de blocos deve ser minimizado para evitar erros de conversão dependentes do sinal. Ainda, para maximizar o tempo disponível que permita o estabelecimento da saída do $M D A C$, e dessa maneira incrementar a velocidade da conversão, o sub-ADC deve ser capaz de entregar sua saída digital tão logo seja possível ao componente $D A C$ do $M D A C$. Então, é usual encontrar que o sub- $A D C$ dos estágios básicos em uma cadeia pipeline utiliza a arquitetura flash [31].

Conceitualmente a mais simples, e potencialmente a mais rápida, a arquitetura flash usa o paralelismo e a quantização distribuída para atingir uma alta velocidade de conversão. Essa topologia inclui um banco de comparadores de tensão, os quais comparam o sinal de entrada do estágio com suas respectivas tensões de referência, para estabelecer em conjunto cada um dos degraus de quantização da função de transferência do estágio. Os limiares de quantização são gerados dentro dos comparadores a partir da tensão de 
referência $\left(V_{\text {ref }}=V_{F S} / 2\right)$. A aplicação desta técnica no $s u b-A D C$ do segundo estágio com 3 bits efetivos, e no primeiro estágio com 4 bits (3 efetivos e 1 de redundância), é apresentada nas figuras 3.12 e 3.13, respectivamente.

Esses circuitos determinam os níveis de quantização na figura 3.11. A utilização de 14 comparadores para o sub-ADC de 4 bits permite a aplicação da correção digital mediante $R S D$. Entretanto, o sub-ADC de 3 bits usa 7 comparadores. O sinal de controle $V_{L A T C H}$ é fundamental para estabelecer os bits no instante certo e impedir o ruído kickback dos comparadores de degradar a saída do estágio anterior. Já o banco de registradores controlados pelas fases $\phi_{1}$ e $\phi_{2}$ sincronizam os bits gerados com o resto do sistema.

A comparação paralela realizada nos sub-ADCs das figuras 3.12 e 3.13 produz os códigos termômetros $\boldsymbol{D}$ de 7 bits e $\boldsymbol{T}$ de 14 bits, os quais são detalhados nas tabelas 3.2 e 3.3, respectivamente. Os registradores na saída dos comparadores são necessários para capturar adequadamente os bits gerados durante o sinal de latch $V_{L A T C H}$. Ainda,

Tabela 3.2: Detalhe do código termômetro para 3 bits.

\begin{tabular}{|c|c|c|c|c|}
\hline \multicolumn{2}{|c|}{$\begin{array}{c}\text { Nível de entrada } \\
\text { diferencial [V] }\end{array}$} & $\begin{array}{c}\text { Saída digital em } \\
\text { código binário }\end{array}$ & $\begin{array}{c}\text { Saída digital em } \\
\text { código Gray }\end{array}$ & $\begin{array}{c}\text { Código termômetro } \\
D_{7} \cdots \cdots D_{1}\end{array}$ \\
\hline \hline 0 & $-1,00 \Rightarrow-0,75$ & 000 & 000 & 0000000 \\
\hline 1 & $-0,75 \Rightarrow-0,50$ & 001 & 001 & 0000001 \\
\hline 2 & $-0,50 \Rightarrow-0,25$ & 010 & 011 & 0000011 \\
\hline 3 & $-0,25 \Rightarrow 0,00$ & 011 & 010 & 0000111 \\
\hline 4 & $0,00 \Rightarrow 0,25$ & 100 & 110 & 0001111 \\
\hline 5 & $0,25 \Rightarrow 0,50$ & 101 & 111 & 0011111 \\
\hline 6 & $0,50 \Rightarrow 0,75$ & 110 & 101 & 011111 \\
\hline 7 & $0,75 \Rightarrow 1,00$ & 111 & 100 & 111111 \\
\hline
\end{tabular}

Tabela 3.3: Detalhe do código termômetro para 4 bits.

\begin{tabular}{|c|c|c|c|c|}
\hline \multicolumn{2}{|c|}{$\begin{array}{c}\text { Nível de entrada } \\
\text { diferencial [V] }\end{array}$} & $\begin{array}{c}\text { Saída digital em } \\
\text { código binário }\end{array}$ & $\begin{array}{c}\text { Saída digital em } \\
\text { código Gray }\end{array}$ & $\begin{array}{c}\text { Código termômetro } \\
T_{14} \cdots \cdots \cdots T_{1}\end{array}$ \\
\hline \hline 0 & $-1,0000 \Rightarrow-0,8125$ & 0000 & 0000 & 00000000000000 \\
\hline 1 & $-0,8125 \Rightarrow-0,6875$ & 0001 & 0001 & 00000000000001 \\
\hline 2 & $-0,6875 \Rightarrow-0,5625$ & 0010 & 0011 & 00000000000011 \\
\hline 3 & $-0,5625 \Rightarrow-0,4375$ & 0011 & 0010 & 00000000000111 \\
\hline 4 & $-0,4375 \Rightarrow-0,3125$ & 0100 & 0110 & 00000000001111 \\
\hline 5 & $-0,3125 \Rightarrow-0,1875$ & 0101 & 0111 & 00000000011111 \\
\hline 6 & $-0,1875 \Rightarrow-0,0625$ & 0110 & 0101 & 00000000111111 \\
\hline 7 & $-0,0625 \Rightarrow 0,0625$ & 0111 & 0100 & 00000001111111 \\
\hline 8 & $0,0625 \Rightarrow 0,1875$ & 1000 & 1100 & 00000011111111 \\
\hline 9 & $0,1875 \Rightarrow 0,3125$ & 1001 & 1101 & 00000111111111 \\
\hline 10 & $0,3125 \Rightarrow 0,4375$ & 1010 & 1111 & 0000111111111 \\
\hline 11 & $0,4375 \Rightarrow 0,5625$ & 1011 & 1110 & 0001111111111 \\
\hline 12 & $0,5625 \Rightarrow 0,6875$ & 1100 & 1010 & 0011111111111 \\
\hline 13 & $0,6875 \Rightarrow 0,8125$ & 1101 & 1011 & 0111111111111 \\
\hline 14 & $0,8125 \Rightarrow 1,0000$ & 1110 & 1001 & 1111111111111 \\
\hline
\end{tabular}


esses códigos termômetro são convertidos em códigos binário para gerar a saída digital do sub-ADC e do correspondente estágio pipeline ao que pertence. A codificação Gray é usada como fase intermediária visando diminuir os efeitos de transientes e erros nos códigos termômetro [1].

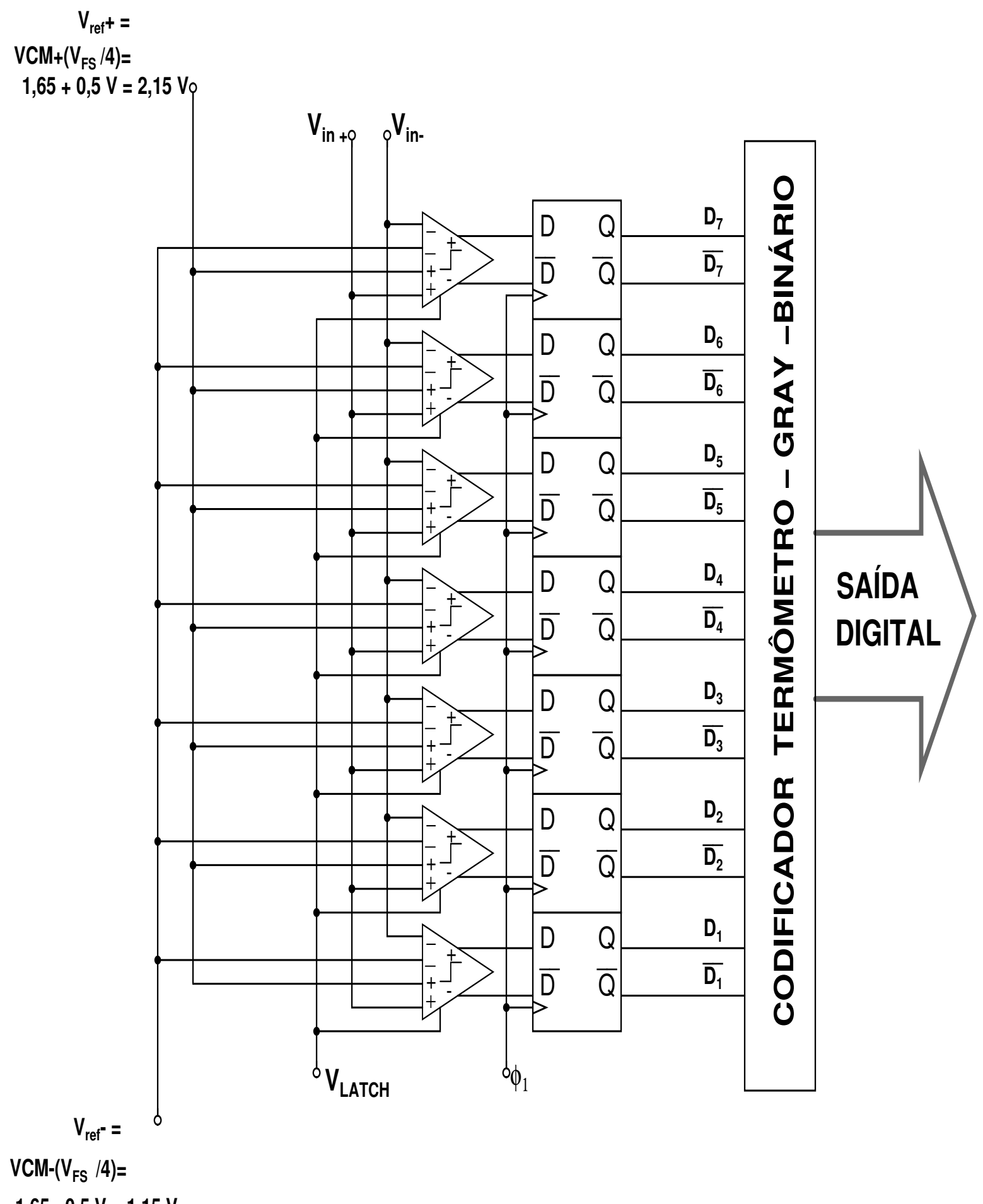

$1,65-0,5 \mathrm{~V}=1,15 \mathrm{~V}$

Figura 3.12: O sub- $A D C$ de 3 bits sem bit de redundância. 


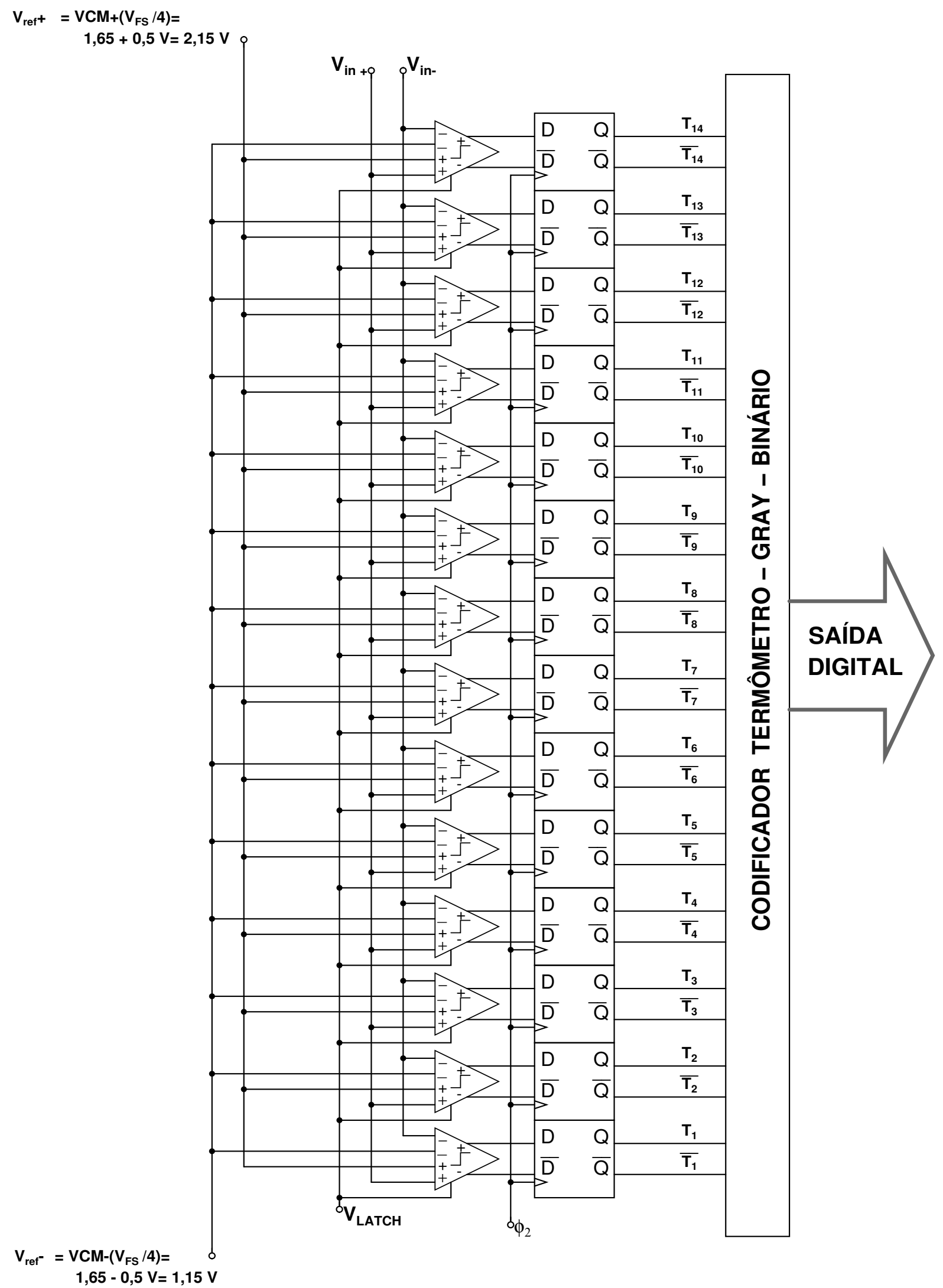

Figura 3.13: $\mathrm{O} s u b-A D C$ de 4 bits com bit de redundância. 


\subsubsection{O $M D A C$}

O outro bloco que faz parte do estágio básico pipeline, e cujo desempenho é o mais crítico para a arquitetura completa do $A D C$, é o multiplying digital-to-analog converter (MDAC), mostrado com o esquema de blocos na figura 3.5. A sua função é retornar ao domínio analógico a saída digital do sub-ADC e logo depois subtraí-la do sinal amostrado e retido na entrada do estágio, para finalmente amplificar o resíduo que será utilizado como entrada do estágio seguinte na cadeia pipeline. Do mesmo modo que o circuito de amostragem e retenção, a implementação do $M D A C$ está baseada normalmente em topologias de capacitores chaveados $(S C)$ [31], e portanto não precisa de uma cadeia resistiva. Pela razão anterior, o $M D A C$ não consome potência estática e sua operação em função da redistribuição de cargas complementa de forma natural o princípio de funcionamento da arquitetura básica do $S C$-SEHH.

Para analisar a forma como o resíduo amplificado é gerado a partir da saída do $S \mathscr{G} H$ e a saída digital do $s u b-A D C$, a tabela 3.4 apresenta as relações que descrevem a geração de $V_{\text {out }}$ para cada um dos 15 valores possíveis do código T. Entretanto, estabelece-se que $n=4$ bits, $V_{\text {ref }}=V_{\text {ref }}^{+}-V_{\text {ref }}^{-}=V_{F S} / 2=1 \mathrm{~V}, V_{\mathbf{T}_{\text {noRSD }}}$ representa os limiares de comparação do sub-ADC de 4 bits sem $R S D$ (figura 3.11) e o offset digital introduzido na saída do $D A C$ na figura 3.9 é igual a $R S D_{\text {offset }}=V_{\text {ref }} / 2^{n}$. Usando as definições anteriores, na expressão (3.2) se descreve a função de transferência para o $M D A C$.

$$
V_{\text {out }}=2^{n-1} \cdot\left[V_{\text {in }}-\left(-\frac{V_{\text {ref }}}{2^{n}}+V_{\mathbf{T}_{\text {noRSD }}}\right)\right]=2^{n-1} \cdot\left[V_{\text {in }}-\frac{\mathbf{T} V_{\text {ref }}}{2^{n}}\right]
$$

Tabela 3.4: Detalhe da operação do $M D A C$ de 4 bits utilizando $R S D$.

\begin{tabular}{|c|c|l|}
\hline $\begin{array}{c}\text { Entrada digital em } \\
\text { código binário }\end{array}$ & $\begin{array}{c}\text { Código termômetro } \\
T_{14} \cdots \cdots \cdots T_{1}\end{array}$ & $\begin{array}{l}\text { Função de transferência do } \boldsymbol{M D A C} \\
V_{\text {out }}=G \cdot\left(V_{\text {in }}+R S D_{\text {offset }}-V_{\mathbf{T}_{\text {noR }}}\right)\end{array}$ \\
\hline \hline 0000 & 00000000000000 & $V_{\text {out }}=8 \cdot\left(V_{\text {in }}+0,875\right)=8 \cdot\left(V_{\text {in }}+1 / 16+13 / 16\right)$ \\
\hline 0001 & 00000000000001 & $V_{\text {out }}=8 \cdot\left(V_{\text {in }}+0,750\right)=8 \cdot\left(V_{\text {in }}+1 / 16+11 / 16\right)$ \\
\hline 0010 & 00000000000011 & $V_{\text {out }}=8 \cdot\left(V_{\text {in }}+0,625\right)=8 \cdot\left(V_{\text {in }}+1 / 16+9 / 16\right)$ \\
\hline 0011 & 00000000000111 & $V_{\text {out }}=8 \cdot\left(V_{\text {in }}+0,500\right)=8 \cdot\left(V_{\text {in }}+1 / 16+7 / 16\right)$ \\
\hline 0100 & 00000000001111 & $V_{\text {out }}=8 \cdot\left(V_{\text {in }}+0,375\right)=8 \cdot\left(V_{\text {in }}+1 / 16+5 / 16\right)$ \\
\hline 0101 & 00000000011111 & $V_{\text {out }}=8 \cdot\left(V_{\text {in }}+0,250\right)=8 \cdot\left(V_{\text {in }}+1 / 16+3 / 16\right)$ \\
\hline 0110 & 00000000111111 & $V_{\text {out }}=8 \cdot\left(V_{\text {in }}+0,125\right)=8 \cdot\left(V_{\text {in }}+1 / 16+1 / 16\right)$ \\
\hline 0111 & 000000011111111 & $V_{\text {out }}=8 \cdot\left(V_{\text {in }}+0,000\right)=8 \cdot\left(V_{\text {in }}+1 / 16-1 / 16\right)$ \\
\hline 1000 & 00000011111111 & $V_{\text {out }}=8 \cdot\left(V_{\text {in }}-0,125\right)=8 \cdot\left(V_{\text {in }}+1 / 16-3 / 16\right)$ \\
\hline 1001 & 00000111111111 & $V_{\text {out }}=8 \cdot\left(V_{\text {in }}-0,250\right)=8 \cdot\left(V_{\text {in }}+1 / 16-5 / 16\right)$ \\
\hline 1010 & 000011111111111 & $V_{\text {out }}=8 \cdot\left(V_{\text {in }}-0,375\right)=8 \cdot\left(V_{\text {in }}+1 / 16-7 / 16\right)$ \\
\hline 1011 & 00011111111111 & $V_{\text {out }}=8 \cdot\left(V_{\text {in }}-0,500\right)=8 \cdot\left(V_{\text {in }}+1 / 16-9 / 16\right)$ \\
\hline 1100 & 001111111111111 & $V_{\text {out }}=8 \cdot\left(V_{\text {in }}-0,625\right)=8 \cdot\left(V_{\text {in }}+1 / 16-11 / 16\right)$ \\
\hline 1101 & 011111111111111 & $V_{\text {out }}=8 \cdot\left(V_{\text {in }}-0,750\right)=8 \cdot\left(V_{\text {in }}+1 / 16-13 / 16\right)$ \\
\hline 1110 & 11111111111111 & $V_{\text {out }}=8 \cdot\left(V_{\text {in }}-0,875\right)=8 \cdot\left(V_{\text {in }}+1 / 16-15 / 16\right)$ \\
\hline
\end{tabular}


A estrutura da função de transferência em (3.2) permite visualizar com clareza as diferentes operações desenvolvidas pelo $M D A C$. Da mesma forma, observa-se o efeito da correção digital mediante $R S D$ na redução pela metade do ganho $\left(2^{n-1}\right)$ e no offset digital de $-L S B / 2=-V_{\text {ref }} / 2^{n}$. A tabela 3.5 mostra explicitamente a formação da tensão que depende do código digital de saída do $s u b-A D C$ usando $R S D\left(V_{\mathbf{T}_{R S D}}\right)$, cujo numerador é o resultado da soma algébrica de valores unitários $\left( \pm V_{\text {ref }}\right)$ segundo o valor de cada bit no código termômetro $\mathbf{T}$.

O esquemático do $M D A C$ é apresentado na figura 3.14, onde são mostrados cada um dos capacitores unitários $C_{u}$ que conformam o banco de amostragem, bem como a implementação das chaves mediante transistores $M O S$ operando entre as regiões de corte e triodo, segundo o nível de tensão aplicado nas suas portas. Os sinais que controlam as chaves são duas fases de relógio não superpostas $\left(\phi_{1}\right.$ e $\left.\phi_{2}\right)$ que determinam o modo de operação no $M D A C$ do mesmo modo que no $S \mathscr{E} H$ da seção anterior, e cada um dos 14 bits no código digital termômetro $\mathbf{T}$ para decidir a polaridade de $\pm V_{\text {ref }}$ que deve se conectar ao capacitor $C_{u}$ associado.

É importante ressaltar que a estrutura apresentada na figura 3.14 não é a única forma de implementar o banco capacitivo de amostragem no $M D A C$. Na literatura existem outras alternativas, como a utilização de capacitores com peso binário $\left(2^{i} \cdot C_{u}, i=0 \ldots n\right)$ em vez de unitários. Essa topologia requer menos capacitores porém de maior valor, bem como a utilização da saída digital do sub- $A D C$ em código binário e não em termômetro [19, 29]. Outra opção é a apresentada em [31, 34], que tem a vantagem que precisa da mesma

Tabela 3.5: Detalhe da tensão $\frac{\mathbf{T} V_{r e f}}{2^{n}}=V_{\mathbf{T}_{n o R S D}}-R S D_{o f f s e t}$ na equação (3.2).

\begin{tabular}{|c|c|c|c|c|c|c|c|c|c|c|c|c|c|c|c|}
\hline $\mathbf{T} V_{r e f}$ & \multicolumn{14}{|c|}{ Código termômetro $\mathrm{T}$} & \multirow{2}{*}{$\begin{array}{l}\text { Código } \\
\text { binário }\end{array}$} \\
\hline $2^{n}$ & $T_{14}$ & $T_{13}$ & $T_{12}$ & $T_{11}$ & $T_{10}$ & $T_{9}$ & $T_{8}$ & $T_{7}$ & $T_{6}$ & $T_{5}$ & $T_{4}$ & $T_{3}$ & $T_{2}$ & $T_{1}$ & \\
\hline$-14 / 16$ & -1 & -1 & $\overline{-1}$ & -1 & $\overline{-1}$ & $\overline{-1}$ & $\overline{-1}$ & $\overline{-1}$ & $\overline{-1}$ & -1 & $\overline{-1}$ & -1 & -1 & $\overline{-1}$ & 20000 \\
\hline$-12 / 16$ & -1 & -1 & -1 & -1 & -1 & -1 & -1 & -1 & -1 & -1 & -1 & -1 & -1 & 1 & 0001 \\
\hline$-10 / 16$ & -1 & -1 & -1 & -1 & -1 & -1 & -1 & -1 & -1 & -1 & -1 & -1 & 1 & 1 & 0010 \\
\hline$-8 / 16$ & -1 & -1 & -1 & -1 & -1 & -1 & -1 & -1 & -1 & -1 & -1 & 1 & 1 & 1 & 0011 \\
\hline $\begin{array}{l}-6 / 16 \\
\end{array}$ & -1 & -1 & -1 & -1 & -1 & -1 & -1 & -1 & -1 & -1 & 1 & 1 & 1 & 1 & 0100 \\
\hline$-4 / 16$ & -1 & -1 & -1 & -1 & -1 & -1 & -1 & -1 & -1 & 1 & 1 & 1 & 1 & 1 & 0101 \\
\hline$-2 / 16$ & -1 & -1 & -1 & -1 & -1 & -1 & -1 & -1 & 1 & 1 & 1 & 1 & 1 & 1 & 0110 \\
\hline $0 / 16$ & -1 & -1 & -1 & -1 & -1 & -1 & -1 & 1 & 1 & 1 & 1 & 1 & 1 & 1 & 0111 \\
\hline $2 / 16$ & -1 & -1 & -1 & -1 & -1 & -1 & 1 & 1 & 1 & 1 & 1 & 1 & 1 & 1 & 1000 \\
\hline $4 / 16$ & -1 & -1 & -1 & -1 & -1 & 1 & 1 & 1 & 1 & 1 & 1 & 1 & 1 & 1 & 1001 \\
\hline $6 / 16$ & -1 & -1 & -1 & -1 & 1 & 1 & 1 & 1 & 1 & 1 & 1 & 1 & 1 & 1 & 1010 \\
\hline $8 / 16$ & -1 & -1 & -1 & 1 & 1 & 1 & 1 & 1 & 1 & 1 & 1 & 1 & 1 & 1 & 1011 \\
\hline $10 / 16$ & -1 & -1 & 1 & 1 & 1 & 1 & 1 & 1 & 1 & 1 & 1 & 1 & 1 & 1 & 1100 \\
\hline $12 / 16$ & -1 & 1 & 1 & 1 & 1 & 1 & 1 & 1 & 1 & 1 & 1 & 1 & 1 & 1 & 1101 \\
\hline $14 / 16$ & 1 & 1 & 1 & 1 & 1 & 1 & 1 & 1 & 1 & 1 & 1 & 1 & 1 & 1 & 1110 \\
\hline
\end{tabular}




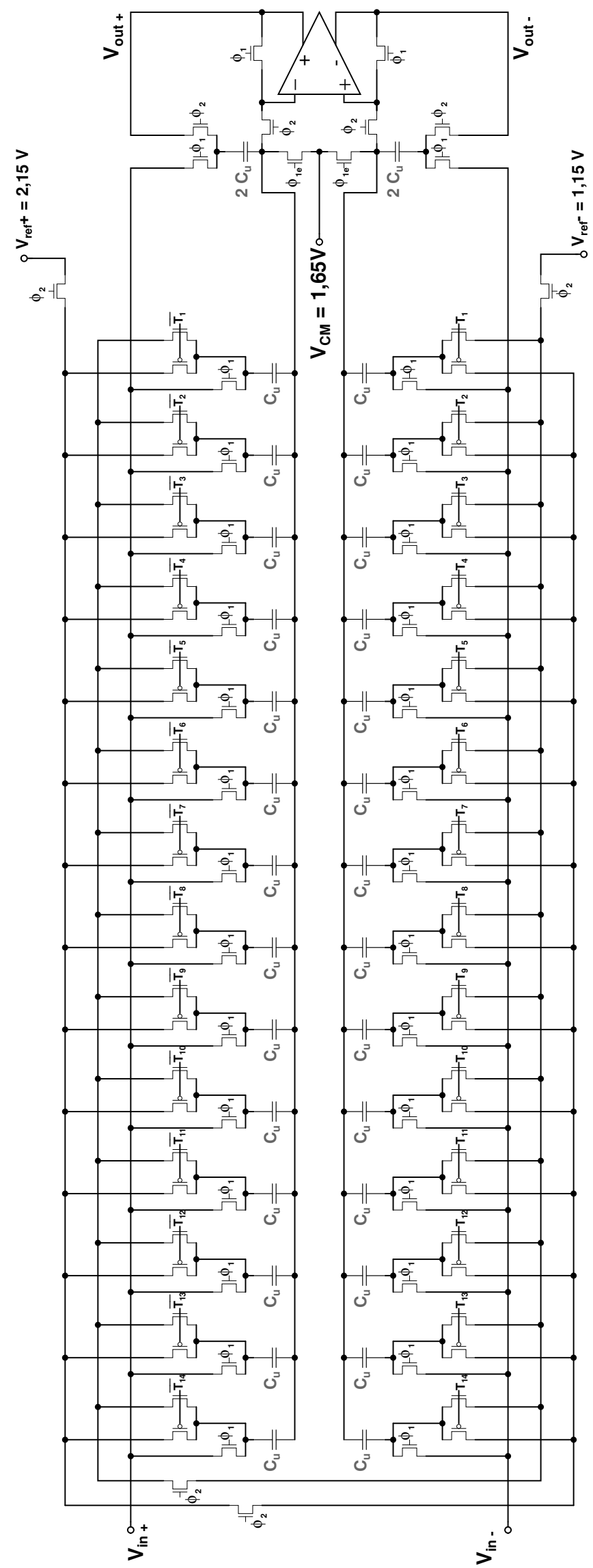

Figura 3.14: O circuito $M D A C$ do primeiro estágio pipeline. 


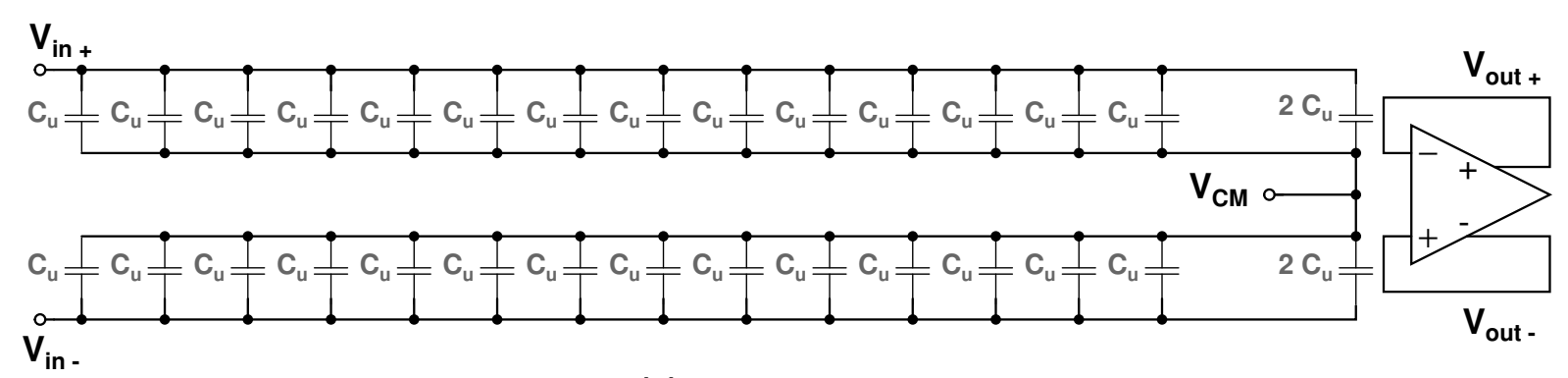

(a)

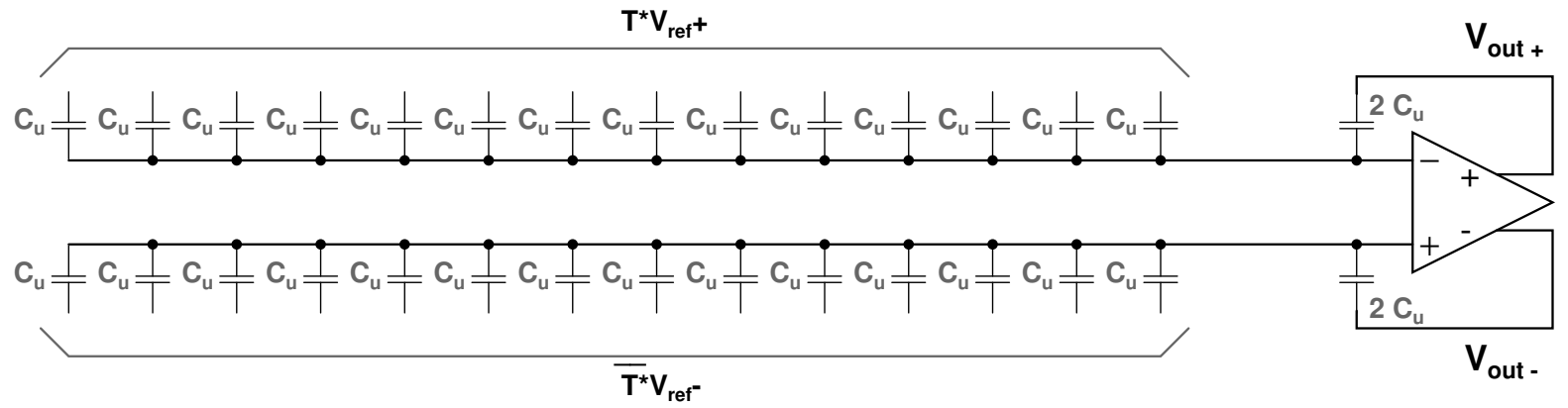

(b)

Figura 3.15: Circuito equivalente do $M D A C$ do primeiro estágio pipeline: operação durante a fase $\phi_{1}(\mathrm{a})$; e durante a fase $\phi_{2}(\mathrm{~b})$.

quantidade de capacitores do que a alternativa anterior, porém com valores unitários $\left(C_{u}\right)$. Evidentemente esta arquitetura possui a menor capacitância total de amostragem $\left(C_{S}\right)$, mas precisa de mais uma codificação especial da saída digital do $s u b-A D C$, que não é nem binária nem termométrica. Em [31] apresenta-se em detalhe esta operação, que inerentemente acrescenta uma latência extra na conversão A/D e D/A em cada estágio.

Neste trabalho se escolhe então uma arquitetura que utiliza $2^{n}$ capacitores unitários $\left(C_{u}\right)$ para amostrar o sinal de entrada, conforme mostrado na figura 3.14 e no seu equivalente para as fases de amostragem $\left(\phi_{1}\right)$ e de amplificação $\left(\phi_{2}\right)$ na figura 3.15. A utilização direta do código termômetro $\mathbf{T}$ gerado pelo sub-ADC permite atingir maior linearidade devido ao menor valor de $D N L$, além de evitar atrasos na sincronização por codificações extras $[1,9]$. Após estudar em detalhe o funcionamento desta topologia, pode se demonstrar que ela consegue implementar a função de transferência na equação (3.2).

Seguindo uma estratégia similar à apresentada na seção anterior para o $S \& H$, extraem-se as especificações para os diferentes componentes presentes no $M D A C$, incluindo capacitores, chaves MOS e o amplificador. Nesse procedimento, novamente as especificações em nível de sistema resumidas na tabela 2.3 constituem a ferramenta inicial, junto a uma modelagem adequada das condições de operação na figura 3.15. 


\subsection{Circuitos digitais}

Os blocos e as funções descritas nas seções anteriores executam as principais tarefas para a conversão A/D na arquitetura time-interleaved pipeline. Porém, ainda são necessárias algumas funções auxiliares executadas no domínio digital, que mesmo sem ser o núcleo de operação da arquitetura, contribuem de forma fundamental para o objetivo global do sistema.

\subsubsection{Gerador de fases de relógio}

A primeira tarefa auxiliar é a geração das diversas fases de relógio usadas para o correto funcionamento do $S \mathscr{E H} H$ na figura 3.3, os sinais de controle dos comparadores nas figuras 3.12 e 3.13, e também para as fases do $M D A C$ na figura 3.14. A figura 3.16 mostra o circuito para implementar esses sinais a partir de um único sinal de relógio externo de frequência $11 \mathrm{MHz}$.

O gerador de fases de relógio da figura 3.16 é uma arquitetura padrão baseada em um circuito síncrono divisor por 2 construído com um D-flipflop [35]. Para gerar as duas fases complementares se usa uma estrutura de portas NAND cruzadas. O duty cycle das fases, bem como os tempos de não-superposição entre elas, são determinados pelos atrasos na cadeia de inversores e as portas $N A N D$. O último inversor de cada canal foi modificado para alinhar as bordas de subida das fases complementares e suas versões adiantadas. Isto aumenta a porção do período disponível para a estabilização das saídas dos amplificadores.

As versões adiantadas $\phi_{1 e}$ e $\phi_{2 e}$ das fases complementares foram apresentadas em seções anteriores para aplicação da técnica de bottom plate sampling nos blocos $S \mathscr{E} H$ (figura 3.3) e $M D A C$. O atraso desses sinais deve ser escolhido cuidadosamente, levando em conta os tempos requeridos pelos transientes e os amplificadores funcionando em determinada fase para garantir amostras corretas e estáveis.Além disso, as cadeias de elementos de atraso não devem ser muito compridas para diminuir o jitter dos relógios $[36,31,34]$.

\subsubsection{Conversões e correções de códigos digitais}

Os códigos digitais termométricos gerados pelos sub-ADCs das figuras 3.12 e 3.13 devem ser convertidos em códigos binários B. Um problema relacionado a esta tarefa é a possibilidade de glitches nas transições termométricas, os quais podem levar a grandes 


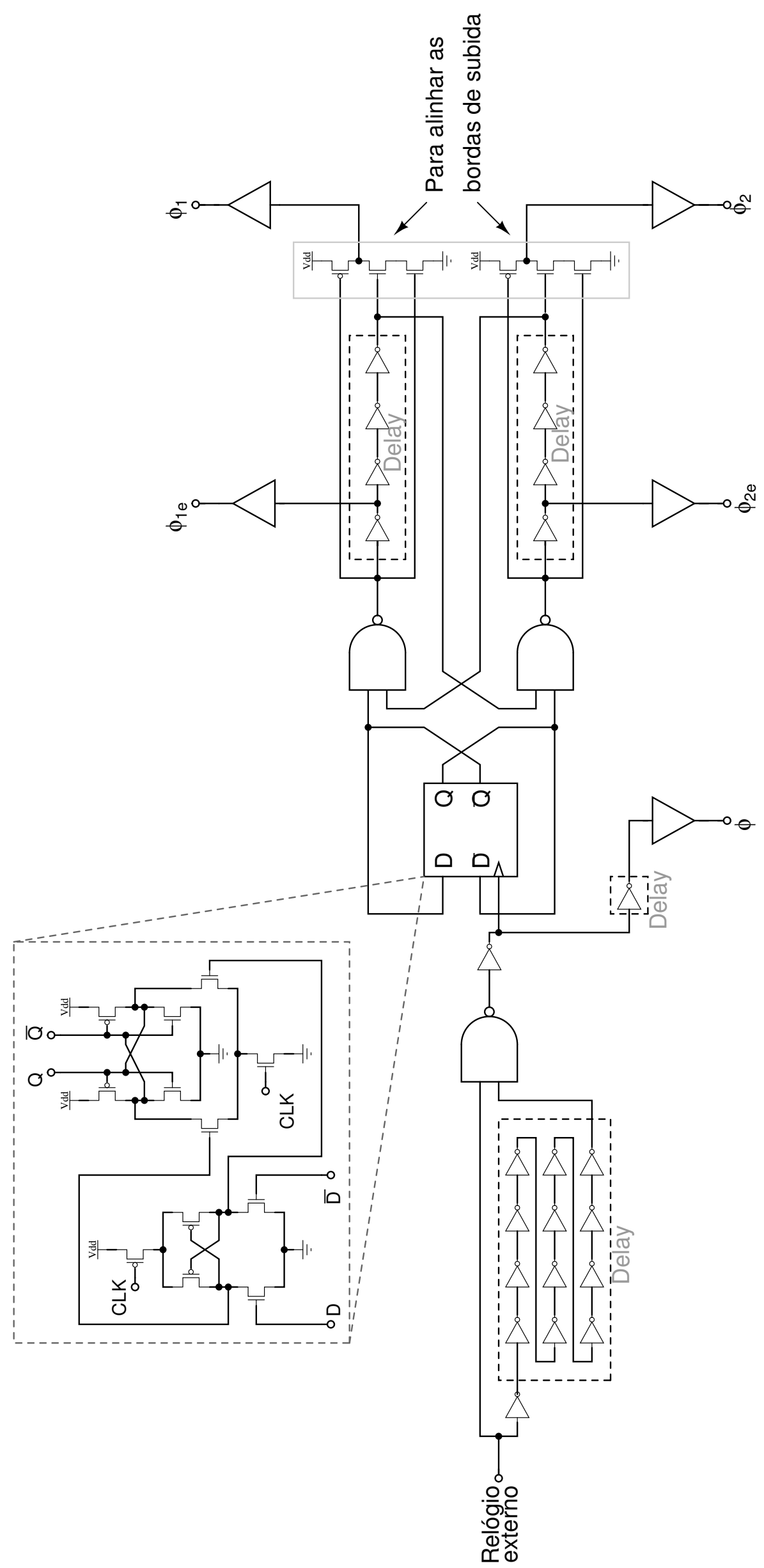

Figura 3.16: Esquema gerador das fases de relógio usadas no $A D C$. 


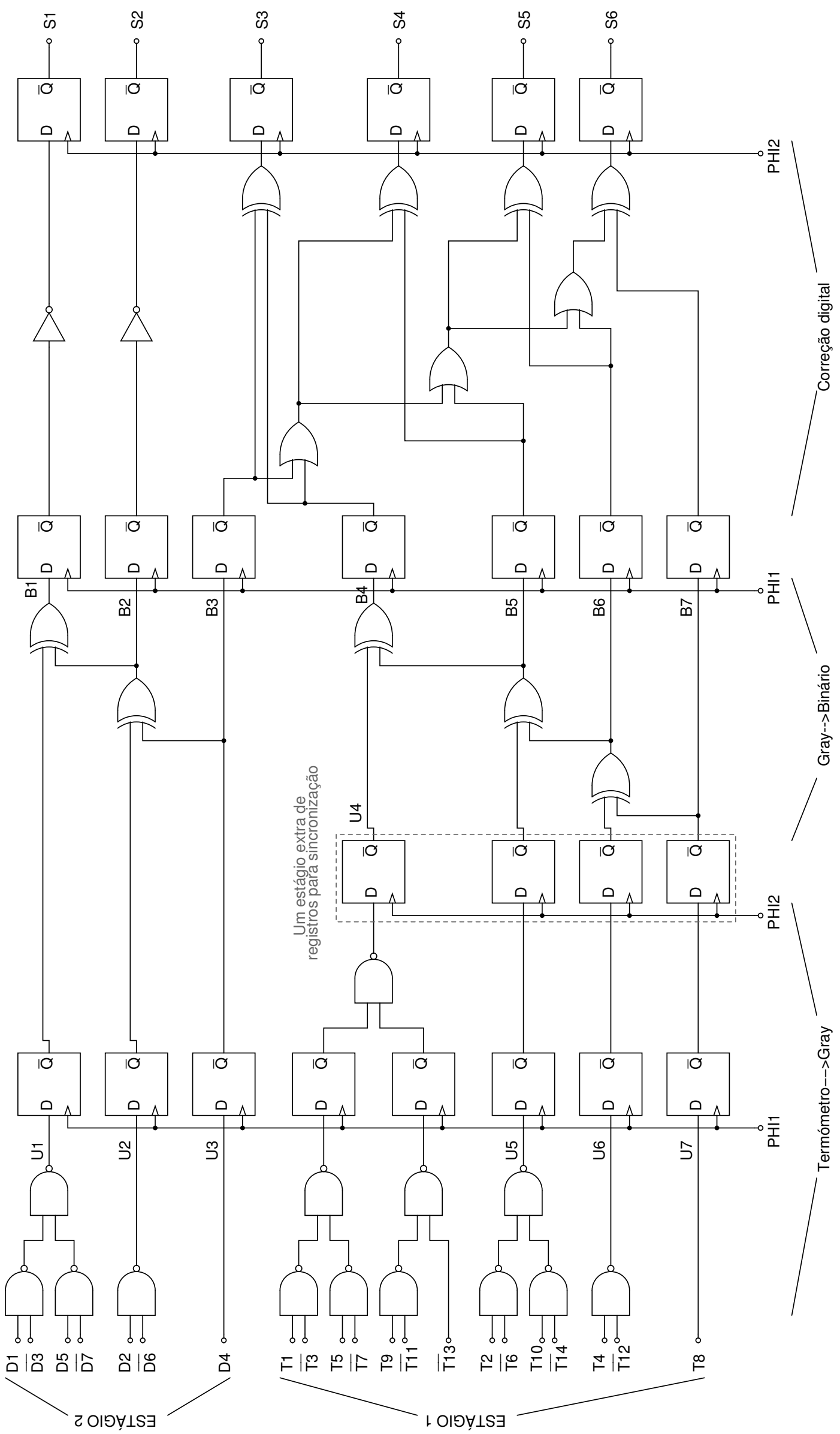

Figura 3.17: Processamento digital do código termómetro após o $s u b-A D C$. 
erros e até perda de códigos. A fim de reduzir os erros causados por esses glitches provenientes de entradas com mudanças rápidas e descasamentos de temporização nos bancos de comparadores, uma conversão intermediária ao código digital Gray U é utilizada [1]. As conversões apresentadas em detalhe nas tabelas 3.2 e 3.3 são executadas pela primeira seção do circuito na figura 3.17, que basicamente desenvolve as seguintes operações lógicas:

$$
\begin{array}{ll}
U_{1}=\overline{\overline{\left(D_{1} \overline{D_{3}}\right)} \cdot \overline{\left(D_{5} \overline{D_{7}}\right)}} & B_{1}=U_{3} \oplus U_{2} \oplus U_{1} \\
U_{2}=\overline{\left(D_{2} \overline{D_{6}}\right)} & B_{2}=U_{3} \oplus U_{2} \\
U_{3}=D_{4} & B_{3}=U_{3}
\end{array}
$$

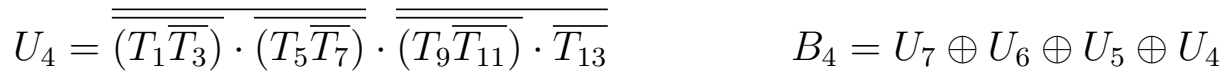

$$
\begin{aligned}
& U_{5}=\overline{\overline{\left(T_{2} \overline{T_{6}}\right)} \cdot \overline{\left(T_{10} \overline{T_{14}}\right)}} \quad B_{5}=U_{7} \oplus U_{6} \oplus U_{5} \\
& U_{6}=\overline{\left(T_{4} \overline{T_{12}}\right)} \quad B_{6}=U_{7} \oplus U_{6} \\
& U_{7}=T_{8} \quad B_{7}=U_{7}
\end{aligned}
$$

Além da conversão termômetro-Gray-binário, o circuito da figura 3.17 realiza outras duas funções. A primeira delas é a sincronização dos códigos digitais gerados pelo primeiro (T) e segundo (D) estágio pipeline, logo após a conversão para o código Gray U. Isto é necessário porque eles são gerados em fases complementares e consecutivas do relógio. O estágio extra de registros na figura 3.17 se encarrega desse trabalho.

A segunda função conclui a aplicação da técnica de correção digital usando o bit de redundância $(R S D)$, que foi explicada em detalhe em seções anteriores. A correção digital é efetuada para gerar a palavra digital $\mathbf{S}$ de 6 bits segundo a figura 3.8, que é repetida aqui para o caso específico dos bits da palavra binária $\mathbf{B}$ :

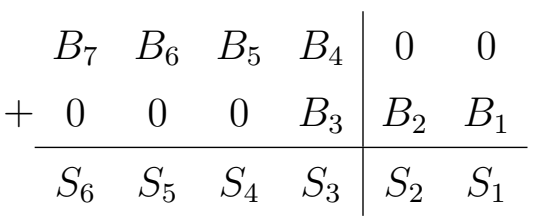

Da operação anterior, já pode se estabelecer que $S_{1}=B_{1}$ e $S_{2}=B_{2}$, enquanto o resto dos bits da palavra $\mathbf{S}$ devem ser obtidos pela soma com dígitos "vai um"indicada à 
esquerda da linha vertical. Dentre as alternativas para realizar esta soma, neste trabalho foi escolhida a estratégia básica do Carry-Lookahead Adder [37]. Para isso, são definidos os vetores $\mathbf{H}$ e $\mathbf{P}$ como variáveis intermediárias na operação, conhecidas na literatura como Generate e Propagate respectivamente, e os símbolos $C_{i}$ e $C_{o}$ como dígitos "vai um" ou Carry. Assim, a operação soma é descrita em detalhe nas seguintes equações:

$$
\begin{array}{ll}
H_{3}=B_{4} \cdot B_{3} & P_{3}=B_{4} \oplus B_{3} \\
H_{4}=B_{5} \cdot 0=0 & P_{4}=B_{5} \oplus 0=B_{5} \\
H_{5}=B_{6} \cdot 0=0 & P_{5}=B_{6} \oplus 0=B_{6} \\
H_{6}=B_{7} \cdot 0=0 & P_{6}=B_{7} \oplus 0=B_{7}
\end{array}
$$

$$
\begin{aligned}
& C_{i, 3}=0 \\
& C_{o, 3}=C_{i, 4}=H_{3}+P_{3} \cdot C_{o, 2}=H_{3}+P_{3} \cdot C_{i, 3}=H_{3}=B_{4} \cdot B_{3} \\
& C_{o, 4}=C_{i, 5}=H_{4}+P_{4} \cdot C_{o, 3}=0+B_{5} \cdot B_{4} \cdot B_{3}=B_{5} \cdot B_{4} \cdot B_{3} \\
& C_{o, 5}=C_{i, 6}=H_{5}+P_{5} \cdot C_{o, 4}=0+B_{6} \cdot B_{5} \cdot B_{4} \cdot B_{3}=B_{6} \cdot B_{5} \cdot B_{4} \cdot B_{3} \\
& C_{o, 6}=C_{i, 7}=H_{6}+P_{6} \cdot C_{o, 5}=0+B_{7} \cdot B_{6} \cdot B_{5} \cdot B_{4} \cdot B_{3}=B_{7} \cdot B_{6} \cdot B_{5} \cdot B_{4} \cdot B_{3}=0
\end{aligned}
$$

Logo, os bits resultantes da soma na saída do canal serão:

$$
\begin{aligned}
& S_{1}=B_{1} \\
& S_{2}=B_{2} \\
& S_{3}=P_{3} \oplus C_{i, 3}=B_{4} \oplus B_{3} \oplus 0=B_{4} \oplus B_{3} \\
& S_{4}=P_{4} \oplus C_{i, 4}=B_{5} \oplus\left(B_{4} \cdot B_{3}\right) \\
& S_{5}=P_{5} \oplus C_{i, 5}=B_{6} \oplus\left(B_{5} \cdot B_{4} \cdot B_{3}\right) \\
& S_{6}=P_{6} \oplus C_{i, 6}=B_{7} \oplus\left(B_{6} \cdot B_{5} \cdot B_{4} \cdot B_{3}\right)
\end{aligned}
$$

O carry $C_{o, 6}=B_{7} \cdot B_{6} \cdot B_{5} \cdot B_{4} \cdot B_{3}$ é sempre igual a "zero" porque esses 5 bits de $\mathbf{B}$ nunca são "um" simultaneamente, devido à aplicação do offset digital explicado nas figuras 3.9 e 
3.10. Em nível de circuito, as operações acima foram implementadas como mostrado na seção final da figura 3.17. Usaram-se as propriedades complementares das portas NAND e $N O R$, bem como da porta $X O R: B_{X} \oplus B_{Y}=\overline{B_{X}} \oplus \overline{B_{Y}}$. Todas as portas lógicas na figura 3.17 foram realizadas com lógica estática, assim como os registros implementados com D-flipflops.

Com o estudo anterior dos circuitos digitais finaliza este capítulo. A maior parte dos blocos na figura 3.1 foram apresentados e abordados em detalhe, descrevendo sequencialmente o processo de conversão do sinal analógico de entrada em uma palavra digital de saída. Portanto, agora é o momento de descer mais um nível na hierarquia do $A D C$, o que será feito no próximo capítulo. 


\section{Circuitos básicos e resultados}

Os resultados do procedimento de extração de especificações desenvolvido nas seções anteriores, são utilizados agora no projeto dos circuitos mais elementares do $A D C$ : o amplificador operacional de transcondutância (OTA, do inglês operational transconductance amplifier) e o comparador. O primeiro deles faz parte do bloco $S \mathscr{G} H$ na entrada e do $M D A C$ no primeiro estágio das duas cadeias pipeline em paralelo. Por outro lado, os $s u b-A D C s$ com arquitetura flash em cada estágio usam comparadores com tensões de referência para estabelecer seus limiares e/ou níveis de quantização. Frequentemente, este par de circuitos básicos constitui o primeiro cenário onde o projetista enfrenta diretamente as limitações tecnológicas do processo de fabricação utilizado, como na hora de tentar incrementar a velocidade ou reduzir a dissipação de potência deles. O projeto é feito mediante o uso da programação geométrica (PG), ferramenta CAD (Computer-Aided Design) que é aplicada neste trabalho para minimizar o consumo de potência estático dos circuitos. Da mesma forma, a PG permite a otimização do desempenho desses circuitos conforme os requisitos específicos do bloco a que pertencem [6, 7].

Além do dito acima, este capítulo exibe também os resultados conseguidos durante o processo de projeto do sistema conversor A/D. Para começar, uma coletânea de simulações é apresentada junto com alguns esquemáticos e testbenches desenvolvidos na plataforma Cadence[38]. Na sequência, são mostrados os testes de um dos blocos básicos que foi fabricado durante o desenvolvimento deste projeto. Essa parte representa uma importante experiência prática deste trabalho, embora não tenha sido com o sistema completo devido à complexidade do mesmo

\subsection{Programação Geométrica}

A PG é um tipo de problema de otimização matemática, onde a função objetivo e as restrições pertencem a um conjunto de funções com uma forma especial, e portanto, cumprem com algumas condições específicas. Um programa geométrico é por si mesmo 
um problema complexo de otimização não linear. O diferencial é que um programa geométrico pode se tornar um problema convexo através de mudanças de variáveis e transformações das funções envolvidas. Desse modo, aproveita-se as três melhores qualidades da otimização convexa quando comparada com outros tipos de otimização matemática [6]:

- Capacidade de encontrar o ótimo global da função objetivo, sempre que o problema seja factível;

- Convergência na solução do problema muito rápida através de algoritmos de pontos interiores;

- Capacidade de identificar, sem possibilidade de erro, se o problema não tem solução factível.

Um programa geométrico é um problema de otimização da forma:

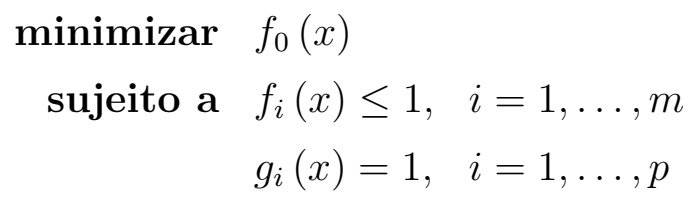

onde $f_{0}$ é chamada de função objetivo, $f_{i}$ função de restrição do tipo desigualdade e $g_{i}$ função de restrição do tipo igualdade. Em um programa geométrico da forma (4.1), as funções $g_{1}, \ldots, g_{p}$ são monômios (equação $(4.2)$ ), as funções $f_{0}, \ldots, f_{m}$ são posinômios (equação $(4.3))$ e $x=\left(x_{1}, \ldots, x_{i}, \ldots, x_{n}\right)$ são as variáveis de otimização, com os $x_{i}$ sendo variáveis reais e positivas (domínio do problema: $x_{i}>0$ ). É importante ressaltar que em um programa geométrico na forma padrão, as restrições tipo igualdade devem ser apenas monômios, enquanto as restrições tipo desigualdade podem ser tanto monômios quanto posinômios [6].

$$
\begin{gathered}
g(x)=c x_{1}^{a_{1}} x_{2}^{a_{2}} \ldots x_{n}^{a_{n}} \mid c \geq 0 \therefore a_{i} \in \mathbb{R} \\
f(x)=\sum_{k=1}^{K} c_{k} x_{1}^{a_{1}{ }_{k}} x_{2}^{a_{2}} \ldots x_{n}^{a_{n_{k}}} \mid c_{k}>0 \therefore a_{i_{k}} \in \mathbb{R}
\end{gathered}
$$

A solução de um programa geométrico é baseada em algoritmos muito eficientes, projetados para otimização convexa. Atualmente existem diferentes empresas e grupos de pesquisa e desenvolvimento que disponibilizam software para resolver problemas de PG. A transformação de um programa geométrico para um problema convexo é uma tarefa tediosa, porém o software disponível faz esse procedimento internamente. Desse modo, a 
entrada de dados para o otimizador é feita diretamente na estrutura padrão do programa geométrico.

A formulação matemática de um projeto via PG implica representar todo o funcionamento do circuito mediante expressões matemáticas simbólicas. Portanto, a aplicação da PG precisa que os modelos do transistor utilizados levem a expressões matemáticas que possam ser implementadas dentro da ferramenta. Como os resultados finais das variáveis de projeto dependerem das especificações, é difícil prever as regiões adequadas para modelagem, e dessa forma diminuir o erro. Para satisfazer este requisito são aplicadas técnicas de ajuste para funções multi-variáveis aos dados gerados pelo simulador. O procedimento anterior é feito dentro de uma estratégia para obter projetos ótimos com PG, e que é sintetizada a seguir:

1. Formulação matemática do circuito na forma padrão de um programa geométrico.

2. Identificação e modelagem dos parâmetros necessários do transistor.

3. Aplicação de PG usando a ferramenta de otimização.

4. Verificação de resultados usando o simulador.

5. Identificação das novas regiões de modelagem a partir da solução do programa geométrico e volta ao passo 2.

A estratégia acima precisa de algumas modificações a fim de contornar incompatibilidades referentes à formulação do programa geométrico. Os resultados da aplicação desta estratégia ao projeto do OTA e do comparador apresentados neste capítulo foram obtidos mediante o uso de um pacote de funções escritas em MATLAB interagindo com a ferramenta de otimização CVX [7].

\subsection{Amplificador Operacional de Transcondutância}

A determinação das especificações para os amplificadores desenvolvida anteriormente, estabelece uma tendência similar entre os níveis de desempenho requeridos desses circuitos. Portanto, é evidente que para atingir a precisão e velocidade dos estágios do $A D C$, precisase de amplificadores com valores significativos de ganho, $G B W$ e $S R$, simultaneamente. Aliás, deve-se ressaltar a natureza capacitiva das cargas na saída desses circuitos. A melhor forma de conseguir essas características é mediante amplificadores de estágio único ou OTAs, como as configurações telescópica e folded cascode [31, 34]. 


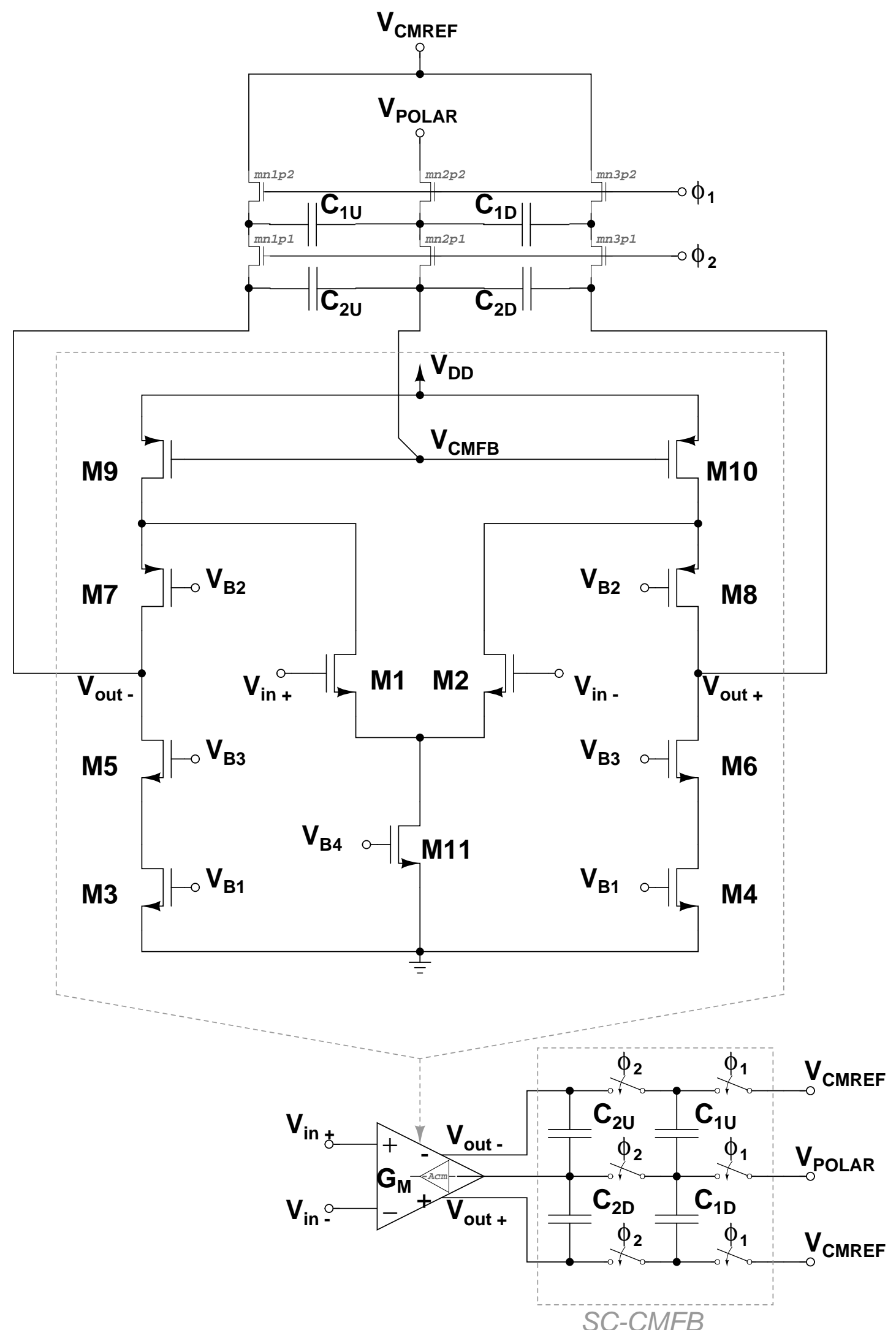

Figura 4.1: O folded cascode OTA com o bloco $S C$-CMFB. 


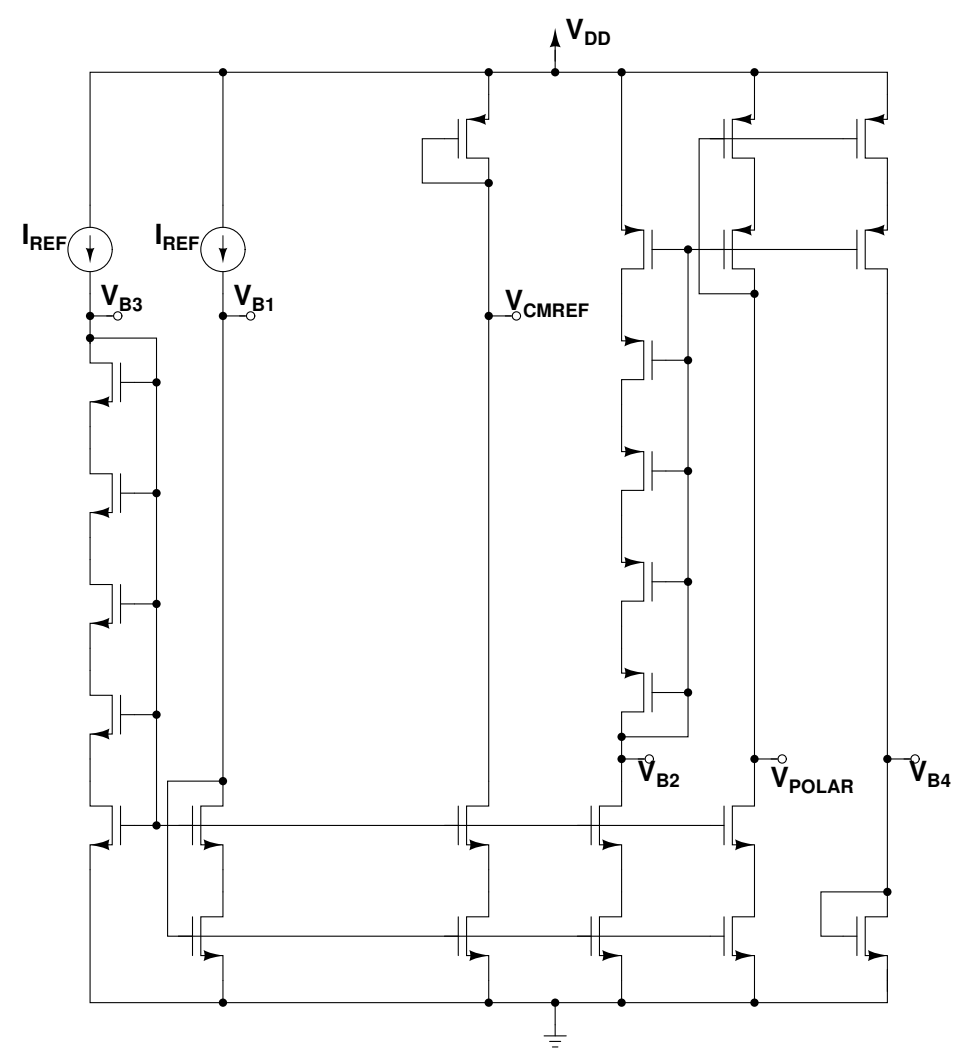

Figura 4.2: Circuito de polarização para o folded cascode OTA da figura 4.1.

Neste trabalho foi escolhida a topologia folded cascode, mostrada na figura 4.1, que é utilizada tanto para o bloco $S \mathscr{G} H$ quanto para o $M D A C$ no primeiro estágio pipeline. Já a figura 4.2 mostra o circuito para gerar as tensões de polarização do amplificador. A preferência por esta configuração está baseada nas suas faixas dinâmicas maiores quando comparadas com as do OTA telescópico, tanto para entrada $\left(D R_{I N}\right)$ quanto para saída $\left(D R_{O U T}\right)$ em modo comum. Essas faixas de excursão são críticas para esta aplicação devido à presença de sinais diferenciais com amplitudes da ordem de grandeza de $V_{F S} / 2=$ $1 V$, especialmente no $S \mathscr{G} H$ na entrada do conversor. Entretanto, a resposta em frequência do folded cascode OTA é inferior a do telescópico, porém superior a dos opamps de dois estágios. Além disso, o consumo de potência da arquitetura escolhida é maior que o da telescópica, já que precisa de uma corrente extra para polarizar os transistores do cascode $[31,29]$.

Antes de aplicar PG ao projeto do OTA (apêndice A), o espaço de projeto foi delimitado a partir de considerações de offset. Desse modo, foi feita uma estimativa teórica do offset randômico na topologia, que aparece na equação (4.4).

$$
v_{o f f s e t}=\Delta V_{t h 1}+\frac{g_{m 3}}{g_{m 1}} \Delta V_{t h 3}+\frac{g_{m 9}}{g_{m 1}} \Delta V_{t h 9}+\frac{V_{G S 1}-V_{t h 1}}{2} \Delta K
$$




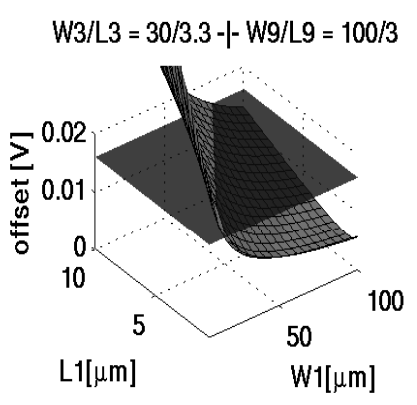

$W 1 / L 1=30 / 3.3-\mid-W 9 / L 9=100 / 3$

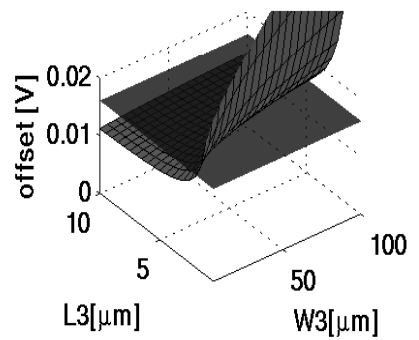

$W 1 / L 1=30 / 3.3+-W 3 / L 3=100 / 3$

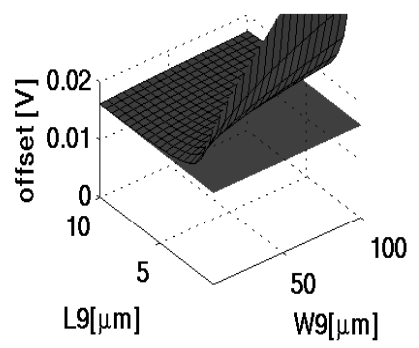

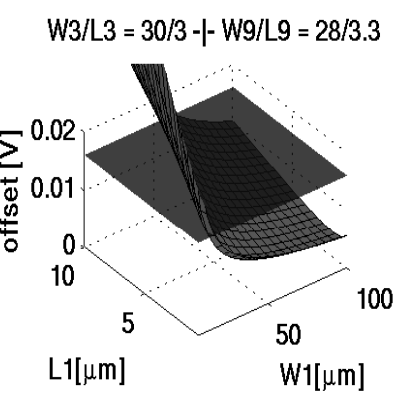

$W 1 / L 1=30 / 3-\mid-W 9 / L 9=28 / 3.3$

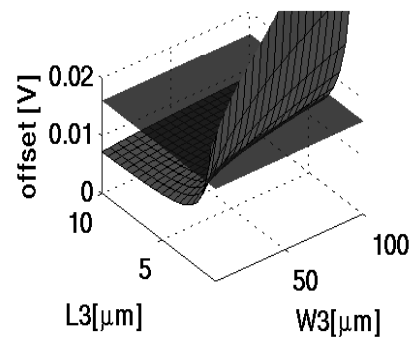

$W 1 / L 1=30 / 3-\mid-W 3 / L 3=28 / 3.3$

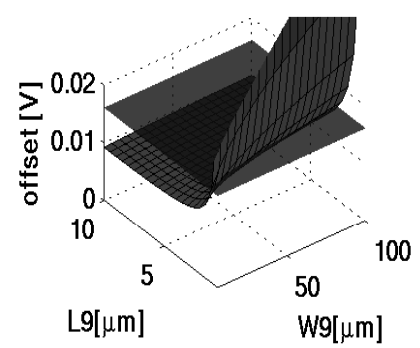

$W 3 / L 3=30 / 3-\mid-W 9 / L 9=100 / 3$

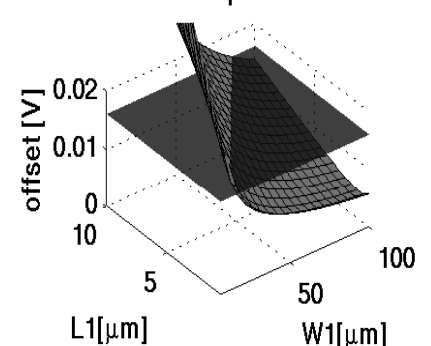

W1[ $[\mu \mathrm{m}]$

$W 1 / L 1=30 / 3-\mid-W 9 / L 9=100 / 3$

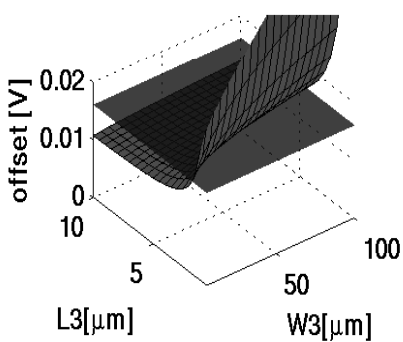

$W 1 / L 1=30 / 3-\mid-W 3 / L 3=100 / 3$

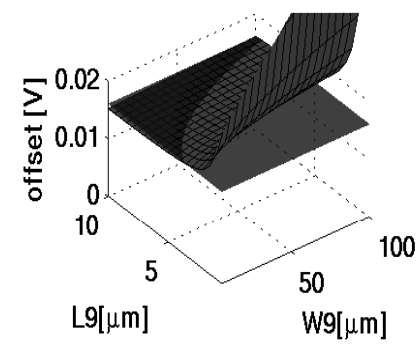

Figura 4.3: Estudo da tensão $v_{\text {of } f \text { set }}$ do $O T A$ em função dos tamanhos de $M 1$-M2, M3-M4 e M9-M10.

onde os símbolos $\Delta V_{t h}$ e $\Delta K$ representam os parâmetros de mismatch da tensão de limiar e do fator de ganho, respectivamente; $g_{m}$ representa a transcondutância e $V_{G S}$ a tensão entre porta e fonte do transistor.

Os parâmetros de mismatch são descritos na documentação do processo de fabricação segundo o modelo de Pelgrom na equação (4.5).

$$
\sigma(\Delta P)=\frac{A_{P}}{\sqrt{W \cdot L}}
$$

onde $\sigma$ é o desvio padrão do parâmetro do transistor caracterizado, $A_{P}$ é uma constante do processo de fabricação, $W$ é a largura e $L$ o comprimento de canal do dispositivo.

Variações paramétricas foram feitas na equação (4.4), como mostrado na figura 4.3, explorando diversas combinações de geometrias para os transistores que contribuem ao offset do OTA. Assim, foram estabelecidos limites nas dimensões dos dispositivos para satisfazer as restrições decorrentes das análises em nível de sistema: $v_{\text {offset }} \leq 16 \mathrm{mV}$ (tabela 2.3). Essas restrições são representadas na figura 4.3 mediante planos de tensão. 


\subsubsection{O $C M F B$}

Os amplificadores com arquiteturas completamente diferenciais como a da figura 4.1, processam sinais diferenciais sem exercer nenhum controle sobre o nível de tensão em modo comum nos nós de alta impedância da saída. Sem o controle adequado a tensão $V_{C M, O U T}$ tende a se deslocar para os extremos da fonte de alimentação em $D C$ (neste caso, $0 \mathrm{~V}$ e $\left.V_{D D}\right)$, devido a variações das fontes de polarização, do processo e de offsets, entre outras. A partir disso, usualmente é necessário acrescentar um laço de realimentação em modo comum ou $C M F B$.

Existem vários fatores que são críticos no projeto do circuito $C M F B$. O número de pólos parasitários no laço em modo comum deve ser minimizado, enquanto a velocidade e o ganho do mesmo devem ser suficientemente grandes para atingir o $V_{C M, O U T}$ desejado com da precisão adequada. Ainda, o $C M F B$ não deve representar uma carga significativa a mais para o OTA diferencial, e a interação entre os laços de modo comum e diferencial deve ser mínima. Enfim, o circuito $C M F B$ não deve degradar o desempenho do amplificador que o utiliza [29].

As principais vantagens da realimentação em modo comum com capacitores chaveados $(S C-C M F B)$ são: alta linearidade e ausência tanto de pólos parasitários adicionais quanto de restrições na máxima excursão diferencial do sinal de saída do OTA, já que está composta apenas por elementos passivos (capacitores) e chaves ${ }^{1}$. No entanto, o $S C$-CMFB injeta ruído nos nós de saída do amplificador, que é decorrente do clock-feedthrough não linear das suas chaves. Além disso, incrementa a carga capacitiva vista pelo OTA [39]. A aplicação desta topologia de $C M F B$ ao OTA projetado com PG pode ser vista na figura 4.1.

A arquitetura $S C$ - $C M F B$ mostrada na figura 4.1 é composta pelo par de capacitores $C_{2 U}$ e $C_{2 D}$ que capturam o nível de saída em modo comum do OTA, e outros dois capacitores $C_{1 U}$ e $C_{1 D}$ que fazem o refresh do circuito, controlados pelas fases de relógio não superpostas $\phi_{1}$ e $\phi_{2}$. Nesta topologia, os capacitores $C_{2 U, 2 D}$ calculam a média das tensões de saída, $V_{C M, O U T}=\left(V_{\text {out }+}+V_{\text {out }-}\right) / 2$, que é usada para gerar o sinal de controle $V_{C M F B}$ que é aplicada na porta das fontes de corrente $M 9$, M10 do OTA. A tensão DC em $C_{2 U, 2 D}$ é determinada pelos capacitores $C_{1 U, 1 D}$, os quais são chaveados periodicamente das fontes $V_{P O L A R}$ e $V_{C M R E F}$ para os capacitores de captura. A fonte $V_{C M R E F}$ representa

\footnotetext{
${ }^{1}$ Se as chaves MOS são implementadas com transistores complementares (CMOS) ou portas de transmissão dupla, as variações em tensão permitidas são próximas à excursão chamada de rail-to-rail $\left(0 \leq V_{\text {in,switch }} \leq V_{D D}\right)$.
} 
a tensão em modo comum desejada, enquanto $V_{P O L A R}$ é a tensão de controle necessária para ajustar $V_{C M, O U T}$ a $V_{C M R E F}$. A operação deste circuito é em essência a de um filtro $S C$ passa-baixas com um nível $D C$ na entrada [29].

A amplitude dos degraus que levam as tensões $V_{C M, O U T}$ e $V_{C M F B}$ a se estabilizarem nos seus valores finais desejados, é influenciada pela proporção $C_{1} / C_{2}$. Quanto maior for a proporção mais rápida é a convergência. Sendo assim, a escolha desta razão de capacitâncias representa um compromisso entre velocidade do $S C$ - $C M F B$ e degradação do desempenho do OTA, devido ao incremento da carga capacitiva [39]. Além disso, a escolha de $C_{1} \gg C_{2}$ também produz menores erros em estado estável por injeção de carga e corrente de fuga. No entanto, se a capacitância $C_{1}$ aumentar, deve-se incrementar simultaneamente o tamanho das chaves MOS para facilitar a carga dos capacitores.

\subsection{Comparador}

Quando a redundância é aplicada para relaxar os requisitos de offset nos comparadores, as arquiteturas dinâmicas são preferidas em estágios de moderada resolução pela baixa potência e área consumida. O comparador dinâmico é desligado quando está inativo, e os transistores com dimensões mínimas são preferidos na sua implementação para minimizar área e potência. As condições anteriores fazem esse tipo de comparador ter maior offset. Isto é por causa do mismatch de transistores e dos transientes no chaveamento [31].

Além do explicado no parágrafo anterior, a implementação de um comparador com geração interna do limiar de comparação é importante porque evita a escada resistiva usada normalmente para gerar as referências em uma arquitetura flash, eliminando dessa forma outra fonte de consumo de potência estática no conversor. Na literatura existem diferentes circuitos para incorporação do limiar, nos quais se procura gerar de forma intencional um offset que determine o limiar desejado. A partir da experiência e dos resultados obtidos em [40], neste trabalho escolhe-se uma arquitetura de comparador de par diferencial, cujo esquemático é mostrado na figura 4.4 [31].

O comparador tem dois modos de operação. Quando o sinal de latch $V_{L A T C H}$ está no nível baixo, $M 5$ e $M 6$ estão na região de corte e portanto, após a resposta transiente, não tem mais fluxo de corrente através do circuito. Ao mesmo tempo, as chaves PMOS $M 9$ e M12 forçam os nós de saída a $V_{D D}$, e por sua vez, M7 e $M 8$ no latch impõem essa tensão também nos drenos dos pares diferenciais, assim estabelecendo-se o estado de reset. Quando $V_{L A T C H}$ vai para o nível alto, as saídas são desconectadas de $V_{D D}$, 


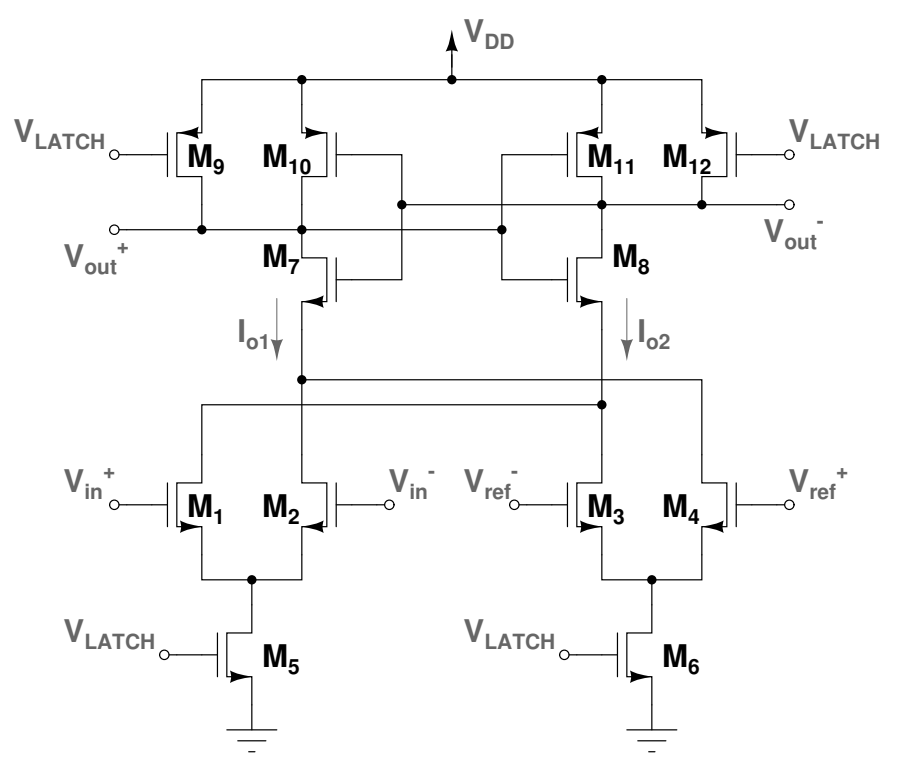

Figura 4.4: Circuito do comparador com par diferencial.

as fontes de corrente $M 5$ e $M 6$ são ligadas e $M 1$ - $M 4$ comparam $V_{i n}=\left(V_{\text {in }}^{+}-V_{\text {in }}^{-}\right)$com $V_{\text {ref }}=\left(V_{\text {ref }}^{+}-V_{\text {ref }}^{-}\right)$. A forte realimentação positiva amplifica a diferença até o latch determinar o resultado da comparação. O consumo de corrente se interrompe de novo após estabilizar a saída [31].

Neste trabalho se aproveita a fase de relógio $\bar{\phi}$ gerada pelo circuito da figura 3.16 para o sinal de latch na figura 4.4. Esse sinal tem frequência igual à frequência total do sistema, e seu duty cicle menor que $50 \%$ (o nível alto é a parte mais estreita), porém suficiente para estabelecer as saídas dos comparadores. Os D-flipflops [35] que seguem aos comparadores nas figuras 3.12 e 3.13 sincronizam os bits com a fase que controla o estágio dentro da cadeia pipeline e evitam que o reset passe ao $M D A C$ do estágio seguinte.

A tensão de limiar do comparador é determinada pela divisão de corrente nos pares diferenciais e entre os ramos interligados. A transição de um estado para outro na saída como resultado da comparação força também a variação em sentido oposto das correntes $I_{o 1}=I_{D 2}+I_{D 4}$ e $I_{o 2}=I_{D 1}+I_{D 3}$. Usando as equações de corrente do transistor para grandes sinais, atendendo as convenções da figura 4.4 e assumindo razões de tamanhos entre os pares diferenciais cruzados $W_{3}=W_{4}=f \cdot W_{1}=f \cdot W_{2}$, entre as correntes $I_{D 5}=d \cdot I_{D 6}$ e para a tensão de limiar $V_{i n}=e \cdot V_{r e f}$, obtém-se a expressão (4.6).

$$
2 d e^{2} I_{D 6} \frac{W_{1}}{L}-K e^{4} V_{r e f}^{2}\left(\frac{W_{1}}{L}\right)^{2}=2 I_{D 6} \frac{W_{3}}{L}-K V_{r e f}^{2}\left(\frac{W_{3}}{L}\right)^{2}
$$

onde $K=\mu \cdot C_{o x}$ é o fator de ganho dos transistores.

A aplicação de PG ao projeto do comparador aparece em [40]. Os resultados desse 


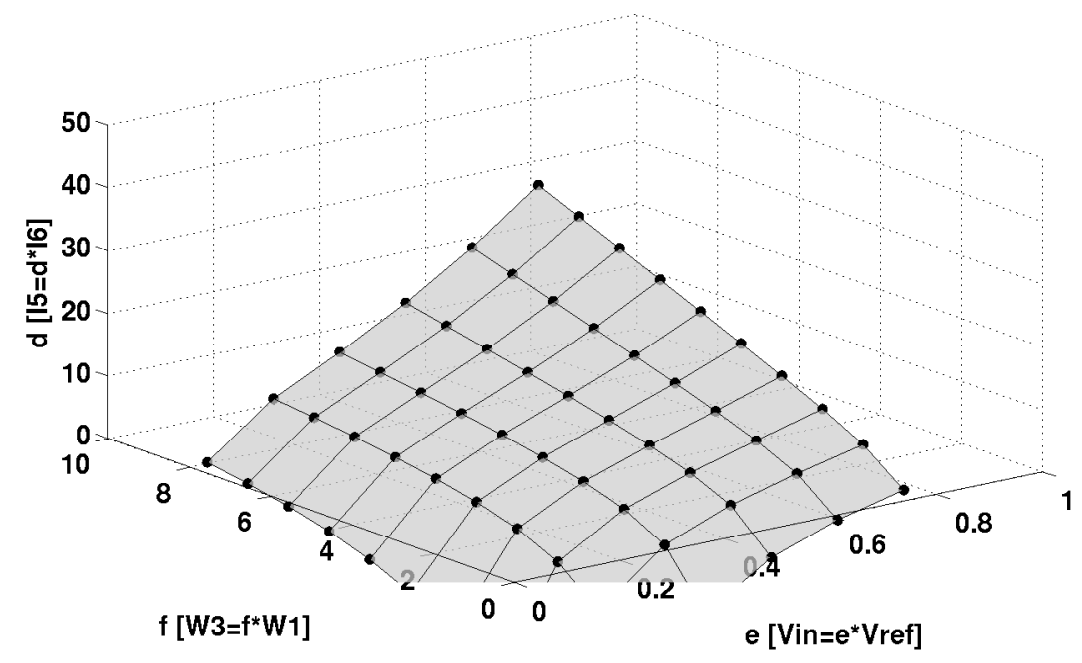

Figura 4.5: Variações do limiar de comparação em função de descasamentos.

trabalho foram usados para determinar as dimensões do comparador básico, com tensão de limiar $V_{\text {ref }}$ estabelecida externamente. Posteriormente, a equação (4.6) é utilizada para estudar as variações dos limiares dependendo dos três parâmetros $d$, e e $f$, conforme mostrado na figura 4.5. A partir da análise anterior, são introduzidos os desbalançamentos necessários no comparador básico para gerar os limiares indicados na figura 3.11.

Neste ponto, a estrutura completa do $A D C$ já foi descrita desde as especificações envolvidas do padrão de comunicações sem fio até os detalhes mais particulares nos circuitos básicos. Consequentemente, resta verificar a funcionalidade desses circuitos e blocos, tanto isolados quanto interligados constituindo o $A D C$, de acordo com o apresentado nos capítulos anteriores. Para realizar essa verificação, os diversos resultados deste trabalho serão exibidos a seguir.

\subsection{Simulações}

A ordem de apresentação dos resultados de simulação será de certa maneira oposta daquela em que o $A D C$ foi estudado ao longo dos capítulos anteriores. Assim, em primeiro lugar serão mostradas as funções mais básicas e gradualmente se subirá na hierarquia até chegar às simulações de topo do conversor. Visando esclarecer o processo de conversão A/D, também será exibida a trajetória feita pelos sinais analógicos durante a transformação na palavra digital de saída.

As simulações foram feitas usando diversas ferramentas, incluindo o ambiente AMS para simulações iniciais com modelos comportamentais em verilogA, e os simuladores 


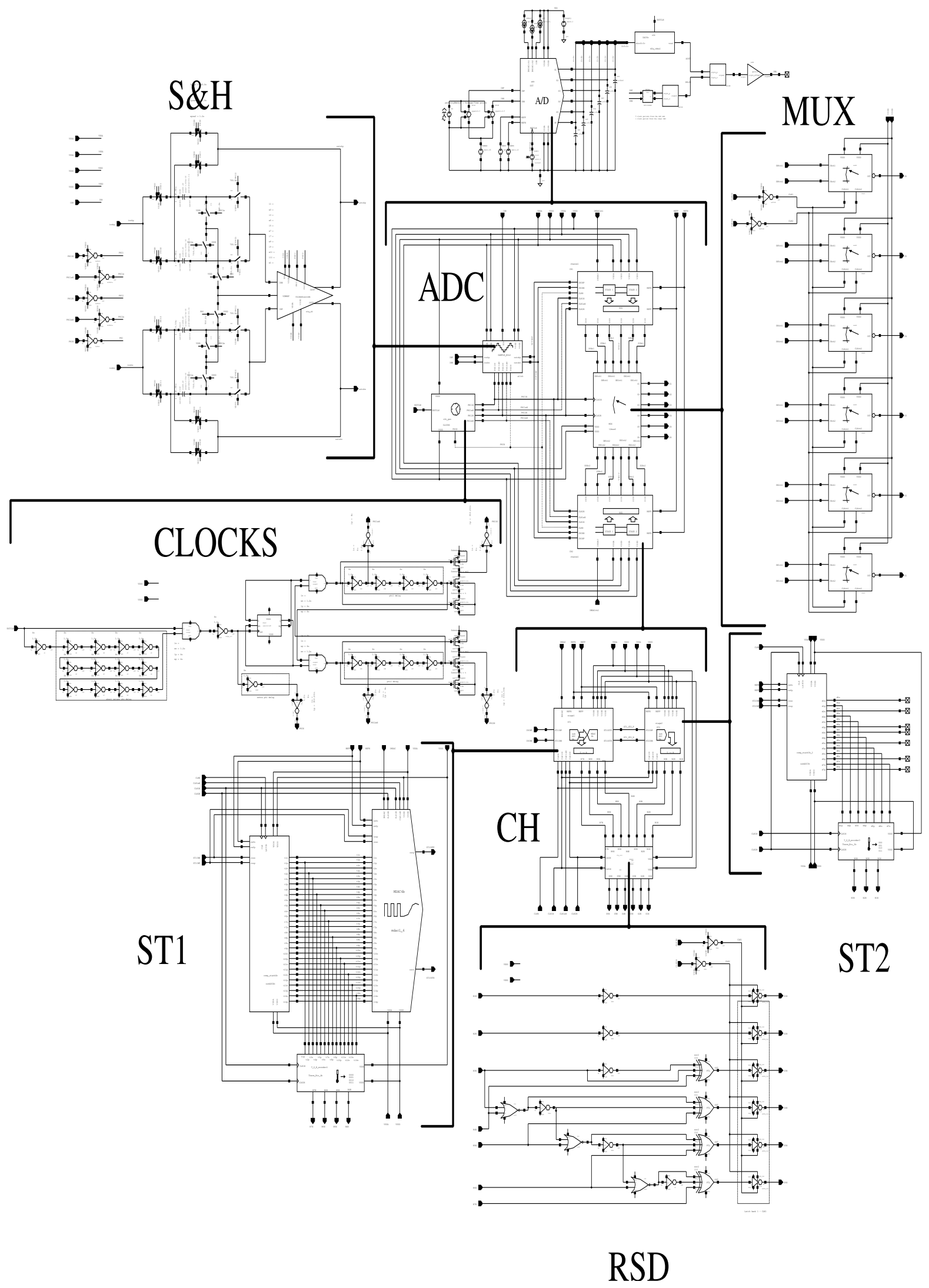

Figura 4.6: Hierarquia de esquemáticos no time-interleaved pipeline $A D C$. 


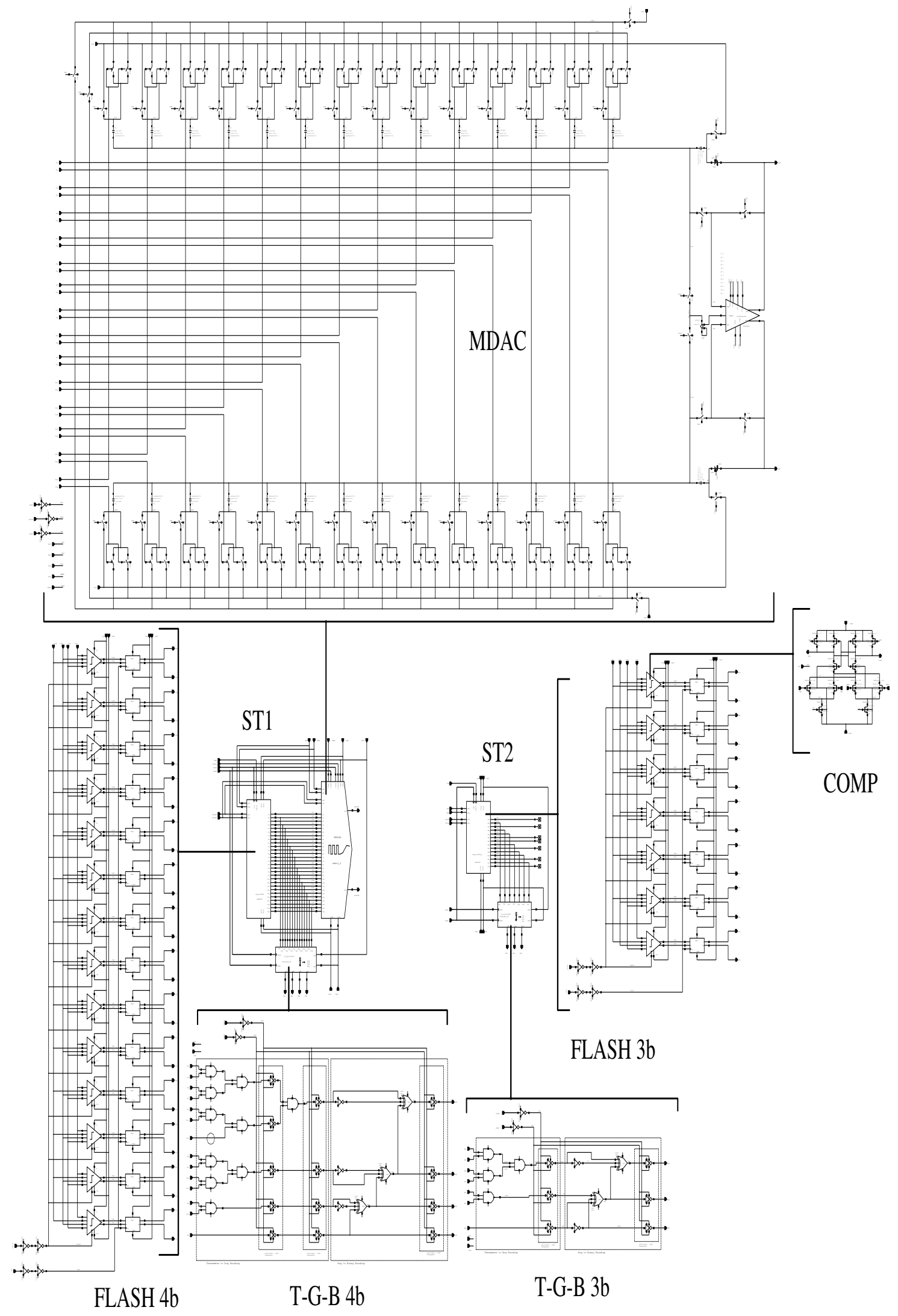

Figura 4.7: Hierarquia de esquemáticos nos estágios pipeline. 


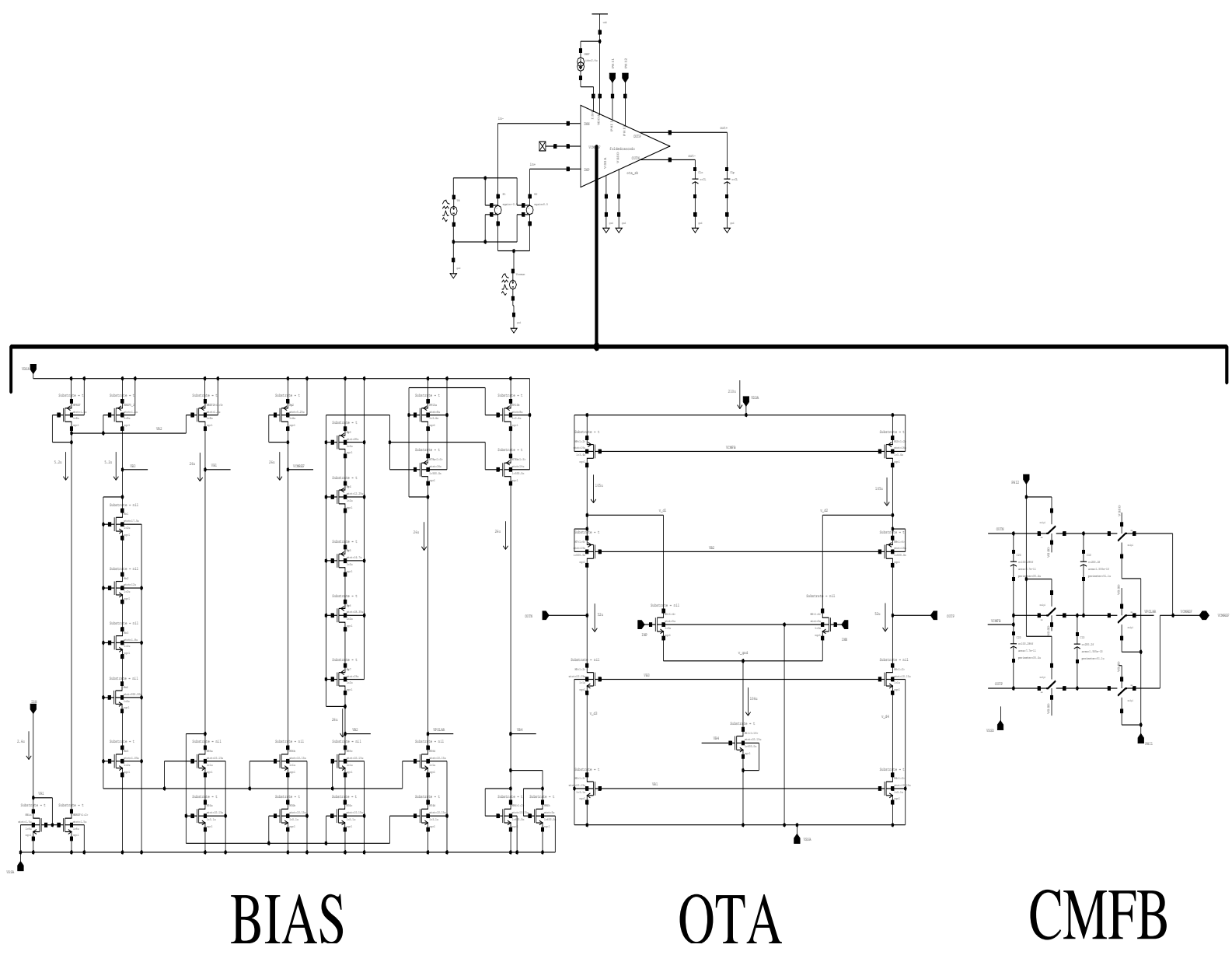

Figura 4.8: Esquema do folded cascode OTA.

UltraSim e Spectre para verificações rápidas e completas em nível de transistor, respectivamente. Junto às simulações, algumas considerações de geometria já são comentadas pensando na elaboração do floorplan e leiautes.

As figuras 4.6 e 4.7 mostram os esquemáticos desenvolvidos no projeto do $A D C$. A hierarquia começa no testbench final do conversor que aparece no topo da figura $4.6 \mathrm{e}$ vai sendo estendida verticalmente para baixo, até chegar nos estágios pipeline. A partir desses dois estágios, na figura 4.7 continua o desdobramento da hierarquia, até chegar no comparador. Já o OTA é mostrado em separado fazendo parte de um testbench da figura 4.8. Deve se notar que o símbolo do OTA inclui tanto o amplificador quanto os circuitos de polarização e realimentação em modo comum.

\subsubsection{OTAs}

Os resultados de simulação dos dois $O T A s$ projetados para o $A D C$ são apresentados na tabela 4.1. O projeto foi baseado na aplicação da PG, conforme explicado em seções 
anteriores e no apêndice A. As dimensões mostradas nessa tabela não são exatamente as geradas pela $\mathrm{PG}$, as quais foram aproximadas e arredondadas para facilitar a aplicação de técnicas para diminuir o mismatch nos transistores, como o leiaute baseado em dedos para dispositivos grandes e o centroide comum para espelhos de corrente e cascodes.

As diferentes polarizações que aparecem na tabela 4.1 são geradas internamente pelo circuito da figura 4.2, como mostrado nos esquemáticos da figura 4.8. Dessa forma, os amplificadores só precisam de uma corrente, duas fases de relógio e a fonte de alimentação $V_{D D}$ para funcionarem. A partir do observado durante a aplicação da $\mathrm{PG}$, a especificação que determinou em ambos os casos a geometria e o consumo de potência dos amplificadores foi a frequência de ganho unitário. Pelo exposto antes, esse foi o parâmetro que ficou mais limitado, enquanto os outros ganharam folga nos seus valores. A corrente $I_{\text {core }}$ quantifica apenas o consumo do amplificador propriamente dito, enquanto $I_{\text {total }}$ inclui também o consumo do circuito de polarização e do $S C$-CMFB.

As figuras 4.9 e 4.10 mostram alguns dos resultados das simulações realizadas para medir os parâmetros da tabela 4.1. As simulações da figura 4.9 foram realizadas com o OTA em laço aberto, fazendo análises transientes para observar a operação do $S C$ $C M F B$, a forma de onda com slewing nas saídas e os consumos rms de corrente; análises em frequência para conferir o ganho e a fase final de saída do circuito; e análises em $D C$ para determinar a faixa de excursão em tensão na saída. A análise $A C$ mostra que

Tabela 4.1: Resultados de simulação dos OTAs projetados com PG.

\begin{tabular}{|c||c||c|}
\hline Parâmetro & $O T A_{S \& H}$ & $O T A_{M D A C}$ \\
\hline \hline$W_{1,2} / L_{1,2}$ & $20 / 3$ & $20 / 1,75$ \\
\hline$W_{3,4} / L_{3,4}$ & $20,3 / 3,1$ & $14,5 / 3,4$ \\
\hline$W_{5,6} / L_{5,6}$ & $20,3 / 1$ & $14,5 / 0,5$ \\
\hline$W_{7,8} / L_{7,8}$ & $96 / 0,5$ & $86 / 0,5$ \\
\hline$W_{9,10} / L_{9,10}$ & $32 / 3,4$ & $86 / 3,2$ \\
\hline$W_{11} / L_{11}$ & $101,5 / 0,6$ & $87 / 0,7$ \\
\hline$V_{D D}$ & $3,3 \mathrm{~V}$ & $3,3 \mathrm{~V}$ \\
\hline$V_{B 1}$ & $0,85 \mathrm{~V}$ & $1,05 \mathrm{~V}$ \\
\hline$V_{B 2}$ & $1,70 \mathrm{~V}$ & $1,86 \mathrm{~V}$ \\
\hline$V_{B 3}$ & $1,20 \mathrm{~V}$ & $1,45 \mathrm{~V}$ \\
\hline$V_{B 4}$ & $0,63 \mathrm{~V}$ & $0,67 \mathrm{~V}$ \\
\hline$C_{L}$ & $1,5 \mathrm{pF}$ & $1,5 \mathrm{pF}$ \\
\hline \hline$v_{\text {offset }}$ & $<7 \mathrm{mV}$ & $<6 \mathrm{mV}$ \\
\hline$A_{o}$ & $70 \mathrm{~dB}$ & $67 \mathrm{~dB}$ \\
\hline$G B W$ & $28 \mathrm{MHz}$ & $46 \mathrm{MHz}$ \\
\hline$S R$ & $65 \mathrm{~V} / \mu \mathrm{s}$ & $98 \mathrm{~V} / \mu \mathrm{s}$ \\
\hline$P M$ & $87^{\circ}$ & $85^{\circ}$ \\
\hline$D R_{I N}, D R_{\text {OUT }}$ & $>1,5 \mathrm{~V}$ & $>1,5 \mathrm{~V}$ \\
\hline$I_{\text {core }}$ & $210 \mu \mathrm{A}$ & $321 \mu \mathrm{A}$ \\
\hline$I_{\text {total }}$ & $350 \mu \mathrm{A}$ & $538 \mu \mathrm{A}$ \\
\hline
\end{tabular}


SLEW RATE

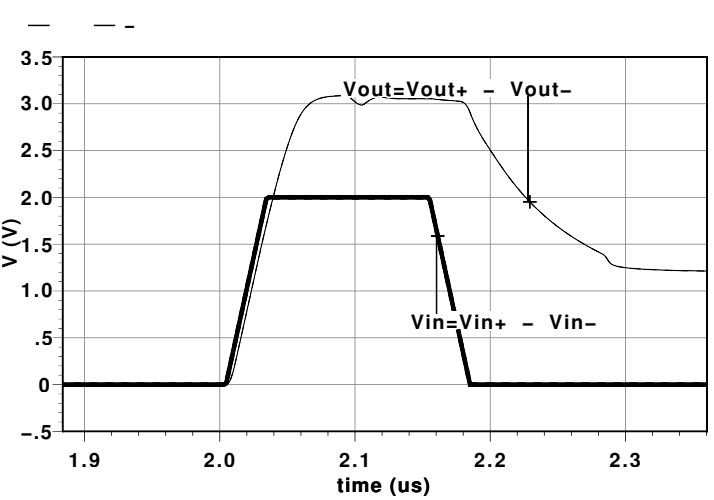

CMFB OPERATION \& CURRENTS

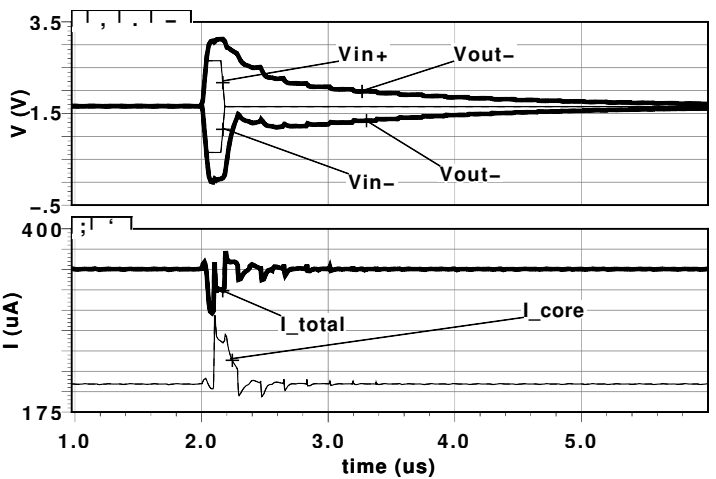

FREQUENCY RESPONSE

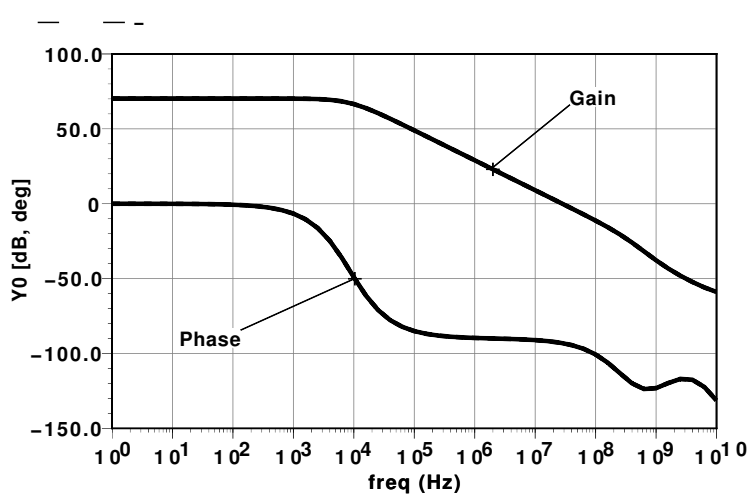

DR OUT

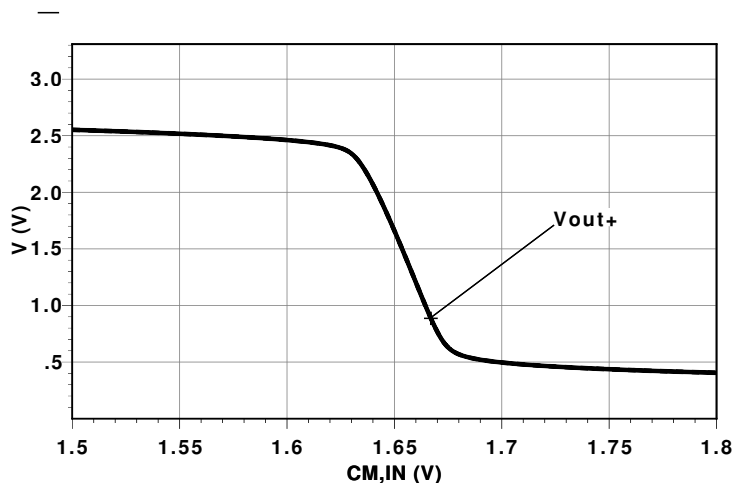

Figura 4.9: Simulações de desempenho do OTA em laço aberto.

o amplificador se comporta como um sistema com um polo dominante, comprovando a suposição feita para algumas das aproximações e simplificações feitas durante a formulação da PG no apêndice A. Além disso, a figura 4.9 também permite verificar que a margem de fase é bastante ampla para garantir a estabilidade do OTA quando for realimentado. Já com respeito a simulação da $D R_{O U T}$, foi observado que esta especificação é determinada pelos limiares de saturação dos transistores cascode M5, M6, M7 e M8 da figura 4.1.

O amplificador é configurado em realimentação unitária para as medidas de offset e faixa de excursão em tensão na entrada, apresentadas na figura 4.10. Devido à presença do bloco $C M F B$, os resultados da figura 4.10 não podem ser obtidos com simples análises em $D C$, como é feito tradicionalmente. Em vez disso, cada valor obtido deve ser medido no final da resposta transiente do $C M F B$, após estabilizarem os nós de saída. Dessa vez, foi observado que a $D R_{I N}$ é determinada pelas fronteiras da região de triodo dos transistores cascode M7, M8 e da fonte de corrente M11, na figura 4.1.

Entretanto, a tensão de offset do OTA é determinada a partir dos parâmetros da distribuição Gaussiana obtida da análise de Monte Carlo incluindo variações de processo 

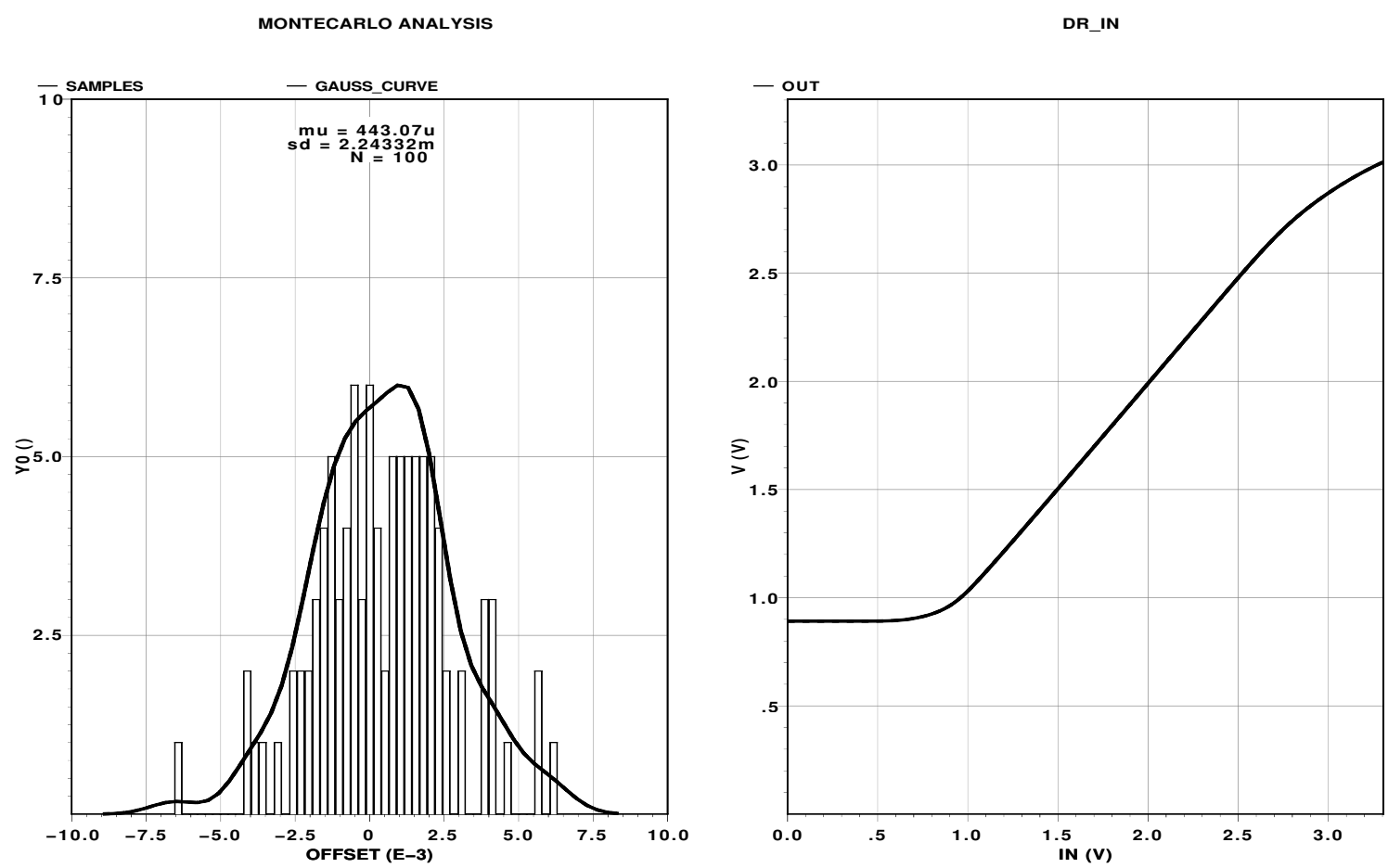

Figura 4.10: Simulações de desempenho do OTA em malha fechada.

e mismatch, mostrada na esquerda da figura 4.10. O valor da especificação reportado na tabela 4.1 é calculado assim: $v_{\text {offset }} \leq \mu \pm 3 \cdot \sigma$, onde $\mu$ e $\sigma$ são a média e o desvio padrão da distribuição Gaussiana na figura 4.10, respectivamente. É importante esclarecer que a análise Monte Carlo feita também inclui as variações dos circuitos de polarização e $S C$ $C M F B$ (principalmente os capacitores), devido a eles estarem dentro do circuito do OTA, como apresentado na figura 4.8.

\subsubsection{Comparadores}

Com a aplicação da PG, em [40] se projeta um circuito comparador base, cujas propriedades são apresentadas na tabela 4.2. A nomenclatura dessa tabela está relacionada com a figura 4.4. Nesse trabalho, o objetivo da estratégia foi diminuir os tempos de atraso do circuito. Já nesta aplicação, esse resultado é adaptado como ponto de partida para implementar os diferentes comparadores que vão gerar internamente os limiares dos sub-ADCs, conforme foi explicado em seções anteriores. As figuras $4.11 \mathrm{e}$ 4.12 mostram esse funcionamento para os dois estágios. Em ambas as figuras alguns dos bits gerados podem ser vistos.

O valor da tensão de offset reportado na tabela 4.2 foi determinado mediante a figura 4.13. Nessa figura são mostrados os desempenhos de 4 dos comparadores projetados a 


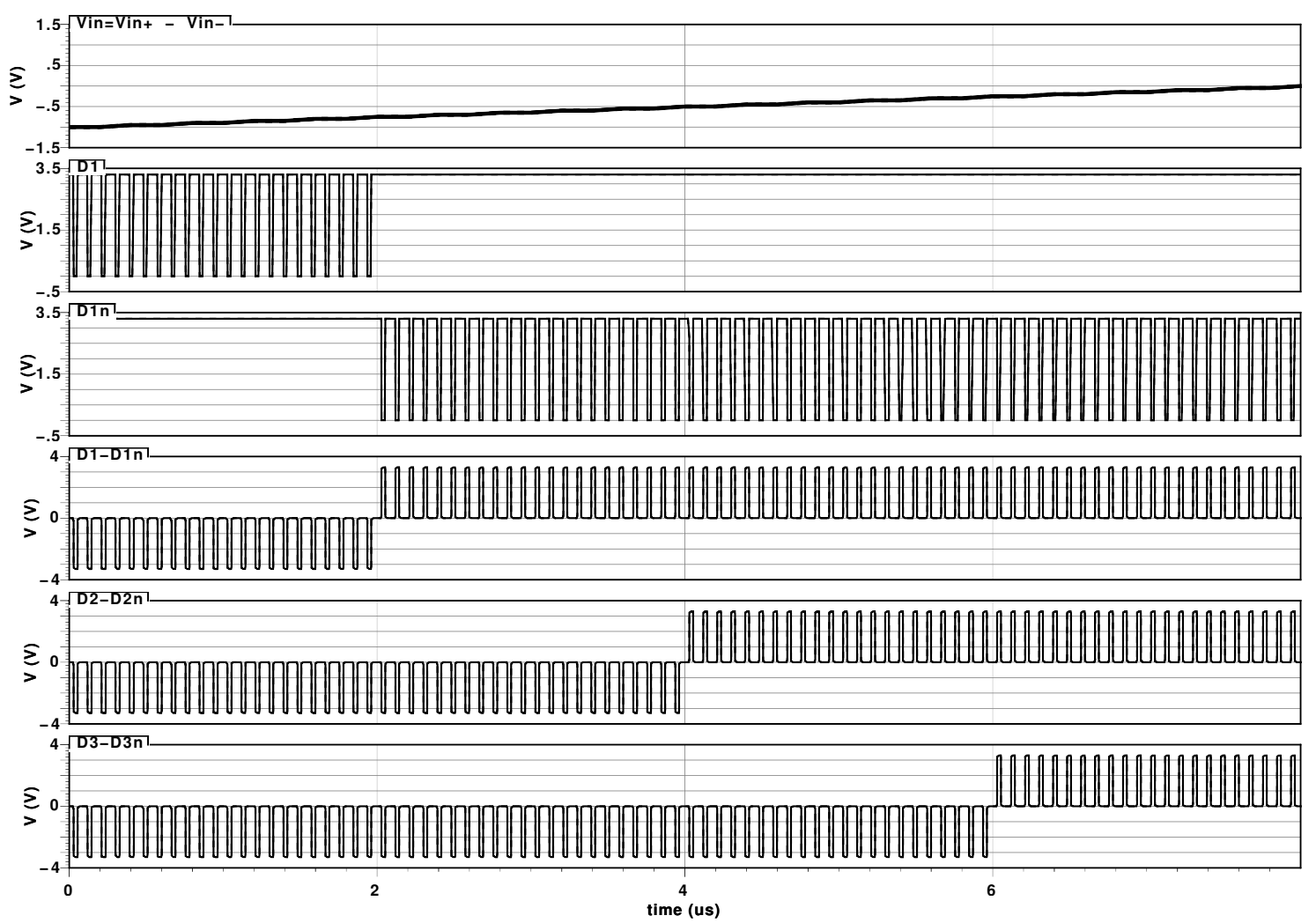

Figura 4.11: Saída do $s u b-A D C$ de 3 bits, antes do banco de registradores.

partir de [40] para os limiares de comparação indicados também na figura. Cada ponto nessa figura corresponde a 100 simulações de Monte Carlo dos comparadores funcionando com as tensões fixas de entrada que aparecem no eixo $x$. Dependendo do limiar de comparação, o desempenho ilustrado corresponde à porcentagem de decisões corretas do circuito. Na figura 4.13 pode ser visto que enquanto mais próxima esteja a tensão de entrada do limiar do comparador, a probabilidade de errar se aproxima a 1/2. Ao invés disso, quando a tensão de entrada se afasta do limiar, a quantidade de acertos se incrementa até $100 \%$.

A tensão de offset de um comparador se define como a tensão que tem que ser aplicada

Tabela 4.2: Características do comparador básico projetado com PG [40].

\begin{tabular}{|c||c||c|c|}
\hline Dimensão & Valor & Parâmetro & Valor \\
\hline \hline$W_{7,8}$ & $1 \mu \mathrm{m}$ & $L_{1-12}$ & $0,35 \mu \mathrm{m}$ \\
\hline$W_{10,11}$ & $1 \mu \mathrm{m}$ & $v_{\text {offset }}$ & $<62,5 \mathrm{mV}$ \\
\hline$W_{1,2,3,4}$ & $3,3 \mu \mathrm{m}$ & $t_{\text {latch }}$ & $266 \mathrm{ps}$ \\
\hline$W_{9,12}$ & $3,1 \mu \mathrm{m}$ & $t_{\text {reset }}$ & $345 \mathrm{ps}$ \\
\hline$W_{5,6}$ & $3,3 \mu \mathrm{m}$ & $P_{\text {dyn }}$ & $544 \mu \mathrm{W}$ \\
\hline
\end{tabular}




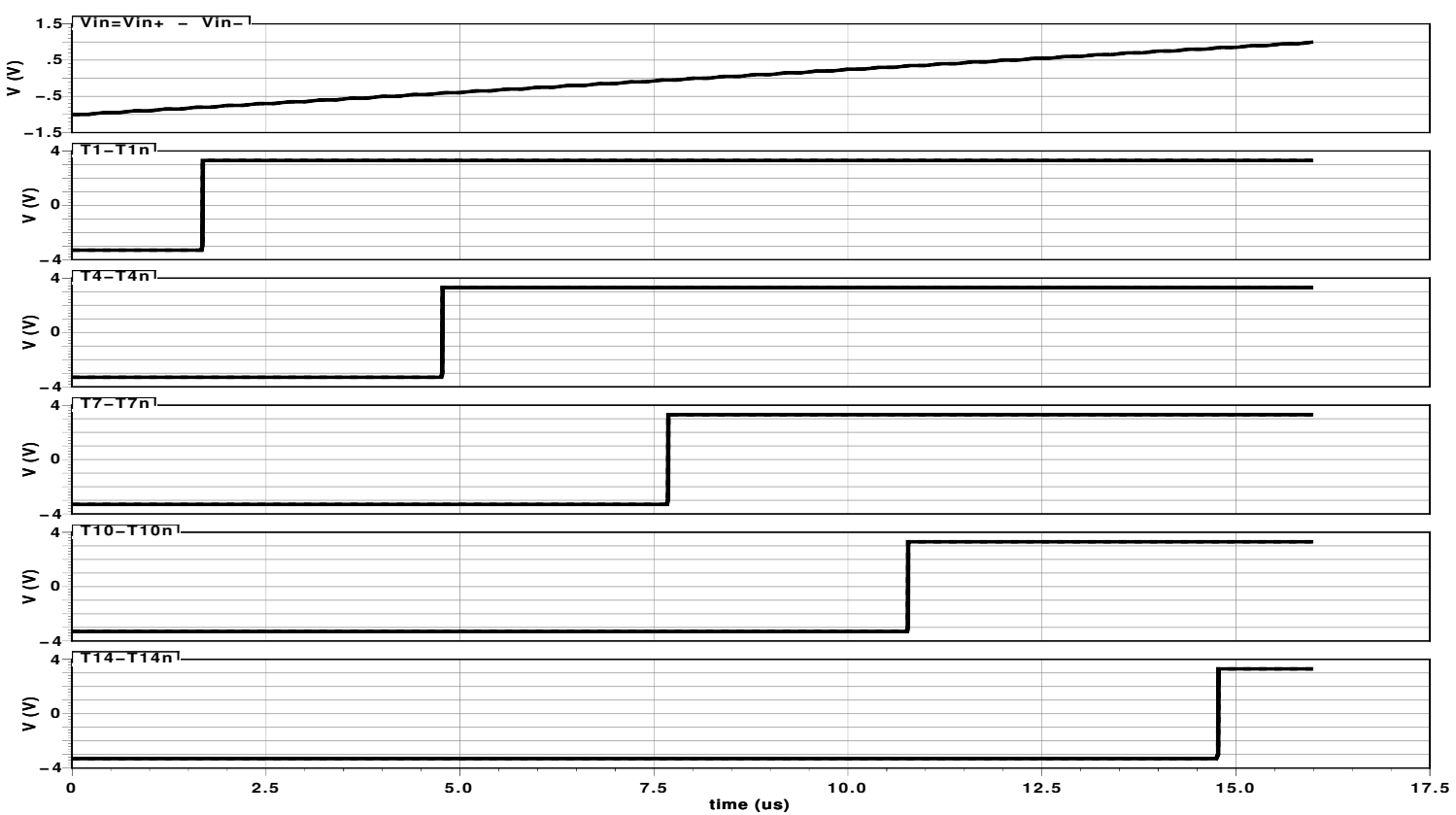

Figura 4.12: Saída do $s u b-A D C$ de 4 bits, após o banco de registradores.

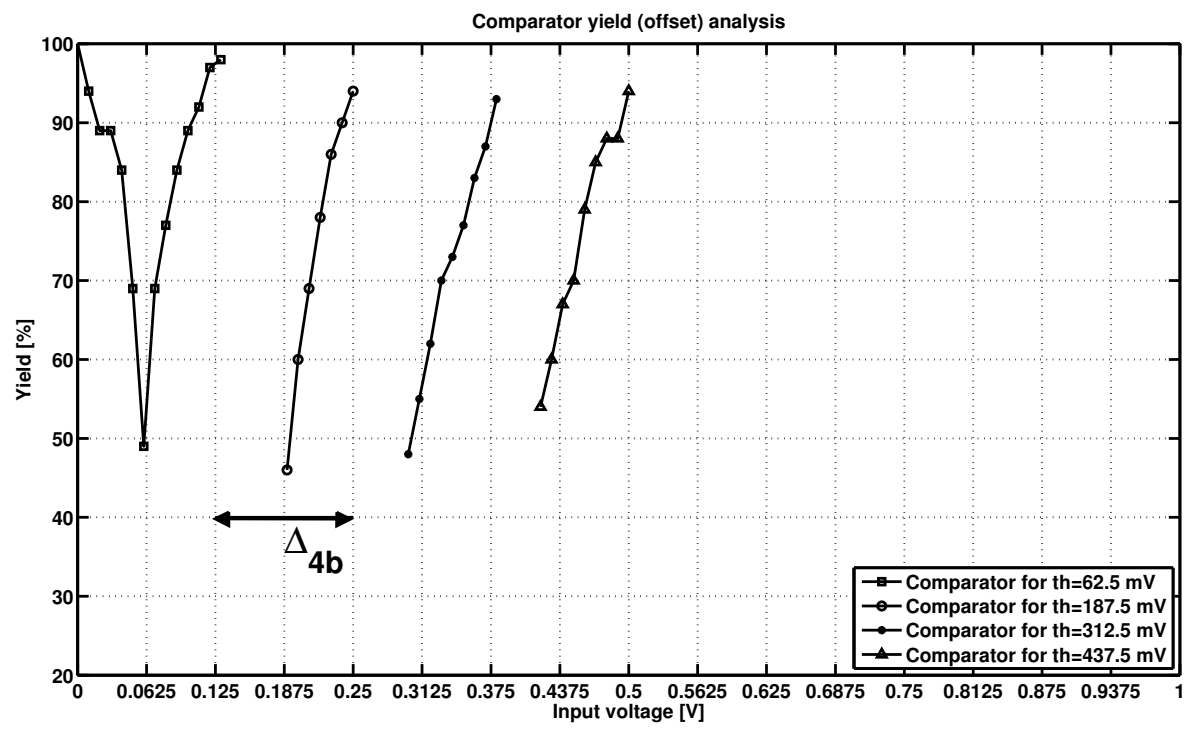

Figura 4.13: Desempenho e probabilidade de offset dos comparadores.

na entrada para levá-lo à metaestabilidade. Do ponto de vista teórico, o desempenho da figura 4.13 é igual à probabilidade de que a tensão de offset do comparador seja menor que $V_{\text {in }}-V_{\text {limiar }}$ [41]. Então, a partir do exposto anteriormente e dos resultados da figura 4.13, pode se estabelecer que os comparadores irão apresentar uma tensão de offset menor que $\Delta_{4 b} / 2$, como é permitido pela correção digital $R S D$. 


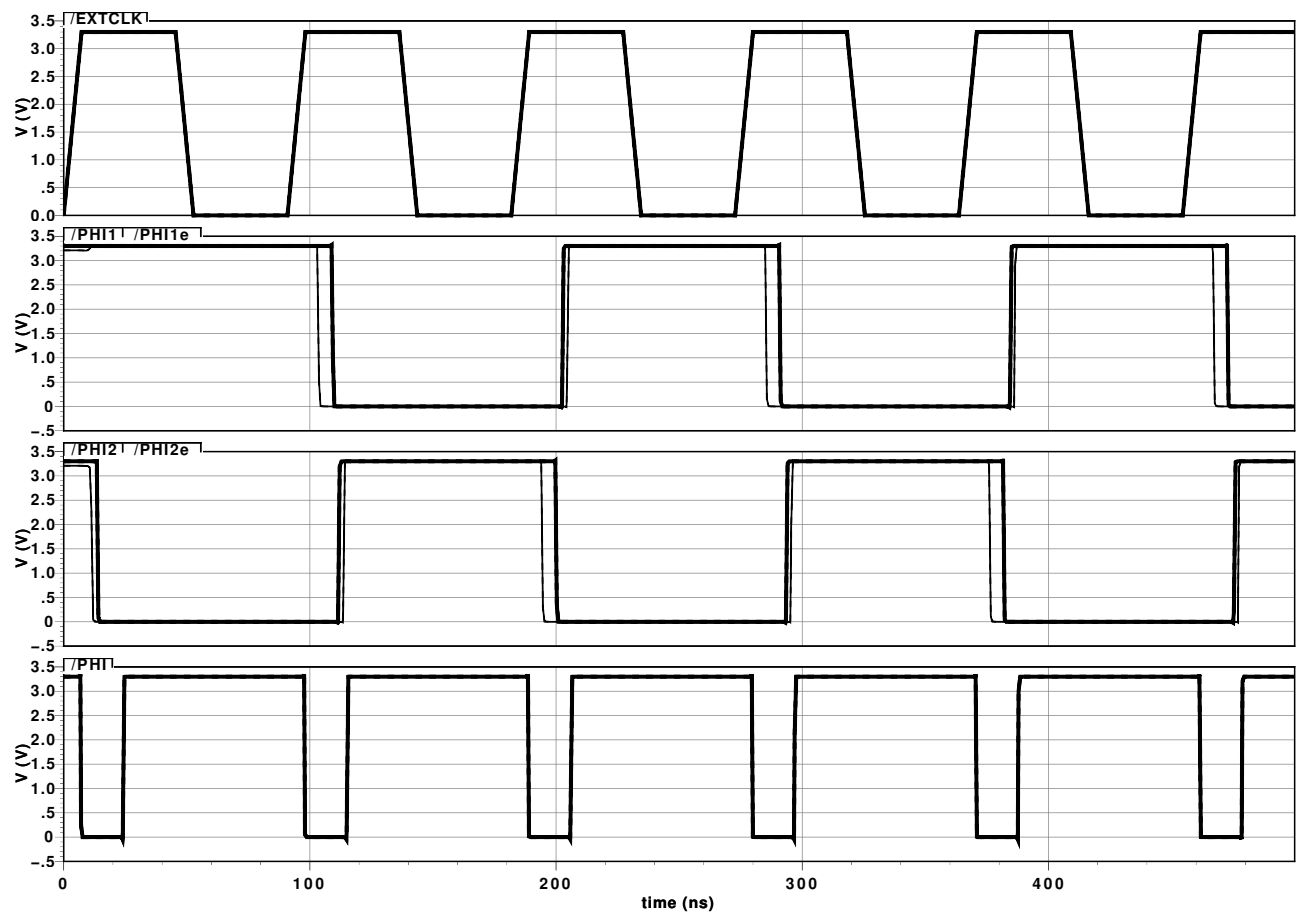

Figura 4.14: Fases de relógio necessárias para o funcionamento do $A D C$.

\subsection{3 $S E H$}

O primeiro bloco que o sinal analógico encontra na entrada do $A D C$ é o $S \mathscr{E} H$. Como foi explicado no capítulo 3, a função dele é discretizar esse sinal de entrada tanto em amplitude quanto em tempo. E para executar essa tarefa, o $S \mathscr{G} H$ precisa de um conjunto de fases de relógio devido ao uso de algumas técnicas para reduzir suas imperfeições. Esses sinais de sincronização são gerados internamente a partir de um único relógio de entrada de $11 \mathrm{MHz}$, como mostrado na figura 4.14. Já o funcionamento do bloco de amostragem e retenção é apresentado na figura 4.15, para o caso de uma rampa de entrada.

Focando a atenção na parte direita da figura 4.15, as especificações de $G B W$ e $S R$ obtidas para os amplificadores são as responsáveis das amostras de saída do $S E B H$ se estabilizarem com uma precisão menor que $\pm L S B / 2$ dentro da faixa de tempo disponível para essa tarefa. Entretanto, os glitches alí observados são causados pela variação não linear da resistência das chaves CMOS. Outra possível causa desses transientes é a diminuição da resistência dos transistores cascode na saída do OTA, devido ao funcionamento próximo da fronteira da região de triodo quando $V_{i n}= \pm V_{F S} / 2$. Por essa razão o amplificador precisa de grandes faixas de excursão em tensão, $D R_{I N}$ e $D R_{O U T}$. 

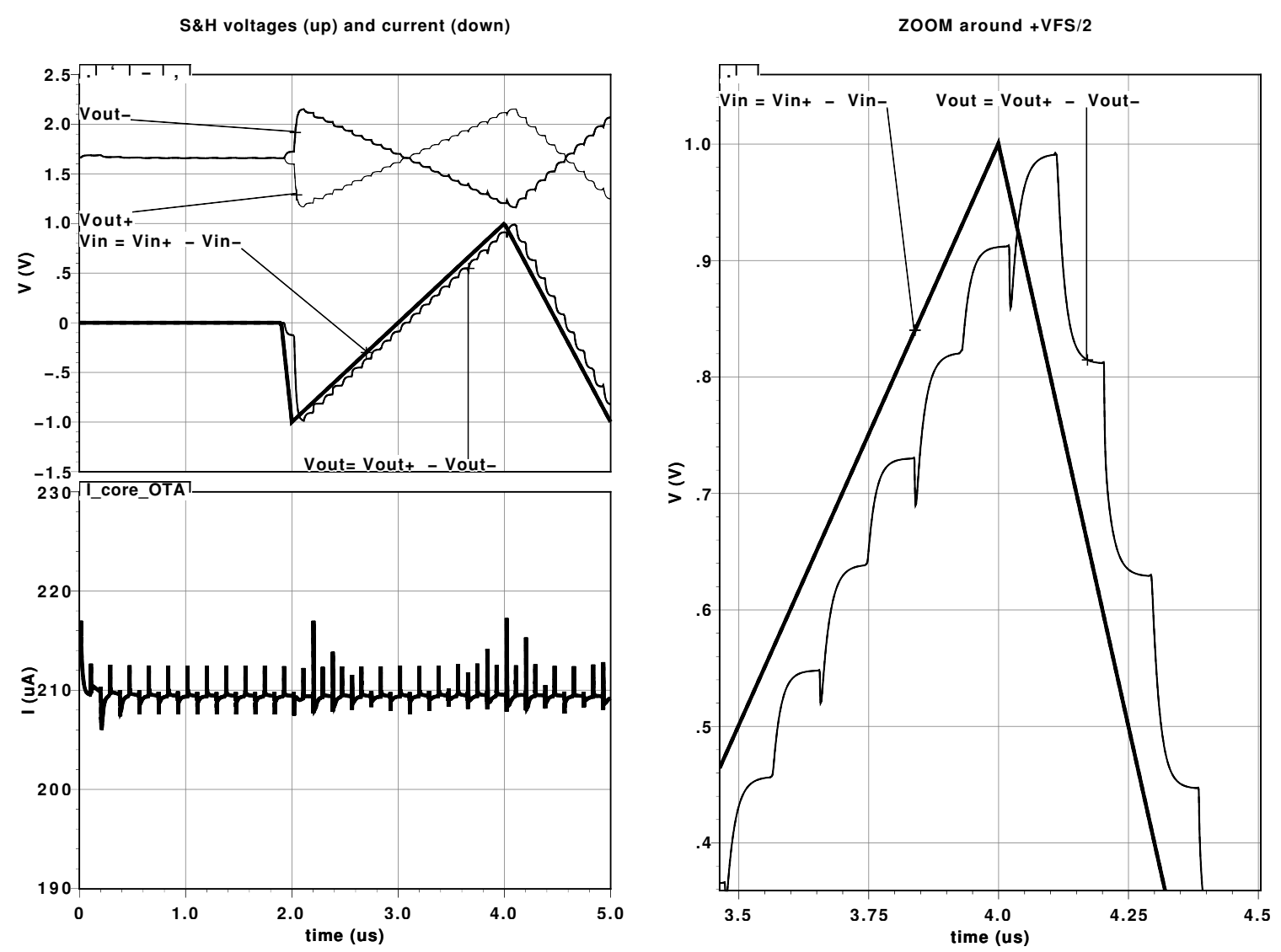

Figura 4.15: Funcionamento do bloco $S \& H$ com um sinal de entrada rampa.

\subsubsection{Canal pipeline}

A figura 4.16 apresenta em detalhe uma parte da conversão A/D através de um dos canais da arquitetura. O sinal de entrada amostrado aparece no topo (sh_out), sendo uma rampa que abrange a faixa completa de excursão na entrada, $V_{F S}$. Logo após a entrada, os sinais mostrados estão agrupados em quatro categorias de cima para baixo: a palavra de saída $\mathbf{S}$ do canal completo, a palavra de 4 bits $\mathbf{B}_{\mathbf{7 - 4}}$ gerada pelo primeiro estágio, a palavra de 3 bits $\mathbf{B}_{\mathbf{3}-\mathbf{1}}$ na saída do segundo estágio, e finalmente alguns dos sinais digitais termométricos na saída do $s u b-A D C$ de 3 bits. Pela natureza do sinal de entrada, espera-se também um comportamento monotônico crescente nos bits gerados pelos blocos da cadeia pipeline.

Comparando os sinais da parte inferior da figura $4.16 \mathrm{com}$ os bits em $\mathbf{B}_{\mathbf{3}-\mathbf{1}}$, pode ser visualizada a transformação de 7 sinais em código termômetro para 3 sinais em código binário. Outro detalhe a ser ressaltado é a diferença das codificações entre o estágio de 4 bits e o de 3 bits: enquanto o primeiro se encarrega de codificar as variações grossas do sinal 


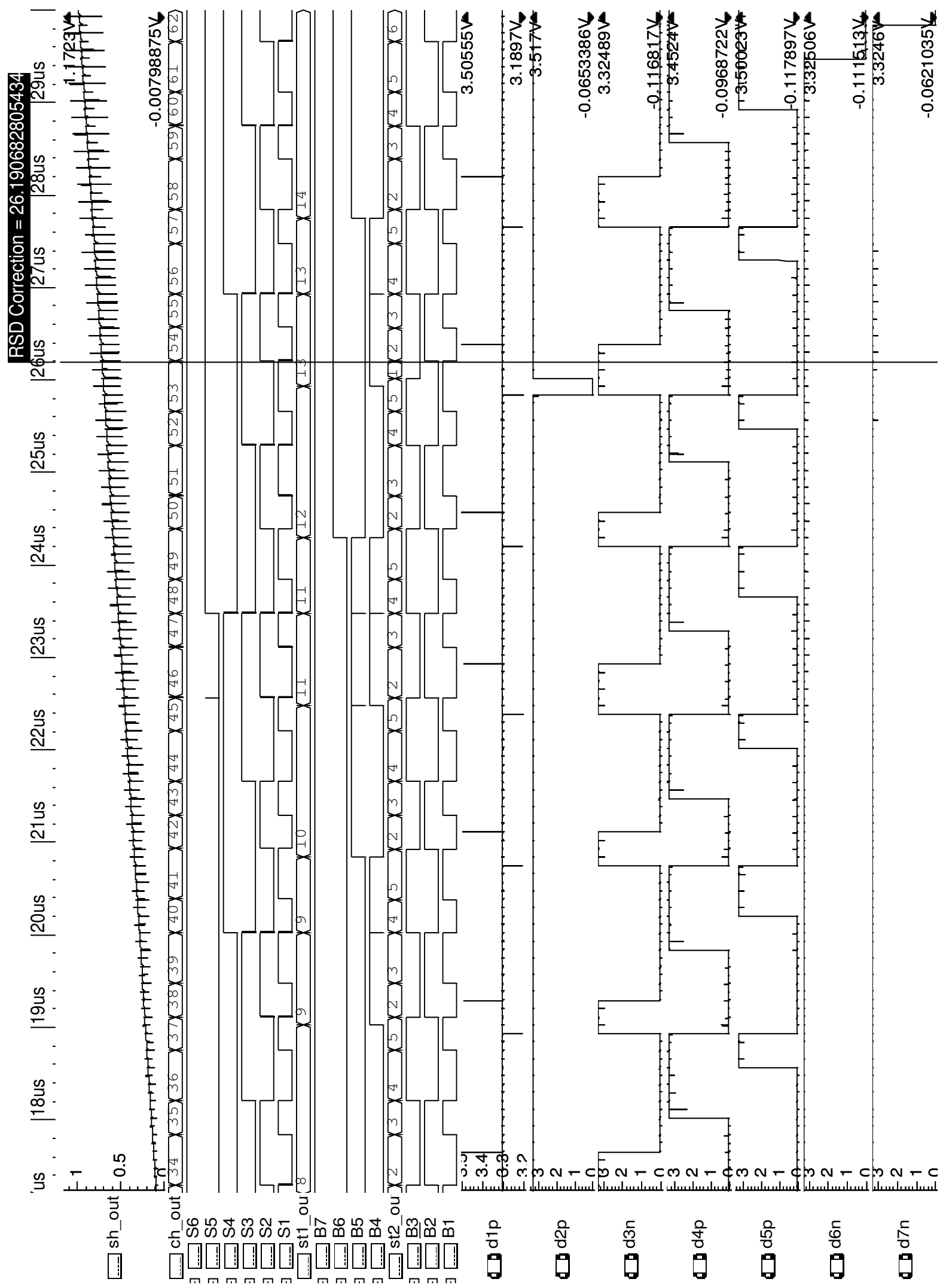

Figura 4.16: Aplicação de correção digital $R S D$ em um dos canais pipeline. 
de entrada, o segundo digitaliza as variações finas. A razão disso é que, como explicado nos capítulos anteriores, o segundo estágio processa o resíduo da operação do primeiro. A seção final do bloco digital mostrado na figura 3.17 é o responsável de combinar e corrigir a palavra digital $\mathbf{B}$ de 7 bits resultante dos dois estágios, para gerar o código digital $\mathbf{S}$ de 6 bits na saída do canal. Nessa conversão, um bit é usado para aplicar a técnica de correção digital $R S D$.

As conversões na figura 4.16 seguem as sequências mostradas na figura 3.10(b), comprovando a aplicação da correção $R S D$. Por essa razão, a palavra st2_out só apresenta os códigos 2, 3, 4 e 5. Quando a anterior sequência é alterada, como mostrado no marcador $\boldsymbol{R S D}$ Correction próximo a $t=26 \mu$ s na figura 4.16, a técnica $R S D$ é aplicada. Antes do marcador, os valores de st1_out e st2_out eram 5 e 12, gerando o código 53 na saída, segundo a operação da figura 3.8. Por causa de um erro no sinal d2p, o código st2_out passa a representar o valor $1 \mathrm{em}$ vez de 2. No entanto, o comportamento monotônico do $A D C$ é conservado porque a combinação do novo valor correto de st1_out (13) e o novo valor errado de st2_out (1) continua produzindo o código 53 na saída do canal, de acordo com o esquema da figura 3.8 .

\subsection{5 $A D C$}

Agora, para finalizar a exploração ao longo do conversor AD, o funcionamento dos dois canais paralelos é apresentado na figura 4.17. Dessa vez o sinal de entrada corresponde ao caso mais exigente do padrão Bluetooth, sendo um tom sinusoidal com frequência equivalente à máxima frequência presente em um canal banda base: $500 \mathrm{kHz}$. Descendo na figura 4.17, logo após o sinal de entrada, pode ser vista a saída diferencial do $S \mathscr{G} H$. As duas fases de relógio principais do $A D C$ aparecem na parte inferior da figura. A aplicação da técnica de amostragem dupla no $S \mathscr{G} H$ permite aproveitar cada uma dessas fases, fornecendo amostras de forma alternada aos dois canais time interleaved.

A seguir, os nomes usados para os sinais das figuras 4.17 e 4.19 são explicados e relacionados com as convenções utilizadas ao longo dos capítulos anteriores:

- IN : tensão diferencial analógica de entrada para o $A D C: V_{i n}=V_{i n}^{+}-V_{i n}^{-}$;

- shOUT: saída diferencial do bloco $S \mathscr{H} H$;

- ch1(2)RES: saída diferencial do primeiro estágio em cada canal do ADC. Esse sinal corresponde também ao resíduo amplificado na saída do bloco $M D A C$; 


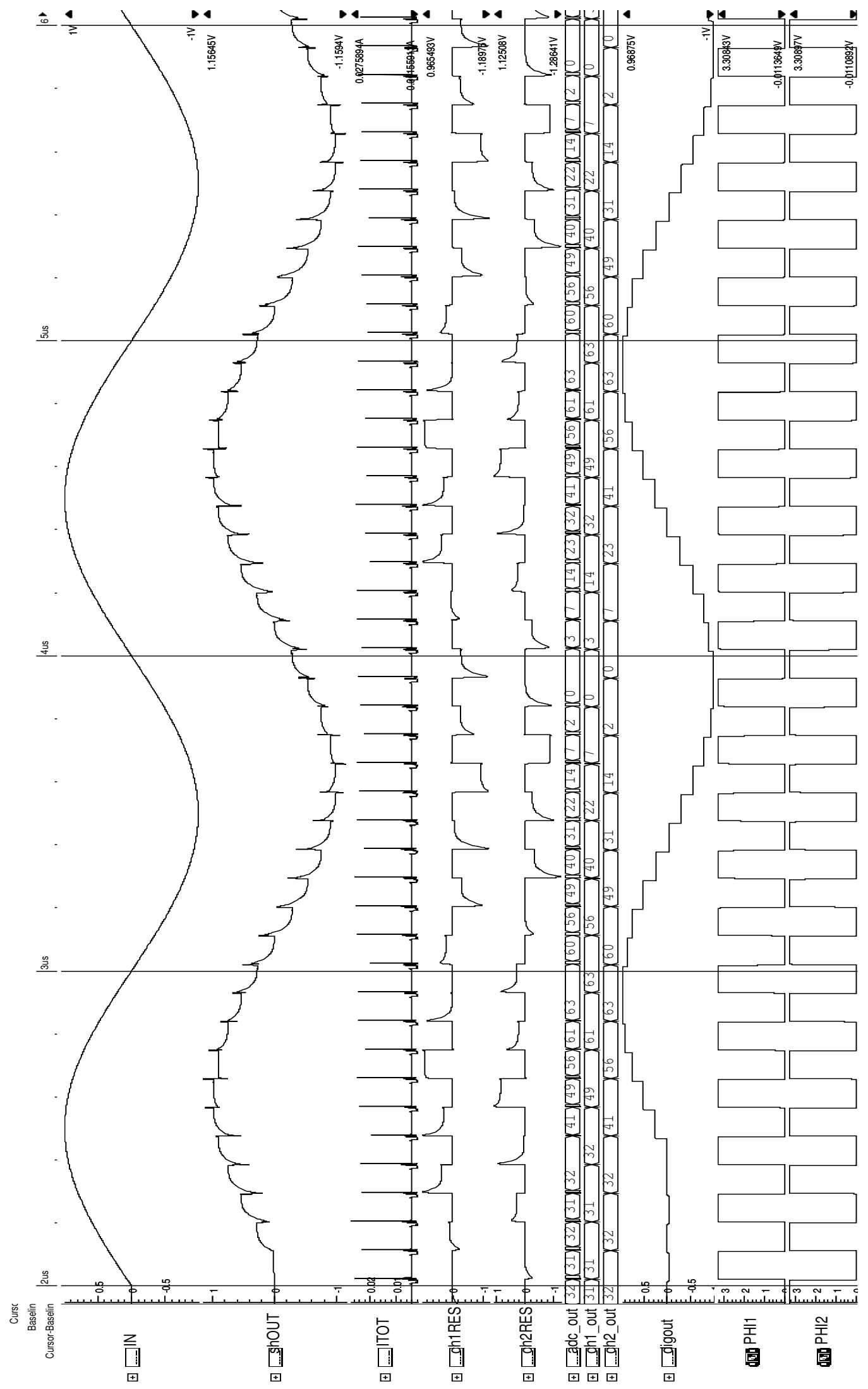

Figura 4.17: Simulação do funcionamento do $A D C$ completo. 
- adc_out: valor decimal da palavra digital de saída $\mathbf{S}$ (6 bits) do conversor completo;

- ch1(2)_out: valor decimal das saídas digitais (6 bits) de cada canal;

- digOUT: saída digital do $A D C$ reconvertida ao domínio analógico mediante um $D A C$ ideal de 6 bits descrito por um modelo comportamental em verilogA.

Como introduzido acima, o revezamento dos canais na conversão A/D da arquitetura também pode ser visualizado nos sinais de resíduo do primeiro estágio de cada canal. Além disso, os próprios códigos de saída de cada canal na figura 4.17, bem como a construção da saída final do $A D C$ a partir da multiplexação dessas saídas parciais, também esclarecem o modo de funcionamento time interleaved. É dessa maneira que o conversor consegue fornecer códigos digitais na frequência total do relógio externo $(11 \mathrm{MHz})$, distribuindo os requisitos de velocidade para não impôr restrições fortes nos circuitos elementares. A condição anterior leva consequentemente a um consumo de potência menor.

A tabela 4.3 apresenta um resumo das características do conversor AD projetado neste trabalho. Os valores desses parâmetros foram obtidos a partir de simulações pre-leiaute, usando dispositivos (transistores NMOS, PMOS e capacitores CMIM) da tecnologia

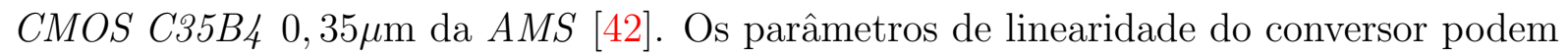
ser calculados a partir dos resultados na figura 4.18. Nessa figura, o sinal digOUT-IN é a subtração analógica entre a entrada e a conversão D/A ideal da palavra de saída do $A D C$, após sincronização para tirar a latência do sistema. A análise desses resultados sob variações em simulações de Monte Carlo exige um tempo de simulação muito grande. Entretanto, a transformada rápida de Fourier (FFT) mostrada na figura 4.19 permite medir os valores de $S N R$ apresentados na tabela 4.3. O valor da frequência de entrada $f_{\text {in }}$ foi escolhido segundo critérios de precisão na aplicação da FFT.

A área estimada do conversor completo é de $0,013 \mathrm{~mm}^{2}$, sendo distribuída como

Tabela 4.3: Especificações do $A D C$ simulado pre-leiaute.

\begin{tabular}{|c|c|}
\hline Parâmetro & Valor \\
\hline \hline Tensão de alimentação & $3,3 \mathrm{~V}$ \\
\hline Consumo de corrente $(r m s)$ & $3,64 \mathrm{~mA}$ \\
\hline Máxima largura de banda de sinal & $500 \mathrm{kHz}$ \\
\hline Frequência de amostragem & $11 M \mathrm{Mz}$ \\
\hline Resolução & 6 bits \\
\hline Latência & 5 ciclos de relógio \\
\hline Excursão total na entrada $\left(V_{F S}\right)$ & $2 \mathrm{~V}_{p p}$ \\
\hline$S N R$ (dentro do canal) & $59.4 \mathrm{~dB}$ \\
\hline$S N R$ (até $\left.f_{s} / 2\right)$ & $46.5 \mathrm{~dB}$ \\
\hline Estimativa de área & $0,013 \mathrm{~mm}^{2}$ \\
\hline
\end{tabular}




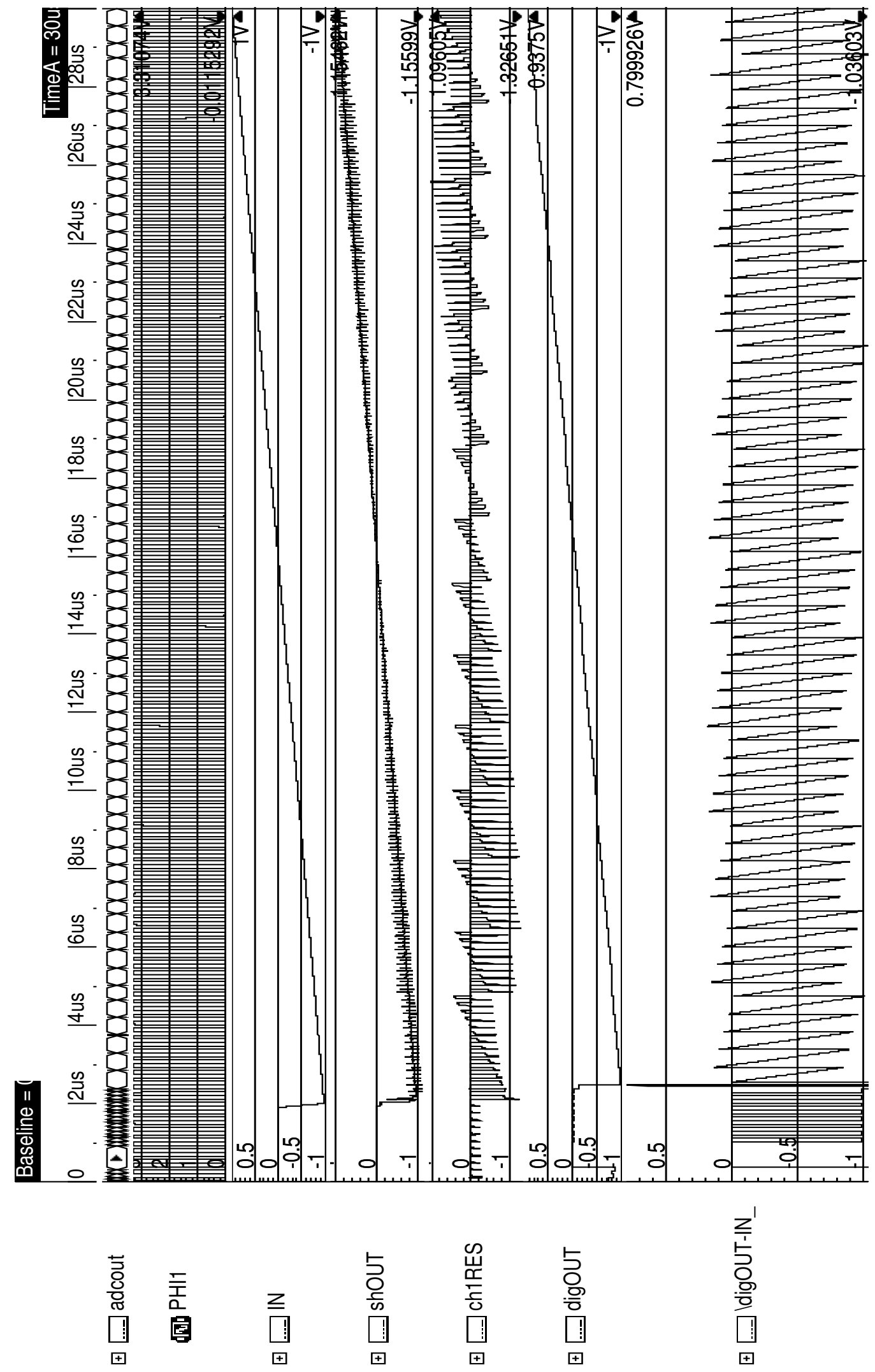

Figura 4.18: Simulação para observar a linearidade do $A D C$. 


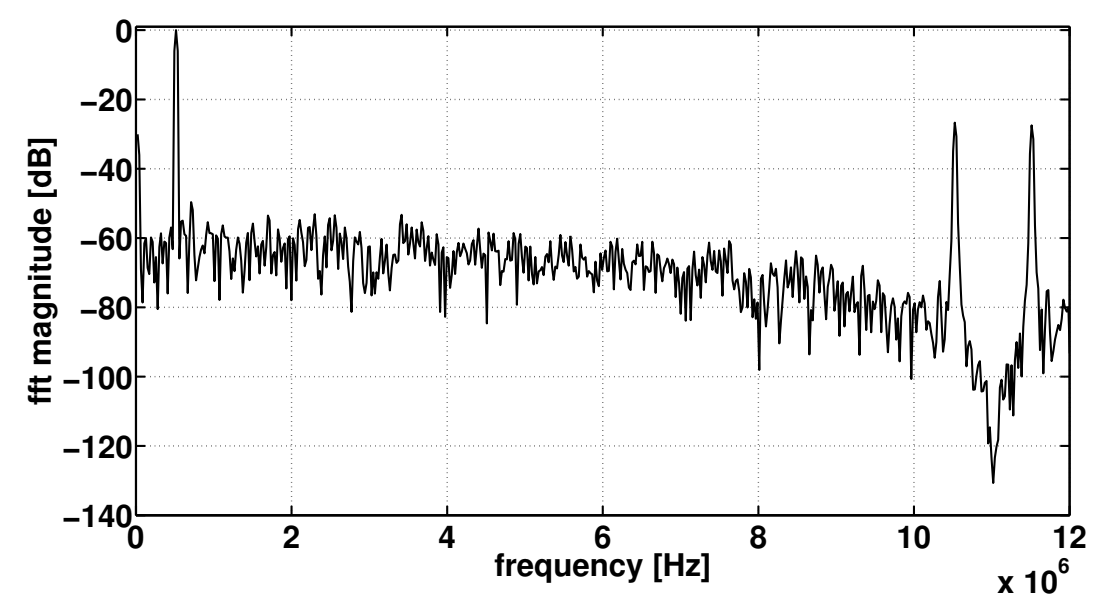

Figura 4.19: Espectro do sinal $\operatorname{dig} O U T$ para $f_{\text {in }}=494 \mathrm{kHz}$ e $f_{s}=11 \mathrm{MHz}$.

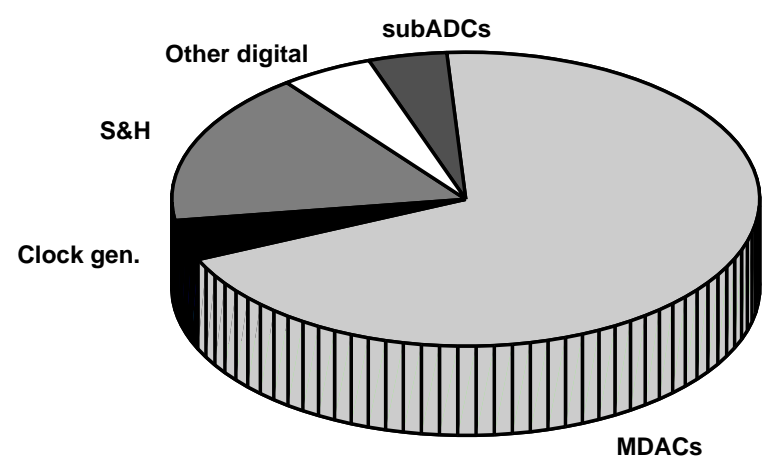

Figura 4.20: Distribuição da área estimada $\left(0,013 \mathrm{~mm}^{2}\right)$ do $A D C$.

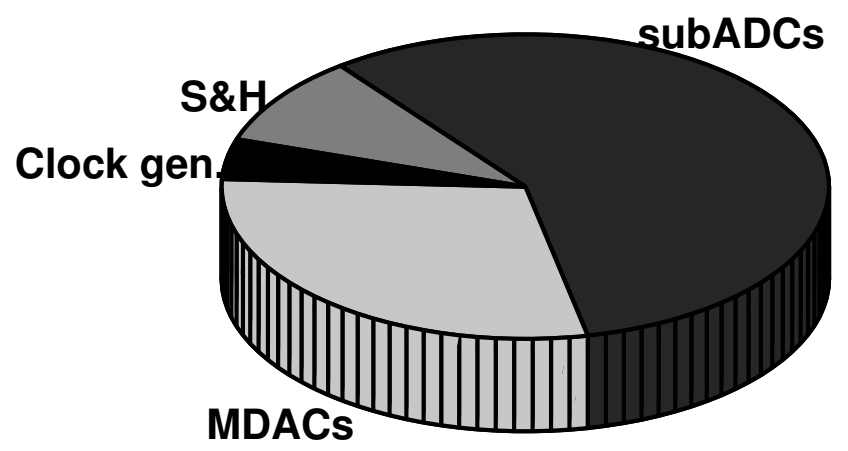

Figura 4.21: Distribuição da potência obtida da simulação do $A D C$.

mostrado na figura 4.20, que permite concluir que os maiores blocos são aqueles compostos pelos amplificadores e os capacitores. Já a distribuição do consumo de corrente total do $A D C$ obtido em simulação e reportado na tabela 4.3 é mostrada na figura 4.21. Neste caso, os sub-ADCs representam a maior contribuição com o banco de latches que seguem aos comparadores, devido ao consumo de potência dinâmica nas transições das fases de relógio. Isto pode ser modificado através da seleção adequada da arquitetura e da fase de relógio que controla esses latches. 


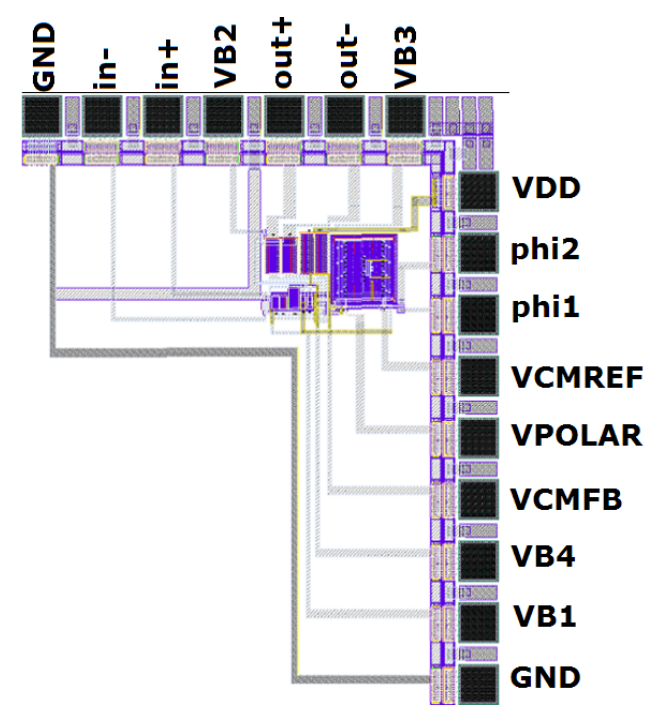

(a)

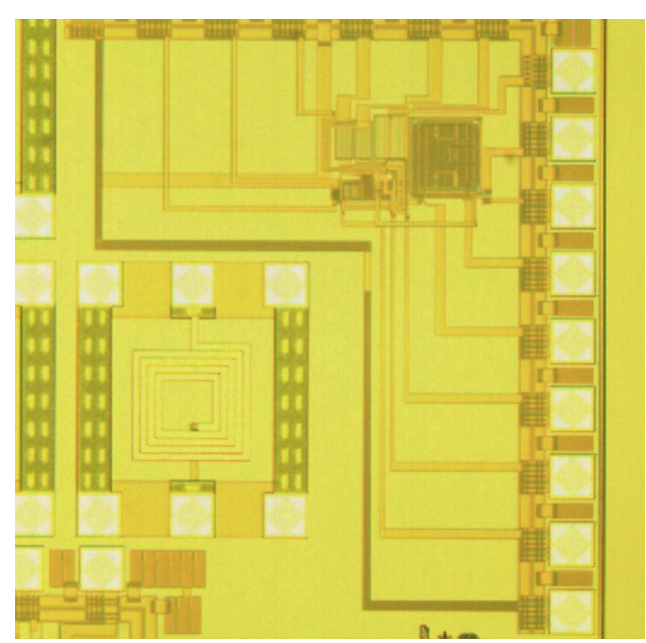

(b)

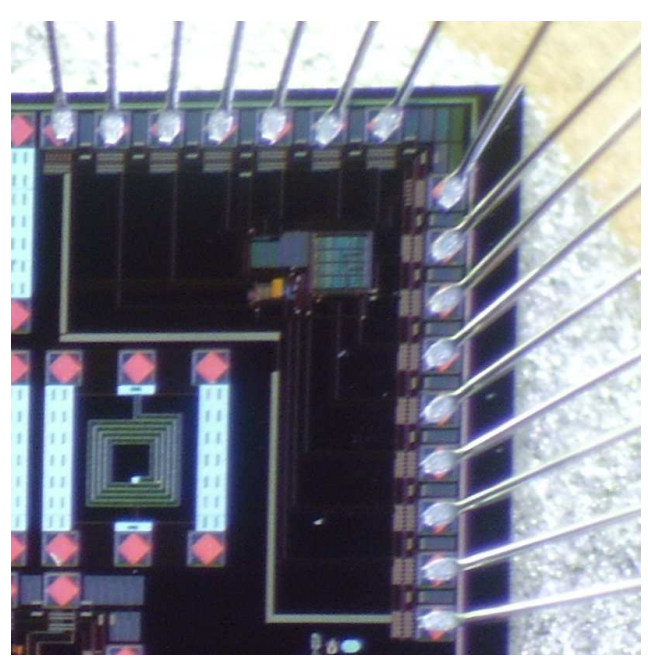

(c)

Figura 4.22: Leiaute (a) e microfotografias (b,c) do OTA fabricado.

\subsection{Fabricação e testes}

Dentro de desenvolvimento deste trabalho, um dos circuitos elementares foi fabricado e parcialmente testado. O protótipo implementado foi o do $O T A$ junto com seu bloco $S C$ $C M F B$, mostrado na figura 4.1, porém sem geração interna das tensões de polarização, porque o circuito da figura 4.2 não tinha sido escolhido nesse momento. O leiaute e algumas fotografias do chip aparecem na figura 4.22. A disponibilidade de vários pinos de polarização, dentre eles a tensão interna de controle $V_{C M F B}$, permite experimentar e testar diversas características para conhecer melhor as topologias implementadas. Os capacitores (a maior área quadrada do leiaute) foram construídos com $C P O L Y$, usando estruturas baseadas em células unitárias com um centroide comum. 


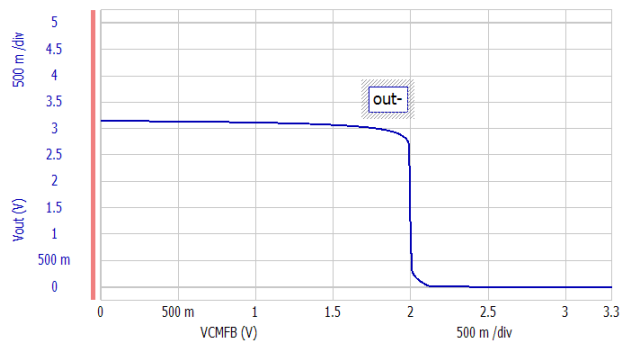

(a)

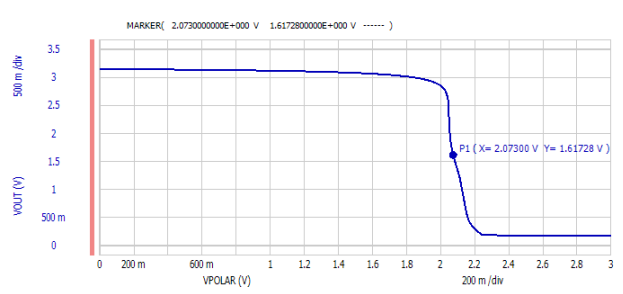

(c)

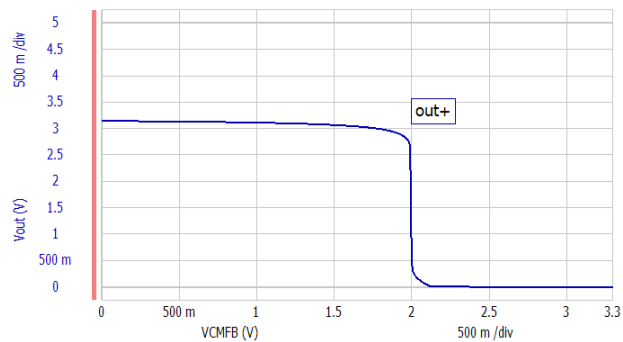

(b)

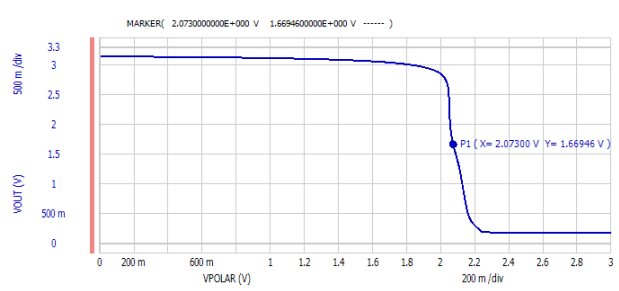

(d)

Figura 4.23: Medições em $D C$ : saída negativa (a) e positiva (b) sem $C M F B$; saída negativa (c) e positiva (d) com $C M F B$.

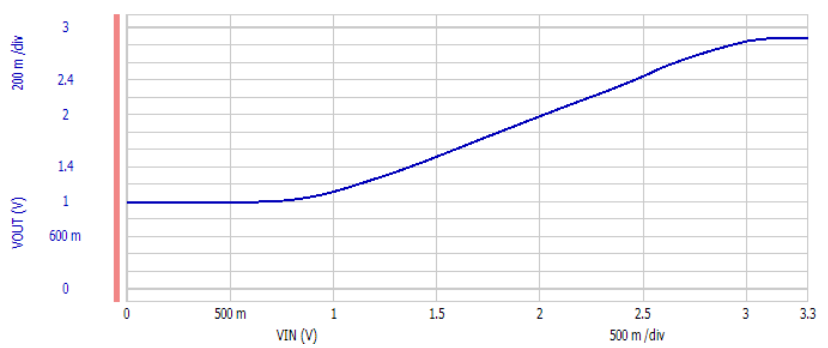

Figura 4.24: Medição da $D R_{I N}$ no $O T A$ fabricado.

O amplificador fabricado não corresponde exatamente aos projetados para o $A D C$ porque essas versões foram concebidas para operarem dentro de um circuito integrado maior e não para teste, onde os instrumentos de medição impõem grandes cargas nos nós testados. Assim, os OTAs usados no $S \mathscr{H} H$ e no $M D A C$ são carregados por capacitâncias internas pequenas, decorrentes de comparadores, chaves e portas lógicas. Pela razão anterior, foi feito um projeto de OTAs para condições de teste, resultando em um circuito com maior área e consumo de potência, porém mais robusto a cargas capacitivas grandes. Nesta tarefa, novamente foi aproveitado o poder da PG para gerar diversas versões da mesma topologia com especificações diferentes.

O primeiro passo nos testes do OTA foi a polarização. Como explicado no início deste capitulo, o grande desafio desta arquitetura diferencial é estabelecer a tensão em modo comum na saída, devido à alta sensibilidade desses nós a qualquer tipo de variações. A 
característica anterior pode ser claramente observada nas figuras 4.23(a) e 4.23(b), onde o amplificador foi testado com o bloco $C M F B$ desligado, impondo manualmente uma tensão de polarização no pino $V_{C M F B}$. A transição abrupta dos nós de saída impede esse controle de ser feito desse modo na prática. É por isso que um bloco $C M F B$ deve ser utilizado.

As figuras 4.23(c) e 4.23(d) mostram os testes feitos com o $C M F B$ ligado, o que é conseguido através dos pinos que recebem os sinais de relógio complementares, $\phi_{1}$ e $\phi_{2}$. Devido à natureza transiente da resposta do $S C$ - $C M F B$, cada ponto mostrado nesses resultados não corresponde a uma simples varredura em $D C$, como no parágrafo anterior. Em vez disso, deve se esperar que o bloco $C M F B$ faça sua função estabilizando os nós de saída ao valor de modo comum determinado pelo pino $V_{C M R E F}$, que neste caso corresponde a $1,65 \mathrm{~V}$. Portanto, dessa vez o controle do modo comum é feito automaticamente, ajustando $V_{C M F B}$ a $V_{P O L A R}$ (eixo $x$ ), conseguindo assim um resultado equivalente ao mostrado nas figuras 4.23(a) e 4.23(b). Caso os nós de saída se desloquem de $V_{C M R E F}$ por alguma razão, como o descasamento de tensões e parâmetros ou pelo ruído, o $C M F B$ sempre tentará puxá-los de volta. Os testes descritos anteriormente foram aplicados em 3 amostras, e os resultados são apresentados na tabela 4.4 .

Assim que o OTA foi corretamente polarizado com a ajuda do $C M F B$, os parâmetros de desempenho especificados na PG podem ser testados e medidos. A faixa de excursão em tensão na entrada pode ser observada na figura 4.24. Porém, nos testes em frequência do amplificador surgiram alguns inconvenientes que dificultaram sua realização. A topologia implementada é diferencial e foi projetada para fornecer um ganho muito alto (80 dB). Portanto, esses testes precisam de instrumentos que forneçam sinais diferenciais de entrada em uma faixa de frequências ampla e com precisão na ordem de grandeza de $\mu \mathrm{V}$, e assim evitar a saturação das saídas, lembrando que $V_{D D}=3,3 \mathrm{~V}$. Além do mais, essa fonte de sinais deve ainda fornecer a tensão de polarização em modo comum na entrada, $V_{C M, I N}=1,65 \mathrm{~V}$, que é necessária para o funcionamento do OTA.

Os inconvenientes descritos acima também aplicam no caso dos testes das respostas transientes para caracterizar o slew rate do OTA. Pelas razões anteriores, esses testes não tinham sido realizados até o momento da entrega deste documento.

Tabela 4.4: Polarização em 3 amostras do OTA fabricado.

\begin{tabular}{|c|c|c|c|c|}
\hline Caso & $V_{P O L A R, C M F B}$ & $V_{\text {out }+}$ & $V_{\text {out }-}$ & $I_{D D}$ \\
\hline \hline Simulado & 2,09 & 1,65 & 1,65 & 2,99 \\
\hline Amostra 1 & 2,073 & 1,676 & 1,620 & 3,11 \\
\hline Amostra 2 & 2,004 & 1,697 & 1,584 & 3,91 \\
\hline Amostra 3 & 2,025 & 1,654 & 1,706 & 3,53 \\
\hline
\end{tabular}




\section{Conclusões e recomendações}

Visando fornecer o conteúdo mais formativo desta dissertação, recopilam-se as conclusões geradas, as observações que merecem ser ressaltadas e as sugestões para motivar e levar em conta na realização de trabalhos futuros relacionados com o tema.

\subsection{Conclusões}

Neste trabalho foi projetado um conversor analógico digital para ser usado no padrão de comunicação sem fio Bluetooth. O ADC projetado é baseado na arquitetura timeinterleaved pipeline, com 2 canais e 2 estágios básicos. Cada canal opera a $5,5 \mathrm{MHz}$ para gerar códigos digitais a uma frequência total de amostragem $f_{s}=11 \mathrm{MHz}$. O primeiro estágio básico em cada cadeia pipeline é formado por um sub-ADC e um $M D A C$ de 4 bits, enquanto o segundo tem apenas um sub- $A D C$ de 3 bits. Assim sendo, o $A D C$ completo tem uma resolução de 6 bits, usando um bit de redundância para aplicar correção digital utilizando a estratégia $R S D$.

Uma análise completa e exaustiva da verdadeira resolução requerida ou número de bits de um $A D C$ é uma tarefa complexa, influenciada por diversos fatores e compromissos, dependendo do esquema de modulação usado pelo padrão de comunicação sem fio que é processado pelo receptor completo. Isto leva à aplicação tradicional, tanto na literatura quanto neste trabalho, de procedimentos que envolvem diversas margens de projeto e suposições. A estratégia anterior provavelmente superestima a especificação do conversor.

A escolha e projeto de uma topologia de $C M F B$ de acordo com as caraterísticas de operação do OTA que vai usá-lo, é fundamental para o bom desempenho dos blocos funcionais do $A D C$, como é o caso do $S \mathscr{E} H$ e o $M D A C$. A justificativa da afirmação anterior é que este circuito ajusta o $V_{C M, O U T}$ projetado mediante $\mathrm{PG}$, o que garante a correta operação do amplificador e o bloco que o usa.

A especificação correta dos parâmetros determinantes no consumo de corrente do 
$O T A$, como o $S R$, tem um grande impacto na dissipação de potência total do $A D C$. Levando em conta o dito anteriormente, este trabalho conseguiu implementar um circuito $S \mathscr{G} H$ de baixo consumo de potência através da análise cuidadosa do verdadeiro requisito de $S R$ no amplificador central do bloco. Mediante esta estratégia, evita-se o superdimensionamento comum na literatura, onde tradicionalmente se assume que a saída do $S \mathscr{G} H$ deve acompanhar degraus de tensão tão grandes como $V_{F S}$. Os benefícios decorrentes da solução anterior são ainda mais valiosos se o $S \mathscr{G} H$ na entrada da arquitetura é reconhecido como o principal consumidor de potência individual do $A D C$, devido a suas fortes restrições de velocidade e resolução, além do seu OTA ser o foco de tal consumo. Ou seja, esta é uma contribuição real deste trabalho de mestrado comparado com outros da literatura.

A contribuição anterior está fundamentada em boa parte na aplicação da PG. Uma das características mais interessantes do projeto formulado como um programa geométrico é que oferece a possibilidade de conhecer o circuito e ganhar experiência e domínio sobre o comportamento do mesmo. Isto faz com que o projetista possa prestar mais atenção na interação entre as especificações dos circuitos e as tendências das suas variáveis de projeto. Finalmente, e mais importante ainda, o dito acima leva à identificação de possíveis focos para a otimização do desempenho global dos sistemas, como o $A D C$ que concerne a este trabalho.

Apesar da automatização do projeto inicial mediante a ferramenta da programação geométrica, o conhecimento e análise cuidadosa dos circuitos, da mesma forma que no método tradicional de projeto, continuam representando uma parte fundamental do trabalho e da solução. Sendo assim, a PG apenas complementa e auxilia a tarefa do projetista. Isto suporta a ideia de que o projeto de circuitos analógicos não pode ser totalmente programável, uma vez que sempre será preciso se valer da criatividade e experiência do projetista, para resolver detalhes e especificações particulares.

A exploração da programação geométrica permite a este projeto se afastar da estratégia comum que é aplicada discretamente em outros trabalhos similares de $A D C s$ com a arquitetura pipeline. Tal estratégia necessita de um tempo considerável apenas para o projeto cuidadoso do primeiro estágio, que tem as especificações mais exigentes. Já os estágios restantes da cadeia são implementados a partir de simples cópias do primeiro, porém com alguns ajustes de escalonamento.

Neste trabalho foi seguida uma estratégia para simular o conversor analógico-digital. Nessa estratégia usou-se ferramentas de simulação de circuitos de sinal de modo misto, 
implementando modelos comportamentais em verilogA (Cadence) da maioria dos blocos com o intuito de reduzir os tempos de simulação. Posteriormente, blocos e circuitos específicos iam sendo substituídos com suas versões em nível de transistores, até completar o sistema completo do $A D C$. Após ter definido e conseguido um sistema completamente funcional, e vindo a avaliar os parâmetros de desempenho do $A D C$, foram usados todos os esquemáticos com os respectivos dispositivos da tecnologia disponível apenas nas simulações finais.

É importante tomar cuidado com os modelos verilogA implementados. Dependendo da natureza analógica ou digital dos circuitos, e também das funções executadas por eles, pode ser fundamental a inclusão ou omissão de não idealidades e descrições comportamentais além da simples transmissão e operação de sinais da entrada para a saída. As condições anteriores influenciam diretamente os resultados e ainda as interpretações das simulações globais do conversor.

O OTA do bloco $S \mathscr{E} H$ foi projetado e fabricado no processo $C M O S C 35 B 4$ 0,35 $\mu \mathrm{m}$ de Austria MicroSystems (AMS). Inicialmente, quando a topologia do folded cascode OTA foi projetada mediante PG, a tensão de saída de modo comum $V_{C M, O U T}$ era ajustada manualmente com alguma tensão de polarização durante as simulações de verificação dos parâmetros de desempenho. A fabricação e testes realizados neste trabalho, do $S C$-CMFB junto ao amplificador, permitiram validar a eficiência do circuito para fazer esse controle automaticamente, e desse modo garantir o ponto de operação correto como condição necessária para o desempenho esperado.

\subsection{Observações e recomendações}

As observações feitas durante o desenvolvimento deste trabalho e algumas sugestões para trabalhos futuros são discutidas a seguir:

O artigo base deste trabalho [9] emprega tecnologia BiCMOS para a implementação do $A D C$. Um processo de fabricação desse tipo fornece algumas vantagens quando comparado com o CMOS convencional. Por exemplo, tem-se um menor nível de offset e ruído nos transistores bipolares que podem ser aproveitados quando eles são usados como estágio de entrada nos amplificadores. Com essa tecnologia também pode-se implementar opamps BiCMOS de maior velocidade e ganho, com um consumo de potência similar aos fabricados em $C M O S$, devido ao valor inerente maior de transcondutância e menores capacitâncias parasitas dos transistores bipolares [1]. Porém, como desvantagem, o 
custo de fabricação é maior. Neste trabalho se contornam as limitações dos transistores MOSFET mediante a aplicação estratégica de técnicas de circuito, e se aproveita da maior integrabilidade e menor custo que fazem a tecnologia $C M O S$ convencional mais acessível.

A análise para determinar a $S N R$ requerida pelo nível de desempenho $(B E R)$ do padrão de comunicação, foi desenvolvida neste trabalho (figura 2.3) usando o modelo mais simples para o canal de transmissão, conhecido como o canal de ruído branco aditivo Gaussiano $(A W G N)$. Por outro lado, na literatura são abordadas diversas análises similares baseadas em modelos mais complexos e realistas, porém que estão fora do escopo deste trabalho. Todavia, é importante ressaltar que esses estudos são realizados apenas em nível de sistema, e não aplicados a implementações práticas como o projeto de circuitos integrados. Desse modo, alguns casos envolvem interferências por canais adjacentes, efeito Doppler, multi-trajetórias com linha de vista e sem ela (urbanos), os quais são caraterizados por diversas distribuições e séries probabilísticas como Gram-Charlier e Nakagami, da que se deriva um dos seus casos especiais mais conhecido: Rayleigh de multi-trajetória.

A obtenção do número real de bits por estágio em uma cadeia pipeline também é uma tarefa complexa e área de ativa pesquisa. Mesmo que neste trabalho se faça uma tentativa de otimizar este parâmetro prestando atenção ao consumo de potência do $A D C$, uma estratégia mais completa deve incluir fatores como a possibilidade de diferentes resoluções por estágio e também a redução da área, como apresentado em [19]. No entanto, um método como esse precisaria da ajuda de ferramentas informáticas por ser um problema multivariável complexo.

A falta de informação detalhada na literatura sobre a implementação dos diferentes blocos funcionais do $A D C$ foi um obstáculo constante durante o desenvolvimento do trabalho. Dessa forma, pormenores relativamente simples, porém fundamentais para a compreensão e adaptação das técnicas de circuitos, dificultaram a realização de alguns detalhes. Três exemplos específicos foram: a) intervalos de tempo e atrasos relativos das diferentes fases de relógio usadas ao longo da cadeia pipeline; b) a forma na que a saída digital do sub-ADC controla o chaveamento do banco de capacitores no $M D A C$; c) as diversas alternativas (nem sempre ótimas e convenientes) para implementar uma mesma função de transferência incluindo o offset digital no estágio básico requerido pela correção mediante $R S D$. Como recomendação para trabalhos futuros, aconselha-se procurar essas informações em referências mais antigas, pois alguns desses detalhes já foram estudados no passado. 
Partindo de um dos exemplos no parágrafo anterior, sugere-se a investigação detalhada das diversas opções para a implementação da função de transferência do $M D A C$ (tabela 3.4). O foco de um estudo dessa natureza seria descobrir uma arquitetura que use o menor banco de capacitores possível. Derivado do anterior, o fator de realimentação $\beta$ aumentaria e as especificações do OTA ficariam menos exigentes.

Investigar a possível redução de potência e área que pode ser conseguida compartilhando-se o OTA dos MDACs em estágios consecutivos.

Investigar os benefícios derivados da reutilização do $O T A$ no $M D A C$ do primeiro estágio básico pipeline, compartilhando-o entre os dois canais operando paralelamente sob o padrão Bluetooth. Isto pode ser conseguido aplicando-se a técnica de amostragem dupla, como no caso do $S \mathscr{E} H$ na entrada do $A D C$.

A aplicação da amostragem dupla favorece a extração mais realista do requisito de $S R$ no $O T A$ do $S \mathscr{G} H$ porque a tensão na saída do mesmo sempre está definida independente da fase de relógio ativa. Entretanto, o anterior não aplica no caso do OTA núcleo do $M D A C$, já que ele usa auto-zeroing durante a fase de amostragem. Se as alternativas apresentadas nos dois parágrafos acima forem aplicadas, as novas condições de operação facilitam a análise detalhada da especificação de $S R$ no amplificador do $M D A C$ de forma semelhante como foi feita no bloco $S \& H$ na entrada do $A D C$.

A não linearidade da chave CMOS é compensada na literatura com outras técnicas que não são abordadas neste trabalho, pela complexidade e incremento notável do hardware e do consumo de potência associado. Duas delas são conhecidas como gate voltage boosting, que basicamente é a utilização de uma tensão de porta maior que $V_{D D}$; e bootstrapped switches que usa como tensão de porta o mesmo sinal de entrada deslocado em um nível $D C$ igual a $V_{D D}[31,34]$.

As chaves CMOS são dimensionadas para evitar a deteriorização da resposta em frequência e atingir outros requisitos como clock feedthrough e linearidade dos circuitos nos quais elas são usadas. Entretanto, frequentemente é necessário redimensionar essas chaves para suprimir eficientemente transientes e glitches indesejados que aparecem durante as simulações dos circuitos projetados.

Visando aplicar a programação geométrica de forma mais eficiente, precisa-se também automatizar a geração e disponibilização de modelos para os transistores. A razão disso é que essa atividade, além de ser tediosa e desgastante para o projetista ou usuário da ferramenta, não contribui muito para o entendimento do circuito. 
O programa geométrico usado para o projeto do OTA neste trabalho faz uma tentativa para incluir, de certa forma, o efeito de corpo dos transistores $N M O S M_{1}, M_{2}$ e $M_{5}, M_{6}$ durante o equacionamento. Para isto, as respectivas tensões de limiar $V_{T}$ são determinadas pela expressão $V_{T}=V_{T 0}+\gamma\left(\sqrt{2 \phi_{f}+V_{S B}}-\sqrt{2 \phi_{f}}\right)$, onde os parâmetros $V_{T 0}, \gamma$ e $\phi_{f}$ dependem da tecnologia de fabricação e a tensão $V_{S B}$ é dada pela combinação das tensões $V_{D S}$ adequadas na figura 4.1.

O programa geométrico para o projeto do folded cascode OTA pode ser complementado acrescentando a equação de ruído térmico referido na entrada, junto com sua respectiva restrição. Isto permite reforçar a hipotese de que as fontes ruidosas dominantes nos circuitos $S C$ são os capacitores de amostragem e as chaves $C M O S$. Além disso, se for requerido por alguma aplicação particular, o programa geométrico pode ser ampliado mediante a inclusão de expressões para outros parâmetros de desempenho, como são o $C M R R$ e o PSRR. Porém, sempre se deve levar em conta o formato restrito das expressões, que deve ser compatível com o programa geométrico padrão.

Pela complexidade do sistema completo do conversor A/D, a elaboração do seu leiaute, bem como a fabricação de um protótipo e seus respectivos testes, não foram incluídos na execução deste trabalho de mestrado. Porém, recomenda-se a realização dessas atividades fundamentais para validar toda a estratégia apresentada neste documento, constituindo a próxima fase do desenvolvimento deste projeto. 


\section{Apêndice A - PG no projeto do $O T A$}

Como se trata do projeto de um circuito diferencial simétrico idealmente casado, isso significa que os diversos pares de transistores na figura 4.1 são iguais: $M 1 \rightleftharpoons M 2, M 3 \rightleftharpoons$ $M 4, M 5 \rightleftharpoons M 6, M 7 \rightleftharpoons M 8$ e $M 9 \rightleftharpoons M 10$. A igualdade desses transistores é equivalente a dizer que suas variáveis tanto elétricas quanto geométricas são similares. Por isso, a maior parte da análise seguinte só leva em conta as variáveis e nomenclatura relacionadas aos dispositivos $M 1, M 3, M 5, M 7, M 9$, e também $M 11$. A partir disso, a metade do circuito em modo comum que será usado para a formulação matemática do folded cascode OTA é mostrado na figura A.1.

O primeiro passo da estratégia é equacionar a operação do OTA de forma compatível com a PG. Para isso, devem ser atendidas as considerações a seguir:

- O efeito de corpo de $M 7, M 8$ é ignorado por se tratar de transistores PMOS, os quais permitem $v_{b s}=0 \mathrm{~V}$ nesta tecnologia mediante a construção de poços $\mathrm{N}$ isolados conectados a difusão da fonte.

- Inicialmente se deixa de lado o circuito de $C M F B$, e por causa disso é necessário ajustar manualmente o nível de modo comum na saída $\left(V_{C M, O U T}\right)$ mediante a tensão $V_{C M F B}$ para verificar os resultados do projeto com PG no simulador.

- As variáveis e constantes envolvidas nas equações são apenas avaliadas em magnitude, e portanto, transistores NMOS e PMOS não se diferenciam desde essa perspectiva no equacionamento.

- O efeito de corpo de $M 1, M 2$ é omitido decorrente da condição $v_{s} \simeq 0 \mathrm{~V}$ para pequenos sinais, pelo fato deles formarem um par diferencial idealmente casado. Portanto, pode se assumir $v_{s b} \simeq 0 \mathrm{~V}$ supondo o corpo de $M 1, M 2$ conectado à menor fonte de tensão do circuito (neste caso $0 \mathrm{~V}$ ). 


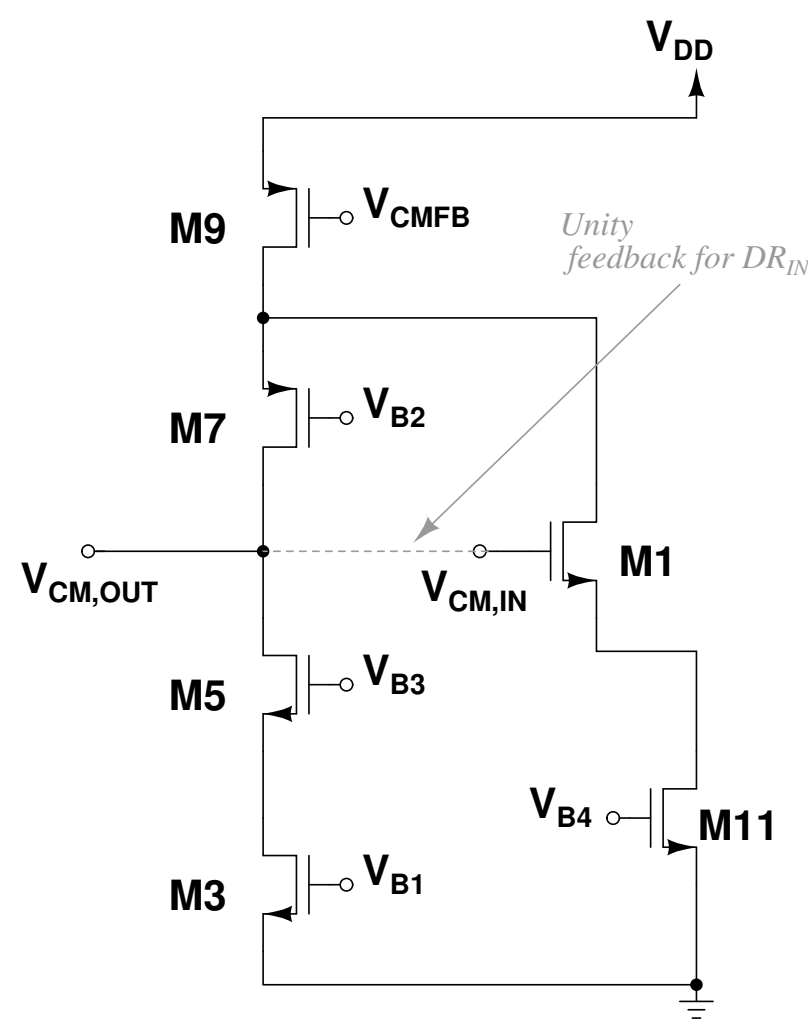

Figura A.1: Meio circuito em modo comum do folded cascode OTA.

- A conexão entre a entrada e a saída do meio circuito na figura A.1 é apenas considerada para identificar o pior caso no cálculo de $D R_{I N}$. Esta especificação é medida com o OTA em configuração de realimentação unitária.

\section{A.1 Polarização, condições de operação e geometria.}

\section{A.1.1 Leis de Kirchhoff}

$$
\begin{gathered}
V_{D D}=V_{D S 9}+V_{D S 7}+V_{D S 5}+V_{D S 3}=V_{D S 9}+V_{D S 7}+V_{C M, O U T} \\
V_{D D}=V_{D S 9}+V_{D S 1}+V_{D S 11} \\
V_{C M, I N}=V_{G 1}=V_{G S 1}+V_{D S 11} \\
V_{C M, O U T}=V_{D S 5}+V_{D S 3} \\
I_{M 9}=I_{M 1}+I_{M 7} \\
I_{M 11}=2 \cdot I_{M 1}
\end{gathered}
$$

As equações (A.1), (A.2), (A.3), (A.4), (A.5) e (A.6) determinam a distribuição de tensões e correntes $D C$ no circuito da figura A.1. Essas expressões são elementares 
e fundamentais, embora todas sejam posinômios tipo igualdade, exceto (A.6). Pela exposto acima, é necessário procurar alternativas para aproximar o comportamento do circuito visando a inclusão dessas expressões no programa geométrico. Para superar estas incompatibilidades, mais adiante serão apresentadas as modificações feitas à estrategia de projeto com PG.

Nas equações anteriores, $V_{D S}$ e $V_{G S}$ representam as tensões entre os terminais dreno e fonte, e porta e fonte dos transistores, respectivamente. De modo similar, $I_{M}$ é a corrente passando através de um dispositivo e $V_{D D}$ é a fonte de alimentação do $O T A$, sendo a mesma que a do $A D C$. Finalmente, $V_{C M, I N}$ e $V_{C M, O U T}$ fazem referência às tensões em modo comum na entrada e na saída, respectivamente.

\section{A.1.2 Potência em estado estável}

O consumo de potência do circuito é o parâmetro a ser otimizado, e está dado pela equação (A.7), que claramente é um monômio de uma variável para a PG. Essa expressão quantifica a potência total do folded cascode OTA, e não apenas a dissipada pelo meio circuito da figura A.1. Por essa razão, aparece o fator 2 na equação (A.7).

$$
P=2 \cdot V_{D D} \cdot I_{M 9}
$$

\section{A.1.3 Transistores ativos e saturados}

O conjunto seguinte de restrições deve ser satisfeito para garantir que cada um dos dispositivos na figura A.1 esteja ligado. Dentro dessas expressões, $(\Delta=100 \mathrm{mv})$ simboliza uma margem de tensão adicional para impedir os transistores de funcionarem próximos à região de corte. Ainda, $V_{T}$ representa a tensão de limiar dos transistores.

$$
\begin{aligned}
V_{G S 1} & \geq V_{T N 1}+\Delta \\
V_{G S 3} & \geq V_{T N 3}+\Delta \\
V_{G S 5} & \geq V_{T N 5}+\Delta \\
V_{G S 7} & \geq V_{T P 7}+\Delta \\
V_{G S 9} & \geq V_{T P 9}+\Delta \\
V_{G S 11} & \geq V_{T N 11}+\Delta
\end{aligned}
$$

Continuando com a formulação matemática do $O T A$, as seguintes restrições são 
necessárias para garantir que os transistores estejam na região de saturação. Dessa vez a margem de projeto $\Delta$ impede os dispositivos de funcionarem próximo da fonteira da região de tríodo.

$$
\begin{array}{lrl}
V_{D S 1} \geq V_{G S 1}-V_{T N 1}+\Delta & V_{D S 7} \geq V_{G S 7}-V_{T P 7}+\Delta \\
V_{D S 3} \geq V_{G S 3}-V_{T N 3}+\Delta & V_{D S 9} \geq V_{G S 9}-V_{T P 9}+\Delta \\
V_{D S 5} \geq V_{G S 5}-V_{T N 5}+\Delta & V_{D S 11} \geq V_{G S 11}-V_{T N 11}+\Delta
\end{array}
$$

\section{A.1.4 Faixas de excursão de tensão}

A equação (A.8) descreve o cálculo da faixa de excursão de tensão na entrada colocando o OTA em realimentação unitária, como mostrado na figura A.1. É importante lembrar que esta especificação é crítica para o $S \mathscr{E} H$, pois esse bloco deve alocar a excursão total esperada na entrada do $A D C$, ou seja $V_{F S}=2 V_{p p}$. As tensões identificadas como $V_{O V}$ $\left(V_{O V E R D R I V E}\right)$ representam os $V_{D S}$ mínimos dos transistores, isto é, na fronteira entre as regiões de saturação e tríodo.

$$
\begin{aligned}
& V_{C M, I N \max }=V_{D D}-V_{O V 9}-V_{O V 7} \quad \therefore \quad V_{C M, I N \min }=V_{G S 1}+V_{O V 11} \\
\Longrightarrow & D R_{I N} \leq V_{C M, I N \max }-V_{C M, I N \min }=V_{D D}-V_{O V 9}-V_{O V 7}-V_{G S 1}-V_{O V 11} \\
\Longrightarrow & D R_{I N} \leq V_{D D}-V_{G S 1}-V_{G S 7}-V_{G S 9}-V_{G S 11}+V_{T P 7}+V_{T P 9}+V_{T N 11}
\end{aligned}
$$

A faixa de excursão em tensão na saída em laço aberto é calculada de acordo com as expressões em (A.9). A excursão de saída é definida como a faixa de tensões que pode estar no nó de saída com todos os dispositivos ainda saturados. No folded cascode OTA, $D R_{O U T}$ é determinado pelas tensões $V_{D S}$ mínimas dos transistores $M 3 \rightleftharpoons M 4$, $M 5 \rightleftharpoons M 6, M 7 \rightleftharpoons M 8$ e $M 9 \rightleftharpoons M 10$. Para obter a maior excursão, estabelece-se que a polarização seja $V_{C M, O U T}=V_{D D} / 2$.

$$
\begin{aligned}
& V_{C M, O U T \max }=V_{D D}-V_{O V 9}-V_{O V 7} \quad \therefore \quad V_{C M, O U T \min }=V_{O V 5}+V_{O V 3} \\
\Longrightarrow & D R_{O U T} \leq V_{C M, O U T \max }-V_{C M, O U T \min }=V_{D D}-V_{O V 9}-V_{O V 7}-V_{O V 5}-V_{O V 3} \\
\Longrightarrow & D R_{O U T} \leq V_{D D}-V_{G S 3}-V_{G S 5}-V_{G S 7}-V_{G S 9}+V_{T N 3}+V_{T N 5}+V_{T P 7}+V_{T P 9}
\end{aligned}
$$

\section{A.1.5 Limite inferior para a corrente}

No intuito de minimizar a função objetivo escrita em (A.7), a corrente $I_{M 9}$ tentará atingir seu valor mínimo permitido. Caso não existir um limite inferior para ela, o programa geométrico não teria solução porque o otimizador forçaria $I_{M 9}$ ao seu menor valor possível 
e nunca encontraria um critério de parada para a função objetivo. Essa característica é comum na solução da $\mathrm{PG}$, razão pela que sempre é recomendável impôr patamares às variáveis de projeto [6], como mostrado na restrição (A.10). O limite $I_{M I N}$ é definido pelo projetista.

$$
I_{M 9} \geq I_{M I N}
$$

\section{A.1.6 Dimensões dos transistores}

A partir da tecnologia de fabricação, dimensões mínimas são estabelecidas para os diversos dispositivos. No caso deste trabalho, usando a tecnologia $A M S 0,35 \mu \mathrm{m}$, os valores mínimos são exibidos no seguinte grupo de restrições. Também se estabelecem valores máximos visando controlar o aumento da área do OTA, e portanto, do $A D C$ completo.

$\begin{array}{llll}L_{o f f A} \leq L_{1} & L_{1} \leq L_{o f f B} & W_{o f f A} \leq W_{1} & W_{1} \leq W_{\text {offB }} \\ L_{o f f C} \leq L_{3} & L_{3} \leq L_{o f f D} & W_{o f f C} \leq W_{3} & W_{3} \leq W_{\text {offD }} \\ L_{M I N} \leq L_{5} & L_{5} \leq L_{M A X} & W_{M I N} \leq W_{5} & W_{5} \leq W_{M A X} \\ L_{M I N} \leq L_{7} & L_{7} \leq L_{M A X} & W_{M I N} \leq W_{7} & W_{7} \leq W_{M A X} \\ L_{o f f E} \leq L_{9} & L_{9} \leq L_{o f f F} & W_{o f f E} \leq W_{9} & W_{9} \leq W_{o f f F} \\ L_{M I N} \leq L_{11} & L_{11} \leq L_{M A X} & W_{M I N} \leq W_{11} & W_{11} \leq W_{M A X}\end{array}$

Nas expressões acima, as variáveis $L$ e $W$ representam o comprimento e a largura de canal dos transistores, respectivamente. A continuidade nos valores numéricos destas dimensões físicas é determinada pela tecnologia de fabricação utilizada. No caso da tecnologia $A M S 0,35 \mu \mathrm{m}$, a mínima resolução do grid é $0,05 \mu \mathrm{m}$. Já as constantes $L_{o f f A-F}$ e $W_{o f f A-F}$ são derivadas da análise do offset do OTA realizada no capítulo 4.

\section{A.1.7 Relação geométrica no cascode}

Visando facilitar a realização de um layout simétrico e robusto frente ao mismatch para os transistores $M 3, M 4$ e $M 5, M 6$, é incluída a condição de geometrias (A.11).

$$
W_{3}=W_{5}
$$




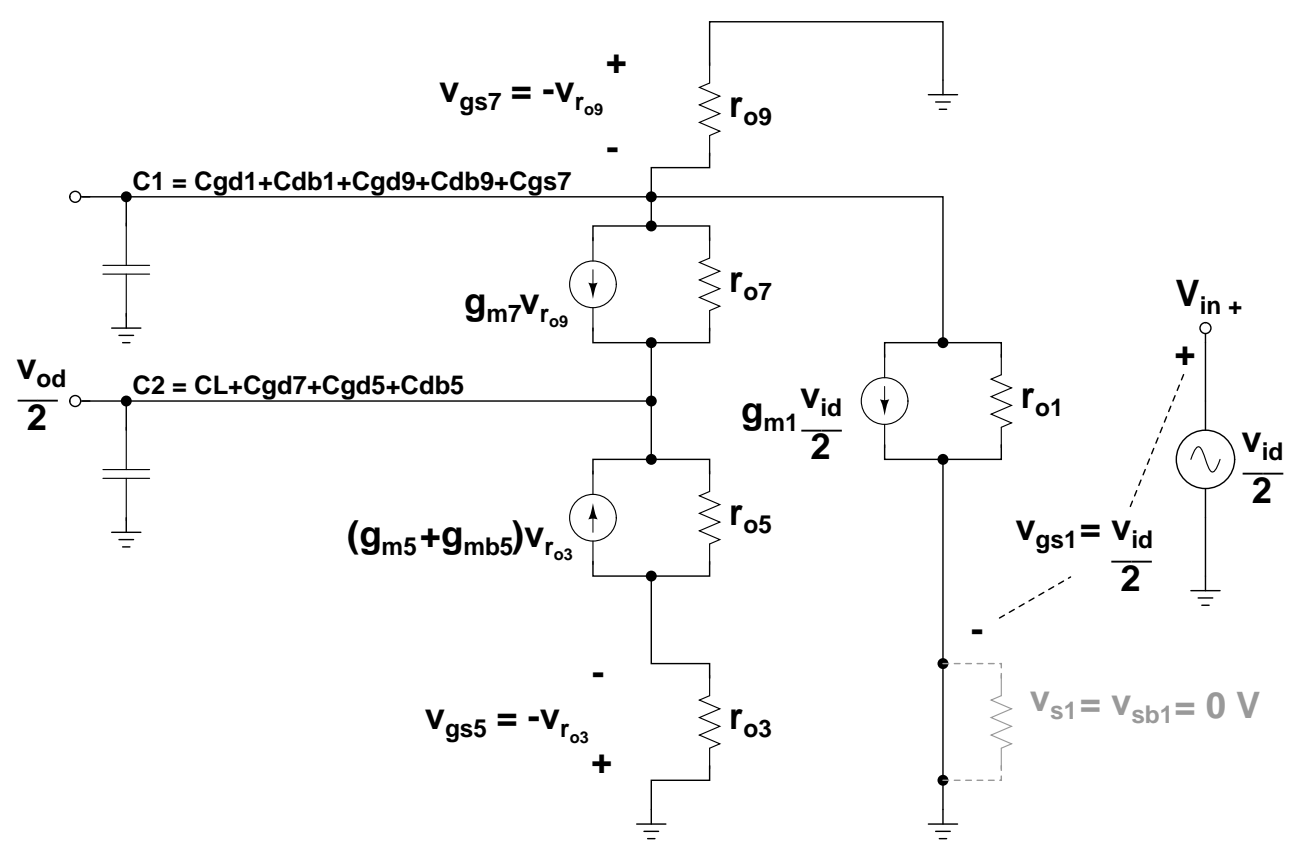

Figura A.2: Meio circuito diferencial do folded cascode OTA para pequenos sinais.

\section{A.2 Parâmetros de desempenho.}

A figura A.2 é usada como guía para a extração das especificações de desempenho do folded cascode OTA. Tanto nessa figura, quanto nas equações apresentadas nesta seção, os símbolos $g_{m}, g_{m b}, r_{o}$ representam a transcondutância da porta do transistor, a transcondutância do corpo (ou segunda porta), e a resistência de saída para pequenos sinais do dispositivo, respectivamente. Esse último símbolo é utilizado mais frequentemente como o inverso dele, $g_{d s}=1 / r_{o}$. Neste trabalho se enfatiza aqueles parâmetros que são de especial relevância para a aplicação sob estudo, que envolve circuitos de capacitores chaveados $(S C)$.

Além do dito acima, os elementos $C_{g s}, C_{g d}, C_{d b}$ na figura A.2 fazem referência às capacitâncias parasitas do transistor entre seus terminais porta-fonte, porta-dreno, e dreno-corpo, respectivamente. As expressões (A.12), (A.13) e (A.14) descrevem a dependência destas capacitâncias com as dimensões geométricas dos transistores, e com outras constantes próprias da tecnologia do processo de fabricação ( $A M S 0,35 \mu \mathrm{m})$. Essas constantes são representadas pelos símbolos $C_{o x}, C_{G S D L}, C_{J}, P_{B}, M_{J}, C_{J S W}, M_{J S W}$, enquanto $V$ indica a tensão $D C$ entre os terminais do transistor nos que aparece a respectiva capacitância parasita. 


$$
\begin{aligned}
& C_{g s}=\frac{2}{3} W L C_{o x}+C_{o l}=\frac{2}{3} W L C_{o x}+W L_{o v} C_{o x}=\frac{2}{3} W L C_{o x}+C_{G S D L} W \\
& C_{g d}=C_{o l}=W L_{o v} C_{o x}=C_{G S D L} W \\
& C_{d b}, C_{s b}=\frac{C_{J}}{\left(1+\frac{V}{P_{B}}\right)^{M_{J}}} \cdot W L+\frac{2 \cdot C_{J S W}}{\left(1+\frac{V}{P_{B}}\right)^{M_{J S W}}} \cdot(W+L)
\end{aligned}
$$

\section{A.2.1 Ganho}

O ganho de laço aberto é dado pela expressão (A.15). No entanto, ela deve ser transformada em (A.16) para fazê-la compatível com a PG. Nota-se ainda que uma restrição $\left|A_{V d}\right| \geq A_{V d m i n}$ pode ser implementada dentro de um programa geométrico.

$$
\begin{gathered}
\left|A_{V d}\right|=g_{m 1} R_{\text {out }}=g_{m 1}\left[\left(\left(g_{m 5}+g_{m b 5}\right) r_{o 3} r_{o 5}\right) \|\left(g_{m 7} r_{o 7}\left(r_{o 1} \| r_{o 9}\right)\right)\right] \geq\left|A_{V d m i n}\right| \\
\left|A_{V d}\right|=\frac{g_{m 1}}{\left(g_{m 5}+g_{m b 5}\right)^{-1} g_{d s 3} g_{d s 5}+g_{m 7}^{-1} g_{d s 7}\left(g_{d s 1}+g_{d s 9}\right)} \geq\left|A_{V d m i n}\right|
\end{gathered}
$$

\section{A.2.2 Função de transferência}

Quando assumidos dois polos suficientemente separados e determinados pelos capacitores $C_{1}$ e $C_{2}$ na figura A.2, a resposta em frequência pode ser aproximada como a de um circuito com dois polos. Portanto, a função de transferência teria a forma de (A.17), onde $\rho_{1}$ e $\rho_{2}$ são os polos, e suas respectivas equações aparecem em (A.18) e (A.19).

$$
\begin{gathered}
|H(s)| \simeq \frac{\left|A_{V d}\right|}{\left(1+\frac{s}{\rho_{1}}\right)\left(1+\frac{s}{\rho_{2}}\right)} \\
\rho_{1}=\frac{g_{m 1}}{\left|A_{V d}\right| C_{2}} \\
\rho_{2}=\frac{g_{m 7}}{C_{1}}
\end{gathered}
$$

\section{A.2.3 Frequência de ganho unitário $(G B W)$}

$$
\omega_{0}=\left.\rho_{1}\right|_{\left|A_{V d}\right|=1}=\frac{g_{m 1}}{C_{2}}=\frac{g_{m 1}}{C_{L}+C_{g d 7}+C_{g d 5}+C_{d b 5}} \geq \omega_{0 m i n}
$$

Supõe-se que o polo de ordem superior não dominante $\left(\rho_{2}\right)$ está acima de $w_{0}$. Dessa forma, $w_{0}$ é dada apenas pelo efeito do polo dominante $\rho_{1}$. Contudo, deve-se comprovar a veracidade da hipótese $\rho_{1} \ll \rho_{2}$ após o projeto usando PG. A equação (A.20) mostra que uma restrição do estilo $w_{0} \geq w_{0 \text { min }}$ pode ser introduzida na PG. 


\section{A.2.4 Margem de fase}

A especificação de margem de fase $(P M)$ deve garantir que o segundo polo $\rho_{2}$ esteja suficientemente afastado de $\omega_{0}$, e dessa forma $\rho_{1}$ domine a resposta em frequência. Além disso, a $P M$ é muito importante para a estabilidade do circuito quando estiver em realimentação. A margem de fase para o amplificador é quantificada na equação (A.21), onde $\rho_{i}$ é o polo $i$.

$$
P M=\pi-\angle H\left(\jmath \omega_{0}\right)=\pi-\sum_{i=1}^{2} \arctan \left(\frac{\omega_{0}}{\rho_{i}}\right)
$$

A equação (A.21) não tem forma posinomial, e portanto, para incluí-la na PG, deve ser simplificada e/ou aproximada. Para isso, usa-se a contribuição de aproximadamente $90^{\circ}(\pi / 2)$ em fase, por parte do primeiro polo, na frequência $w_{0}$. Isto é verdade para amplificadores com ganhos de laço aberto maior que $20 \mathrm{~dB}$, e com polos de ordem superior. No projeto de amplificadores operacionais é comum encontrar margens de fase por volta de $60^{\circ}$, garantindo dessa forma que o OTA se comporta como um circuito de um polo dominante.

Conforme já dito acima, e supondo uma margem de fase desejada superior a $60^{\circ} \mathrm{e}$ uma contribuição do polo dominante de $90^{\circ}$ em $\omega_{0}$, a fase total que os restantes polos de ordem superior contribuem deve ser menor a $30^{\circ}$. Por consequência, é possível usar a aproximação $\arctan (x) \simeq x$, que faz um bom ajuste para ângulos menores a $30^{\circ}[6]$. Sendo assim, uma expressão para a margem de fase compatível com a PG pode ser obtida, como mostrado nas equações (A.22), onde $P M_{\text {min }}$ é a especificação de entrada.

$$
\begin{aligned}
& P M=\pi-\sum_{i=1}^{2} \arctan \left(\frac{\omega_{0}}{\rho_{i}}\right) \geq P M_{\text {min }} \\
& \Longrightarrow \quad \pi-\arctan \left(\frac{\omega_{0}}{\rho_{1}}\right)-\arctan \left(\frac{\omega_{0}}{\rho_{2}}\right) \geq P M_{\text {min }} \\
& \quad \text { Aplicando as aproximações } \ldots \\
& \Longrightarrow \quad \pi-\frac{\pi}{2}-\frac{\omega_{0}}{\rho_{2}} \geq P M_{\text {min }} \\
& \Longrightarrow \quad \frac{\pi}{2}-P M_{\min } \geq \frac{\omega_{0}}{\rho_{2}} \\
& \Longrightarrow \quad \frac{\pi}{2}-P M_{\text {min }} \geq \frac{g_{m 1}}{C_{2}} \frac{C_{1}}{g_{m 7}}
\end{aligned}
$$

Conferindo com cuidado o resultado de (A.22), pode se perceber que quando for levada ao formato padrão da $\mathrm{PG}, f_{i}(x) \leq 1$, a expressão não terá forma posinomial porque $C_{2}$ é 
um posinômio de algumas variáveis de projeto. Com o intuito de incluir esta restrição no programa geométrico, usa-se a aproximação $C_{2} \simeq C_{L}$. Finalmente, a restrição da margem de fase é formulada na expressão (A.23).

$$
\frac{\pi}{2}-P M_{\min } \geq \frac{g_{m 1}}{C_{L}} \frac{C_{g d 1}+C_{d b 1}+C_{g d 9}+C_{d b 9}+C_{g s 7}}{g_{m 7}}
$$

\section{A.2.5 Slew Rate}

Este parâmetro é muito importante para o tempo de estabelecimento do OTA e pode ser formulado como mostrado na equação (A.24). O slew rate tem um compromisso forte com $\omega_{0}$, e por causa disso não é possível incrementar cada um deles independentemente. Portanto, é normal que una especificação mais forte de $S R$ leve também a um maior valor de $G B W$ no circuito [29]. Além disso, visando garantir um efeito de slewing simétrico, a corrente do ramo de saída $\left(I_{M 7}\right)$ se faz usualmente igual àquela dos transistores de entrada $\left(I_{M 1}\right)[29,31]$.

$$
S R=\frac{I_{M 11}}{C_{2}}=\frac{I_{M 11}}{C_{L}+C_{g d 7}+C_{g d 5}+C_{d b 5}} \geq S R_{\min }
$$

\section{A.3 Estratégia de projeto e modificações.}

Como apresentado ao longo das seções anteriores, a formulação matemática do problema de projeto pode ser classificada em duas partes: a descrição das considerações de operação, polarização e geométricas, e a caracterização dos parâmetros de desempenho. Geralmente, os parâmetros de desempenho estão em função de parâmetros do transistor, e as considerações de operação, polarização e geométricas em função de variáveis elétricas ou geométricas dos dispositivos. A partir dessas últimas variáveis se escolhem as variáveis de projeto do circuito [6].

Continuando a estratégia de projeto, geram-se os modelos dos parâmetros do transistor necessários, a partir das expressões obtidas na formulação matemática dos parâmetros de desempenho. A escolha do ajuste de dados com funções tipo monômio para $V_{G S}$ (expressões (A.25) e (A.26)) está fundamentada nos resultados de [6], obtendo erros menores com esse modelo simples. Outra justificativa é a presença de termos como $V_{G S}^{-1}$ em algumas condições de operação, forçando $V_{G S}$ a ter forma monomial.

De modo similar, estudando as expressões (A.16), (A.20) e (A.23), nota-se que quando elas forem levadas ao formato padrão da PG, aparecerão termos como $g_{m}^{-1}$ e $g_{d s}$. Em [6] se conclui que esses parâmetros se ajustam bem tanto a modelos posinomiais quanto a 
funções convexas - pwl. Porém, a principal justificativa para escolher o tipo de modelagem $p w l$ é a velocidade e a disponibilidade do software. Enquanto os modelos $p w l$ podem ser obtidos com algumas funções escritas em MATLAB, os modelos posinomiais precisam de algoritmos para programação não linear difíceis de encontrar [6].

$$
\begin{aligned}
& V_{G S, \bmod N}=f\left(I_{M}, V_{D S}, W, L\right)=K_{N X} \cdot I_{M}^{A N} \cdot V_{D S}^{B N} \cdot W^{C N} \cdot L^{D N} \\
& V_{G S, \bmod P}=f\left(I_{M}, V_{D S}, W, L\right)=K_{P X} \cdot I_{M}^{A P} \cdot V_{D S}^{B P} \cdot W^{C P} \cdot L^{D P}
\end{aligned}
$$

Finalmente, a revisão de (A.23) contém um termo $g_{m 1}$. Como $g_{m 1}^{-1}$ já foi modelado anteriormente com funções convexas-pwl, esse mesmo ajuste não pode ser aplicado para $g_{m 1}$ porque o inverso de um posinômio não é um posinômio. Portanto, é necessário gerar um modelo monomial a mais para $g_{m 1}$ (equação (A.27)), e conferir que os parâmetros obtidos mediante dois ajustes diferentes coincidem no final em resultados similares.

$$
g_{m 1, \bmod N}=f\left(I_{M 1}, V_{D S 1}, W_{1}, L_{1}\right)=K_{N 1 g} \cdot I_{M 1}^{A N 1 g} \cdot V_{D S 1}^{B N 1 g} \cdot W_{1}^{C N 1 g} \cdot L_{1}^{D N 1 g}
$$

Com o parágrafo anterior termina a primeira e segunda etapa do processo de projeto, enquanto a terceira é a implementação do programa geométrico. Como o formato das leis de Kirchhoff não é compatível com o padrão da PG, é necessário incluir as relações apresentadas nas equações (A.1), (A.2), (A.3), (A.4), e (A.5) de uma maneira indireta. Uma alternativa é estabelecer tensões $V_{D S}$ constantes, porém cumprindo com as leis de Kirchhoff. Entretanto, a equação (A.5) pode ser incluída fixando o valor de $I_{M 1}$ e $I_{M 7}$, mas, visando diminuir o número de variáveis fixadas, assume-se que $I_{M 9}$ é $\alpha$ vezes $I_{M 7}$. Isto introduz a nova variável de projeto $\alpha$ e (A.5) é substituída pelo resultado em (A.28).

$$
I_{M 9}=I_{M 1}+I_{M 7} \quad \Longrightarrow \quad I_{M 1}=I_{M 9}-I_{M 7}=I_{M 7} \cdot(\alpha-1), I_{M 9}=\alpha \cdot I_{M 7}
$$

Como existem diversas possibilidades para combinar as tensões $V_{D S}$ na figura A.1, é proposta uma modificação na estratégia de projeto. A ideia é variar recursivamente $V_{D S 9}$ e $V_{D S 11}$ entre um valor mínimo e máximo que dependem de outras constantes de polarização, enquanto $V_{D S 1}$ e $V_{D S 7}$ também mudam seu valor de acordo com (A.1) e (A.2). No interior dessas variações, $V_{D S 3}$ e $V_{D S 5}$ são combinados iterativamente para satisfazer 
(A.4), com $V_{C M, O U T}=V_{D D} / 2$. Para cada possível combinação dos anteriores pontos de operação em $D C$, um programa geométrico é resolvido e se itera novamente, visando encontrar o melhor ótimo, que neste caso corresponde ao projeto com menor consumo de potência. As restrições de saturação são também revisadas em cada iteração. Certamente o resultado é válido porque todas as restrições de projeto estão sendo atendidas [6].

Como não é prático analisar todas as possíveis combinações dos $V_{D S}$, não pode se afirmar que esta estratégia encontra o ótimo global do projeto, desde a definição matemática estrita. Porém, com certeza o resultado final está muito perto desse ótimo. Embora os valores de $V_{D S}$ sejam fixados em cada otimização, enfatiza-se que $V_{D S}$ ainda é mais uma variável de projeto, dentro do contexto geral da metodologia proposta.

A excursão em tensão na saída constitui uma das especificações críticas para a aplicação do OTA a ser projetado. Portanto, tenta-se forçar os transistores $M 3$ e M9 a funcionar próximos da fronteira da região de tríodo. Para isto se retomam as condições de saturação desses dois dispositivos para serem modificadas e incluídas na PG como restrições em igualdade. As novas expressões são apresentadas em (A.29) e (A.30).

$$
\begin{aligned}
& V_{D S 3}=V_{G S 3}-V_{T N 3}+\Delta \\
& V_{D S 9}=V_{G S 9}-V_{T P 9}+\Delta
\end{aligned}
$$

Os limites das varreduras em tensão para $V_{D S 9}$ e $V_{D S 11}$ são apresentados a seguir. Nessas operações, assume-se que os valores $V_{C M, I N}, V_{C M, I N, M I N}, V_{C M, I N, M A X}$ e $V_{O V, M I N}$ são constantes, e a especificação deles é critério do projetista.

\section{A.3.1 Limites para $V_{D S 9}$}

Se $V_{G D 1}>V_{T N 1}$, o transistor $M 1$ na entrada do OTA pode entrar na região de tríodo, que deve ser evitado.

$$
\begin{aligned}
V_{D S 9}=V_{D D}-\left(V_{C M, I N}-V_{G D 1}\right) & \Longrightarrow V_{G D 1}=V_{D S 9}+V_{C M, I N}-V_{D D} \leq V_{T N 1} \\
& \Longrightarrow V_{G D 1, M A X}=V_{D S 9, M A X}+V_{C M, I N, M A X}-V_{D D}=V_{T N 1} \\
& \Longrightarrow \mathbf{V}_{\mathbf{D S 9 , M A X}}=\mathbf{V}_{\mathbf{D D}}+\mathbf{V}_{\mathbf{T N 1}}-\mathbf{V}_{\mathbf{C M}, \mathbf{I N}, \mathbf{M A X}} \\
& \therefore \mathbf{V}_{\mathbf{D S 9 , M I N}}=\mathbf{V}_{\mathbf{O V}, \mathbf{M I N}}
\end{aligned}
$$




\section{A.3.2 Limites para $V_{D S 11}$}

Se $V_{G S 1}<V_{T N 1}$, o transistor $M 1$ na entrada do $O T A$ pode entrar na região de corte, que deve ser evitado.

$$
\begin{aligned}
V_{G S 1}=V_{C M, I N}-V_{D S 11} \geq V_{T N 1}+\Delta & \Longrightarrow V_{G S 1, M I N}=V_{C M, I N, M I N}-V_{D S 11, M A X}=V_{T N 1}+\Delta \\
& \Longrightarrow \mathbf{V}_{\text {DS11,MAX }}=\mathbf{V}_{\mathbf{C M}, \mathbf{I N}, \mathrm{MIN}}-\left(\mathbf{V}_{\mathbf{T N 1}}+\Delta\right) \\
& \therefore \mathbf{V}_{\mathbf{D S 1 1 , M I N}}=\mathbf{V}_{\mathbf{O V}, \mathbf{M I N}}
\end{aligned}
$$

\section{A.3.3 Inclusão dos $V_{D S}$ resultantes do processo iterativo}

Para poder conferir a combinação de tensões $V_{D S}$ que levou ao melhor ótimo selecionado pela metodologia de projeto, elas mesmas são incluídas na PG como restrições em igualdade. Essas condições são representadas pelas identidades a seguir, onde os diferentes $V_{X}$ indicam os valores em cada iteração. Mais uma vez se enfatiza que embora os $V_{D S}$ sejam constantes para o programa geométrico, eles ainda representam variáveis de projeto sob o ponto de vista do circuito real.

$$
V_{D S 1}=V_{1} \quad V_{D S 3}=V_{3} \quad V_{D S 5}=V_{5} \quad V_{D S 7}=V_{7} \quad V_{D S 9}=V_{9} \quad V_{D S 11}=V_{11}
$$

\section{A.3.4 Formulação padrão do programa geométrico}

Agora toda a formulação matemática desenvolvida até este ponto, é transformada ao formato padrão da PG. Sendo assim, o primeiro elemento para apresentar é a função objetivo, que corresponde à potência total em estado estável dissipada pelo OTA. Esse é o valor que o programa geométrico visa minimizar.

$$
\left(2 \cdot V_{D D}\right) \cdot I_{M 9}
$$

Daqui em diante se apresentam as restrições que compõem o programa geométrico.

$$
\begin{array}{rrr}
\alpha \cdot I_{M 9}^{-1} I_{M 7}=1 & (\alpha-1) \cdot I_{M 7} I_{M 1}^{-1}=1 & 2 \cdot I_{M 1} I_{M 11}^{-1}=1 \\
\left(V_{C M, I N}-V_{D S 11}\right)^{-1} \cdot V_{G S 1} \leq 1 & I_{M I N} I_{M 9}^{-1} \leq 1 & W_{3} W_{5}^{-1}=1
\end{array}
$$




$$
\begin{array}{rrr}
\left(V_{D S 1}+V_{T N 1}-\Delta\right)^{-1} \cdot V_{G S 1} \leq 1 & \left(V_{D S 7}+V_{T P 7}-\Delta\right)^{-1} \cdot V_{G S 7} \leq 1 \\
\left(V_{D S 3}+V_{T N 3}-\Delta\right) \cdot V_{G S 3}^{-1}=1 & \left(V_{D S 9}+V_{T P 9}-\Delta\right) \cdot V_{G S 9}^{-1}=1 \\
\left(V_{D S 5}+V_{T N 5}-\Delta\right)^{-1} \cdot V_{G S 5} \leq 1 & \left(V_{D S 11}+V_{T N 11}-\Delta\right)^{-1} \cdot V_{G S 11} \leq 1
\end{array}
$$

$$
\begin{array}{r}
\left(V_{D D}+V_{T P 7}+V_{T P 9}+V_{T N 11}-D R_{I N}\right)^{-1} \cdot\left(V_{G S 1}+V_{G S 7}+V_{G S 9}+V_{G S 11}\right) \leq 1 \\
\left(V_{D D}+V_{T N 3}+V_{T N 5}+V_{T P 7}+V_{T P 9}-D R_{O U T}\right)^{-1} \cdot\left(V_{G S 3}+V_{G S 5}+V_{G S 7}+V_{G S 9}\right) \leq 1
\end{array}
$$

$$
V_{1}^{-1} V_{D S 1}=1 \quad V_{3}^{-1} V_{D S 3}=1 \quad V_{5}^{-1} V_{D S 5}=1 \quad V_{7}^{-1} V_{D S 7}=1 \quad V_{9}^{-1} V_{D S 9}=1 \quad V_{11}^{-1} V_{D S 11}=1
$$

$\begin{array}{llll}L_{\text {off } A} L_{1}^{-1} \leq 1 & L_{\text {off }}^{-1} L_{1} \leq 1 & W_{\text {offA }} W_{1}^{-1} \leq 1 & W_{1} W_{\text {off }}^{-1} \leq 1 \\ L_{\text {offC }} L_{3}^{-1} \leq 1 & L_{\text {offD }}^{-1} L_{3} \leq 1 & W_{\text {offC }} W_{3}^{-1} \leq 1 & W_{3} W_{\text {offD }}^{-1} \leq 1 \\ L_{M I N} L_{5}^{-1} \leq 1 & L_{M A X}^{-1} L_{5} \leq 1 & W_{M I N} W_{5}^{-1} \leq 1 & W_{5} W_{M A X}^{-1} \leq 1 \\ L_{M I N} L_{7}^{-1} \leq 1 & L_{M A X}^{-1} L_{7} \leq 1 & W_{M I N} W_{7}^{-1} \leq 1 & W_{7} W_{M A X}^{-1} \leq 1 \\ L_{\text {offE }} L_{9}^{-1} \leq 1 & L_{\text {offF }}^{-1} L_{9} \leq 1 & W_{\text {offE }} W_{9}^{-1} \leq 1 & W_{9} W_{\text {offF }}^{-1} \leq 1 \\ L_{M I N} L_{11}^{-1} \leq 1 & L_{M A X}^{-1} L_{11} \leq 1 & W_{M I N} W_{11}^{-1} \leq 1 & W_{11} W_{M A X}^{-1} \leq 1\end{array}$

$$
\begin{array}{rr}
\left(V_{T N 1}+\Delta\right) \cdot V_{G S 1}^{-1} \leq 1 & \left(K_{N 1} \cdot I_{M 1}^{A N 1} \cdot V_{D S 1}^{B N 1} \cdot W_{1}^{C N 1} \cdot L_{1}^{D N 1}\right)^{-1} \cdot V_{G S 1}=1 \\
\left(V_{T N 3}+\Delta\right) \cdot V_{G S 3}^{-1} \leq 1 & \left(K_{N 3} \cdot I_{M 7}^{A N 3} \cdot V_{D S 3}^{B N 3} \cdot W_{3}^{C N 3} \cdot L_{3}^{D N 3}\right)^{-1} \cdot V_{G S 3}=1 \\
\left(V_{T N 5}+\Delta\right) \cdot V_{G S 5}^{-1} \leq 1 & \left(K_{N 5} \cdot I_{M 7}^{A N 5} \cdot V_{D S 5}^{B N 5} \cdot W_{5}^{C N 5} \cdot L_{5}^{D N 5}\right)^{-1} \cdot V_{G S 5}=1 \\
\left(V_{T N 7}+\Delta\right) \cdot V_{G S 7}^{-1} \leq 1 & \left(K_{P 7} \cdot I_{M 7}^{A P 7} \cdot V_{D S 7}^{B P 7} \cdot W_{7}^{C P 7} \cdot L_{7}^{D P 7}\right)^{-1} \cdot V_{G S 7}=1 \\
\left(V_{T N 9}+\Delta\right) \cdot V_{G S 9}^{-1} \leq 1 & \left(K_{P 9} \cdot I_{M 9}^{A P 9} \cdot V_{D S 9}^{B P 9} \cdot W_{9}^{C P 9} \cdot L_{9}^{D P 9}\right)^{-1} \cdot V_{G S 9}=1 \\
\left(V_{T N 11}+\Delta\right) \cdot V_{G S 11}^{-1} \leq 1 & \left(K_{N 11} \cdot I_{M 11}^{A N 11} \cdot V_{D S 11}^{B N 11} \cdot W_{11}^{C N 11} \cdot L_{11}^{D N 11}\right)^{-1} \cdot V_{G S 11}=1
\end{array}
$$

$\left|A_{V d m i n}\right| \cdot g_{m 1}^{-1}\left(g_{m 5}+g_{m b 5}\right)^{-1} g_{d s 3} g_{d s 5}+\left|A_{V d m i n}\right| \cdot g_{m 1}^{-1} g_{m 7}^{-1} g_{d s 1} g_{d s 7}+\left|A_{V d m i n}\right| \cdot g_{m 1}^{-1} g_{m 7}^{-1} g_{d s 7} g_{d s 9} \leq 1$ 


$$
\begin{aligned}
& \omega_{0 m i n} \cdot g_{m 1}^{-1}\left[C_{L}+C_{G S D L P} \cdot W_{7}+C_{G S D L N} \cdot W_{5}+\right. \\
& \left.+\frac{C_{J N}}{\left(1+\frac{V_{D B 5}}{P_{B N}}\right)^{M_{J N}}} \cdot W_{5} L_{5}+\frac{2 \cdot C_{J S W N}}{\left(1+\frac{V_{D B 5}}{P_{B N}}\right)^{M_{J S W N}}} \cdot\left(W_{5}+L_{5}\right)\right] \leq 1 \\
& \frac{1}{C_{L}\left(\frac{\pi}{2}-P M_{m i n}\right)} \cdot g_{m 1} g_{m 7}^{-1}\left[C_{G S D L N} \cdot W_{1}+\frac{C_{J N}}{\left(1+\frac{V_{D B 1}}{P_{B N}}\right)^{M_{J N}}} \cdot W_{1} L_{1}+\right. \\
& +\frac{2 \cdot C_{J S W N}}{\left(1+\frac{V_{D B 1}}{P_{B N}}\right)^{M_{J S W N}}} \cdot\left(W_{1}+L_{1}\right)+C_{G S D L P} \cdot W_{9}+ \\
& +\frac{C_{J P}}{\left(1+\frac{V_{D B 9}}{P_{B P}}\right)^{M_{J P}}} \cdot W_{9} L_{9}+\frac{2 \cdot C_{J S W P}}{\left(1+\frac{V_{D B 9}}{P_{B P}}\right)^{M_{J S W P}}} \cdot\left(W_{9}+L_{9}\right)+ \\
& \left.+\frac{2}{3} C_{o x P} \cdot W_{7} L_{7}+C_{G S D L P} \cdot W_{7}\right] \leq 1 \\
& S R_{\text {min }} \cdot I_{M 11}^{-1}\left[C_{L}+C_{G S D L P} \cdot W_{7}+C_{G S D L N} \cdot W_{5}+\right. \\
& \left.+\frac{C_{J N}}{\left(1+\frac{V_{D B 5}}{P_{B N}}\right)^{M_{J N}}} \cdot W_{5} L_{5}+\frac{2 \cdot C_{J S W N}}{\left(1+\frac{V_{D B 5}}{P_{B N}}\right)^{M_{J S W N}}} \cdot\left(W_{5}+L_{5}\right)\right] \leq 1 \\
& \left(K_{N 1 g} \cdot I_{M 1}^{A N 1 g} \cdot V_{D S 1}^{B N 1 g} \cdot W_{1}^{C N 1 g} \cdot L_{1}^{D N 1 g}\right)^{-1} \cdot g_{m 1}=1
\end{aligned}
$$

A tabela A.1 mostra as 38 variáveis de projeto que participam no programa geométrico apresentado anteriormente. A variável $g_{m T 5}^{-1}$ faz referência ao inverso da soma das transcondutâncias do transistor $M 5$, isto é, $g_{m T 5}^{-1}=1 / g_{m T 5}=1 /\left(g_{m 5}+g_{m b 5}\right)$. Essa declaração permite incluir o efeito de corpo do transistor $M 5$, conforme necessário pela restrição de ganho na equação (A.16).

As restrições anteriores são permanentes no programa geométrico do OTA. Conferindo

Tabela A.1: Variáveis de projeto na PG para o folded cascode OTA.

\begin{tabular}{|c|c|c|c|c|c|c|}
\hline$V_{G S 1}$ & $W_{1}$ & $L_{1}$ & $V_{D S 1}$ & $g_{d s 1}$ & $I_{M 9}$ & $g_{m T 5}^{-1}$ \\
\hline$V_{G S 3}$ & $W_{3}$ & $L_{3}$ & $V_{D S 3}$ & $g_{d s 3}$ & $I_{M 7}$ & $g_{m 7}^{-1}$ \\
\hline$V_{G S 5}$ & $W_{5}$ & $L_{5}$ & $V_{D S 5}$ & $g_{d s 5}$ & $I_{M 1}$ & \\
\hline$V_{G S 7}$ & $W_{7}$ & $L_{7}$ & $V_{D S 7}$ & $g_{d s 7}$ & $I_{M 11}$ & \\
\hline$V_{G S 9}$ & $W_{9}$ & $L_{9}$ & $V_{D S 9}$ & $g_{d s 9}$ & $g_{m 1}$ & \\
\hline$V_{G S 11}$ & $W_{11}$ & $L_{11}$ & $V_{D S 11}$ & $g_{d s 11}$ & $g_{m 1}^{-1}$ & \\
\hline
\end{tabular}


com cuidado, todas as considerações de operação, polarização e geometria, bem como os parâmetros de desempenho e os modelos monomiais foram incluídos. Só estão faltando as restrições relacionadas com a modelagem dos parâmetros $g_{m}^{-1}$ e $g_{d s}$ mediante ajustes com funções convexas-pwl. A razão dessa omissão é a quantidade variável de termos nesses modelos, decorrente dos níveis de erros aceitáveis. 


\section{Referências}

[1] XIA, B. Analog-to-Digital Interface Design for Wireless Receivers. Tese (Doutorado) - Texas and A\&M University, Dec. 2004.

[2] CARVAJAL, W.; ROA, E.; NOIJE, W. M. V. Diseño de un OTA Cascodo Doblado a $23 \mathrm{MHz}$ GBW / $460 \mu \mathrm{W}$ para un S\&H. In: XIV Iberchip Workshop. Puebla, Mexico: [s.n.], 2008. CD-ROM.

[3] CARvajal, W.; ROA, E.; NOIJE, W. M. V. A $23 \mathrm{MHz}$ GBW $460 \mu \mathrm{W}$ Folded Cascode OTA for a Sample and Hold Circuit Using Double Sampling Technique. In: Conference on Integrated Circuits and Systems DCIS. Grenoble, France: [s.n.], 2008. CD-ROM.

[4] CARVAJAL, W. Diseño de un Conversor Analógico-Digital Configurable Integrado en Tecnología CMOS. Trabalho de formatura da Universidad Industrial de Santander: [s.n.], 2007.

[5] HERNáNDEZ, H.; CARVAJAL, W.; ROA Élkim. Conversores: Digital-Analógico y Analógico-Digital. Una Perspectiva del Diseño de Sistemas Inalámbricos. 1. ed. Carrera 27 con calle 29, Ciudad Universitaria, Bucaramanga, Colombia: División de Publicaciones UIS, 2009.

[6] CABrerA, D. J.; Oliveros, J. A. Aplicación de la Programación Geométrica en el Diseño de Amplificadores Operacionales Integrados en Tecnología CMOS. Trabalho de formatura da Universidad Industrial de Santander: [s.n.], 2006.

[7] GRANT, M.; BOYD, S. CVX: Matlab Software for Disciplined Convex Programming, version 1.21. Oct. 2010. http://cvxr.com/cvx.

[8] BLUETOOTH SIG. Specification of the Bluetooth System, Version $2.0+$ EDR. Nov. 2004. http://www. bluetooth.com.

[9] XIA, B.; VALDES-GARCIA, A.; SáNCHEZ-SINENCIO, E. A 10-bit 44-MSs 20mW Configurable Time-Interleaved Pipeline ADC for a Dual-Mode 802.11b/Bluetooth Receiver. IEEE J. Solid-State Circuits, v. 41, n. 3, p. 530-539, Mar. 2006.

[10] XIA, B.; VALDES-GARCIA, A.; SáNCHEZ-SINENCIO, E. A Configurable TimeInterleaved Pipeline ADC for Multi-Standard Wireless Receivers. In: Proc. European Solid-State Circuits Conf. IEEE. [S.l.: s.n.], 2004. p. $259-262$.

[11] AHMED, I.; JOHNS, D. A $50 \mathrm{MS} / \mathrm{s}(35 \mathrm{~mW})$ to $1 \mathrm{kS} / \mathrm{s}(15 \mu \mathrm{W})$ Power Scaleable 10b Pipelined ADC with Minimal Bias Current Variation. In: IEEE ISSCC. [S.l.: s.n.], 2005. p. 280-281. 
[12] PERRAUD, L. et al. A Direct-Conversion CMOS Transceiver for the $802.11 \mathrm{a} / \mathrm{b} / \mathrm{g}$ WLAN Standard Utilizing a Cartesian Feedback Transmitter. IEEE J. Solid-State Circuits, v. 39, n. 12, p. 2226 - 2238, Dec. 2004.

[13] JUNG, Y.-J. et al. A 2.4-GHz 0.25- $\mu \mathrm{m}$ CMOS Dual-Mode Direct-Conversion Transceiver for Bluetooth and 802.11b. IEEE J. Solid-State Circuits, v. 39, n. 7, p. 1185 - 1190, Jul. 2004.

[14] VAZ, B.; GOES, J.; PAULINO, N. A 1.5-V 10-b 50 MS/s Time-Interleaved SwitchedOpamp Pipeline CMOS ADC with High Energy Efficiency. In: Symposium on VLSI Circuits. [S.l.: s.n.], 2004. p. 432-435.

[15] MILleR, M. R.; PETRIE, C. S. A Multibit Sigma-Delta ADC for Multimode Receivers. IEEE J. Solid-State Circuits, v. 38, n. 3, p. 475 - 482, Mar. 2003.

[16] SAlO, T.; LINDFORS, T. H. S.; HALONEN, K. A Dual-Mode 80 MHz Bandpass Delta-Sigma Modulator for a GSM/WCDMA IF-Receiver. In: IEEE ISSCC. [S.l.: s.n.], 2002. p. 218-461.

[17] LEE, S. W. A Single-Chip 2.4 GHz Direct-Conversion CMOS Transceiver with GFSK Modem for Bluetooth Application. In: IEEE Symp. VLSI Circuits Dig. Tech. Papers. [S.l.: s.n.], 2001. p. 245-246.

[18] RAZAVI, B. A 2.4-GHz CMOS Receiver for IEEE 802.11 Wireless LANs. IEEE J. Solid-State Circuits, v. 34, p. 1382-1385, Oct. 1999.

[19] GOES, J.; VITAL, J.; FRANCA, J. Systematic Design for Optimization of HighSpeed Self-Calibrated Pipelined A/D Converters . IEEE Trans. Circuits Syst. II, v. 45, n. 12, p. $1513-1526$, Dec. 1998.

[20] LIN, C.-H.; BULT, K. A 10-b, 500-MSample/s CMOS DAC in $0.6 \mathrm{~mm}^{2}$. IEEE J. Solid-State Circuits, v. 33, n. 12, p. 1948 - 1958, Dec. 1998.

[21] CONROY, C.; CLINE, D.; P.R.GRAY. An 8-b 85-MS/s Parallel Pipeline A/D Converter in 1- $\mu \mathrm{m}$ CMOS. IEEE J. Solid-State Circuits, v. 28, n. 4, p. 447 454, Apr. 1993.

[22] VAlBURG, J. van; PLACE, R. van de. An 8b $650 \mathrm{MHz}$ Folding ADC. In: IEEE ISSCC Dig. Tech. Papers. [S.l.: s.n.], 1992. p. 30-31.

[23] YOTSUYANAGI, M.; ETOH, T.; HIRATA, K. A 10b 50 Msample/sec Pipelined CMOS A/D Conveter with S/H. In: Proc. Custom Integrated Circuits Conf. [S.l.: s.n.], 1992. p. 16.7.1-16.7.4.

[24] LEE, S.-H.; SONG, B.-S. Digital-Domain Calibration of Multistep Analog-to-Digital Converters. IEEE J. Solid-State Circuits, v. 27, n. 12, p. 1679 - 1688, Dec. 1992.

[25] YIN, G.; EYNDE, F.; SANSEN, W. A High-Speed CMOS Comparator with 8-b Resolution. IEEE J. Solid-State Circuits, v. 27, n. 2, p. 208 - 211, Feb. 1992.

[26] KARANICOLAS, A. et al. A High-Frequency Fully Differential BiCMOS Operational Amplifier. IEEE J. Solid-State Circuits, v. 26, n. 3, p. 203 - 208, Mar. 1991. 
[27] ISHIKAWA, M.; TSUKAHARA, T. An 8-bit 50-MHz CMOS Subranging A/D Converter with Pipelined Wide-Band S/H. IEEE J. Solid-State Circuits, v. 24, n. 6, p. 1485-1491, Dec. 1989.

[28] XIA, B. et al. A Dual-Mode 802.11b/Bluetooth Receiver in 0.25- $\mu$ m BiCMOS. In: IEEE ISSCC. [S.l.: s.n.], 2004. p. $270-527$.

[29] GUSTAVSSON, M.; WIKNER, J. J.; TAN, N. N. CMOS Data Converters for Communications. New York, Boston, Dordrecht, London, Moscow: Kluwer Academic Publishers, 2002.

[30] NEWASKAR, P. P.; BLAZQUEZ, R.; CHANDRAKASAN, A. P. A/D Precision Requirements for an Ultra-Wideband Radio Receiver. Microsystems Technology Laboratory, Massachusetts Institute of Technology: [s.n.], 2002.

[31] SUMANEN, L. Pipeline Analog-to-Digital Converters for Wide-Band Wireless Communications. Tese (Doutorado) - Helsinki University of Technology, December 2002.

[32] REY, E. V. Diseño de un Amplificador y un Filtro Banda Base Integrado en Tecnología CMOS. Trabalho de formatura da Universidad Industrial de Santander: [s.n.], 2006.

[33] EUROPEAN TELECOMMUNICATIONS STANDARDS INSTITUTE, SECOND ED. European Digital Cellular Telecommunications System (Phase 2), Radio Transmission and Reception (GSM 05.10). Jul.

[34] WALtARI, M. Circuit Techniques for Low-Voltage and High Speed A/D Converters . Tese (Doutorado) - Helsinki University of Technology, June 2002.

[35] YUAN, J.; SVENSSON, C. New Single-Clock CMOS Latches and Flipflops with Improved Speed and Power Savings. IEEE J. Solid-State Circuits, v. 32, n. 1, p. 62 - 69, Jan. 1997.

[36] KHOO, K. B.-H. Programmable, High-Dynamic Range Sigma-Delta A/D Converters for Multistandard, Fully-Integrated RF Receivers. Tese (Doutorado) — University of California at Berkeley, December 1998.

[37] RABAEY, J. M. Digital Integrated Circuits, A Design Perspective. Prentice Hall Electronics and VLSI Series, Upper Saddle River, NJ: Prentice Hall, Inc, 1996.

[38] CDNS. Cadence Design Systems. 1988. http://www.cadence.com.

[39] CHOKSI, O.; CARLEY, L. R. Analysis of Switched-Capacitor Common-Mode Feedback Circuit . IEEE Trans. Circuits Syst. II, v. 50, n. 12, p. 906 - 917, Dec. 2003.

[40] ORTIZ, H. I. G.; DELGADO, J. A. S. Diseño de un Comparador Integrado en Tecnología CMOS. Trabalho de formatura da Universidad Industrial de Santander: [s.n.], 2009. 
[41] WICHT, B.; NIRSCHL, T.; SCHMITT-LANDSIEDEL, D. Yield and Speed Optimization of a Latch-Type Voltage Sense Amplifier. IEEE J. Solid-State Circuits, v. 39, n. 7, p. 1148-1158, Jul. 2004.

[42] AMS. austriamicrosystems, a leap ahead in analog. http://www . austriamicrosystems.com. 